\title{
From Galvanism to Electrodynamics: The Transformation of German Physics and Its Social Context
}

\author{
By Kenneth L. Caneva*
}

"On what sorts of occasions, and by what processes and procedures, are the fundamental concepts or constellations of presuppositions characteristic of the modes of thought current in one human generation discredited and abandoned in favour of other successor-concepts or presuppositions?"1

\section{Introduction}

2. The Science of the Concrete

The Qualitative Nature of Experiment

The Role of Experiment: The Inductivist Ideal and the Rejection of the

Hypothetico-Deductive Method

Mathematical versus Physical Theories

Explanation as Schematization

3. The Science of the Abstract

Mathematics and Abstraction

Experiment and Measurement

The Hypothetico-Deductive Method

4. External Factors in the Transition from Concretizing to Abstracting Science

The Institutional and Social Context of Scientific Change

Toward the Professionalization of Science

Toward the Redefinition of the Individual in Society

The Social Dimension of Scientific Knowledge

The Legitimation of Scientific Activity: A Functional Analysis

Social and Scientific Styles of Thought: A Structural Comparison

*Centrum Algemene Vorming, Vrije Universiteit, De Boelelaan 1083, Postbus 7161, Amsterdam-Buitenveldert, The Netherlands. This paper is based on a dissertation written under Thomas S. Kuhn, for whose original guidance and encouragement I remain grateful. In its present form it has profited from the criticisms of Louis Boon, Lewis Pyenson, Martin Rudwick, Jane Sugarman, and Steven Turner.

1Stephen Toulmin, Human Understanding (Princeton, 1972), 1, 75, paraphrasing Robin George Collingwood, An Essay on Metaphysics (Oxford, 1940), p. 73. 


\section{INTRODUCTION}

Historians have long been aware that German science underwent a profound qualitative and quantitative transformation during the first half of the nineteenth century. This paper investigates the qualitative aspects of that change in a single field of study, electricity and magnetism. Because this area of physical research was more actively pursued, and pursued by a greater number of individuals, than any other, it may reasonably serve as a first approximation to the state of affairs in other areas of physics as well. Only future research will indicate whether certain generalizations based on this study depend upon factors peculiar to research in electricity and magnetism.

A broad overview of the developments in electricity and magnetism in Germany during this period reveals the following picture. The early years of the century saw a flurry of activity on the voltaic pile and various associated electrostatic and electrochemical phenomena by men such as Ritter, Erman, Jäger, Pfaff, and, in the 1810's, Schweigger. (See Table 1 for dates and given names.) With the discovery of electromagnetism in 1820 came contributions by Seebeck, Muncke, Poggendorff, Pohl, and Schmidt, in addition to continued work by Erman, Pfaff, and Schweigger. These individuals set the tone for the study of electricity in Germany during the first quarter of the nineteenth century. Although some of them remained active in the field into the 1830's (Erman and Muncke), 1840's (Pfaff and Pohl), and even later (Poggendorff), a new approach to the study of physics had already begun to emerge in the late 1820's, represented first by Ohm's and Fechner's treatment of current and the pile. In the next decade this new approach was extended to electromagnetism by Lenz, Jacobi, Gauss, and Weber and to terrestrial magnetism and static electricity by Moser and Riess. In the mid-1840's it appeared in the theoretical electrodynamics of Fechner, Weber, Neumann, and Grassmann. These twenty individuals were, with Dove, the most important contributors to electricity and magnetism in Germany during the period 1800 to 1846 , their importance being judged on the basis of contemporary and subsequent recognition and extent of publication in the leading scientific journals. The sample represented in Table 1 has been checked for completeness against two extensive specialized bibliographies and a standard history, even though it is impossible to select a historiographically useful sample solely on the basis of an objective procedure such as entry-counting. ${ }^{2}$

2For a discussion of other possible candidates for inclusion, see Kenneth L. Caneva, Conceptual and Generational Change in German Physics: The Case of Electricity, 1800-1846 (diss., Princeton Univ., 1974), pp. 19-22, for the results of a numerical tabulation based 
Table. 1. Principle German Contributors to Electricity and Magnetism during the First Half of the Nineteenth Century

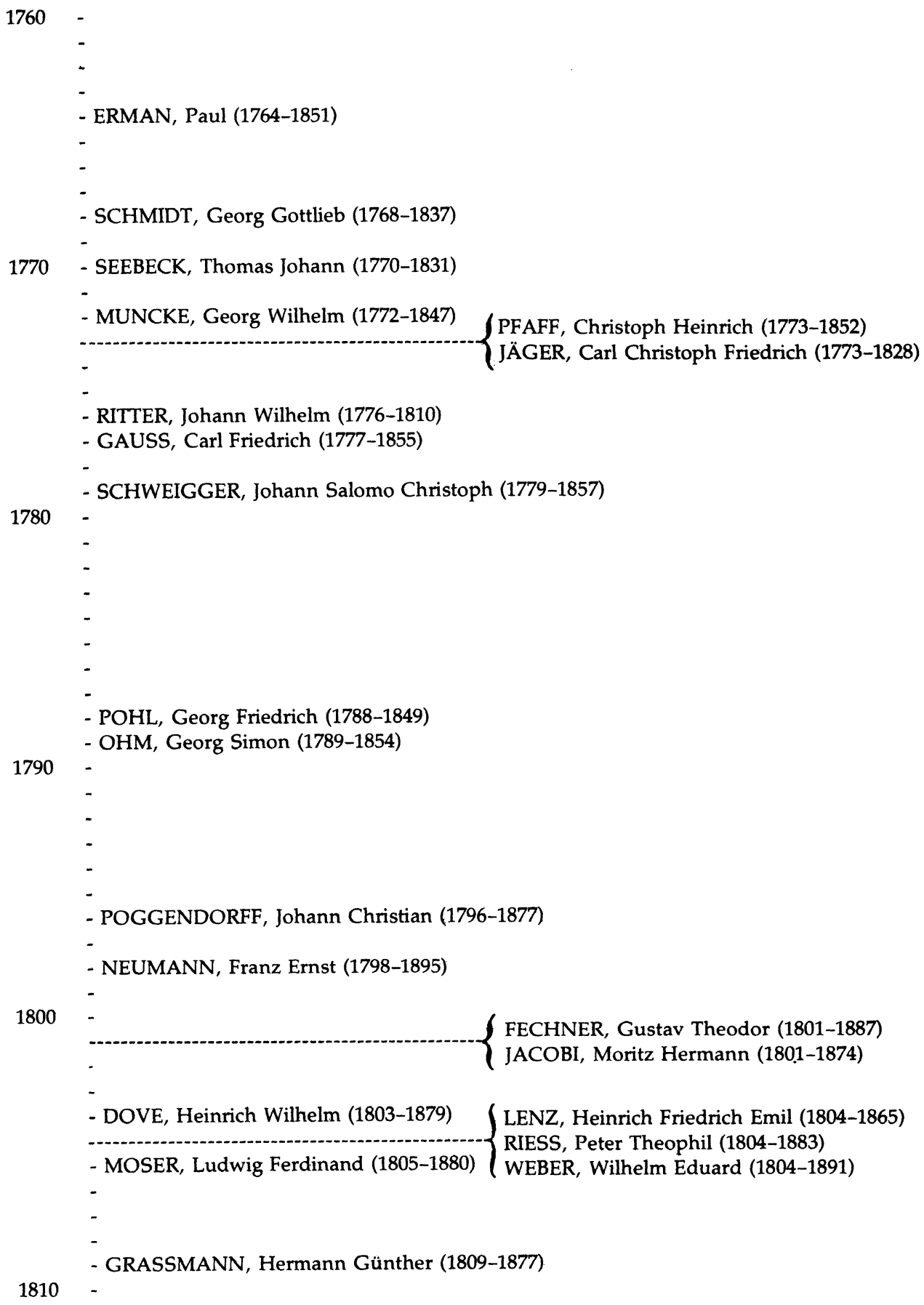


It is the major thesis of this paper that these scientists represented two very different paradigms of science, a distinction implicit in the above sketch of major figures and areas of research. ${ }^{3}$ The earlier approach, called "concretizing science" in Section 2, was characterized in particular by the qualitative nature of its experiments, by the belief that experience is a direct and epistemologically primary source of scientific knowledge, and by the notion that there is an essential distinction between physical understanding and mathematical description. The later approach, the "abstracting science" of Section 3, was, in contrast, marked by an overriding concern with quantitative measurement, by the free use of theoretical assumptions in conjunction with their subsequent hypothetico-deductive control, and by the relative abstractness of what it regarded as scientific knowledge. The explication of these two paradigms and the presentation of evidence that they were in fact held by the members of the two groups will be the task of the next two sections of this paper.

To some extent these groups have been identified not only in terms of their attachment to a particular paradigm, but also on the basis of their intercommunication and attention to the same problems. ${ }^{4}$ Schmidt, for example, whose appreciation for mathematics and use of the hypothetico-deductive method were atypical of his generation, has nevertheless been classed among the concretizing scientists, albeit as something of an exception, because he was clearly a member of the same larger community and addressed himself to it and to its problems; for example, to the anti-Amperian theory of transversal magnetism. His work was unknown to the younger scientists. Pohl, well known in his day as virtually the only exponent of Naturphilosophie among German university physicists, was regarded se-

on the following three works: Heinrich Wilhelm Dove, "Literatur des Magnetismus und der Elektricität," Repertorium der Physik, 5 (1844), 152-288; Catalogue of the Wheeler Gift of Books, Pamphlets and Periodicals in the Library of the American Institute of Electrical Engineers, ed. William D. Weaver, 2 vols. (New York, 1909); and Edmund Hoppe, Geschichte der Elektricität (Leipzig, 1884; rpt. Wiesbaden, 1969). My termini for this tabulation were 1800 and 1846: 1800 is a meaningful beginning because Volta's announcement of his pile in that year began a new era in electricity; 1846 is convenient because it includes the important electrodynamics work of 1845-1846 but excludes almost all the early papers of men such as Kirchhoff and Beetz, who belonged to the next generation of German physicists born around 1820 .

"I use the word "paradigm" to mean "the entire constellation of beliefs, values, techniques, and so on shared by the members of a given community" (Thomas S. Kuhn, The Structure of Scientific Revolutions, 2nd ed. [Chicago \& London, 1970], p. 175).

${ }^{4} \mathrm{On}$ this basis it proved impossible to place Dove, most of whose work was in meterology but who also did experimental work on electromagnetic induction, particularly with respect to qualitative differences between frictional and galvanic electricity. In addition to the idiosyncratic quality of his work, he seems not to have interacted with anyone except Riess, who, as an amateur studying static electricity, was himself something of an anomaly. See also note 213. 
riously enough by his contemporaries to warrant consideration, and his papers continued to be published in Poggendorff's Annalen der Physik, the supposed enemy of Naturphilosophie. 5 Pohl addressed himself to the same problems that occupied the other representatives of concretizing science, although his treatment was different in some respects. Poggendorff, the oldest member of the younger generation, was intellectually more at home with the science of the preceding generation than with the style of physics being developed by his contemporaries. As might be suspected, his pivotal position as editor of the Annalen der Physik has contributed to a distorted image of physics in Germany during the second quarter of the nineteenth century. Poggendorff was not among those who assimilated Ohm's theory; that was done by Fechner, Jacobi, Lenz, Moser, Neumann, Weber, and Gauss. The separation of the two groups was so great that the few cases of contact between representatives of the two paradigms, such as between Muncke and Lenz and Pohl and Ohm, serve only to underscore the extent to which they represented different and even noncommunicating styles of science.

The most striking feature of Table 1 is that the scientists in it fall, with two exceptions, into two well-defined generations according to year of birth. Indeed, there is some evidence that this generational split was not confined to electricians but was a general feature of German science. Johannes Müller (1801-1858), the great anatomist and physiologist, noted the change as it was taking place. He wrote of the 1828 Naturforscherversammlung in Berlin that "the predominant impression was one of fresh, ambitious youth, alongside the old men also present in large numbers-that is very significant." 6 This genera-

\footnotetext{
${ }^{5} \mathrm{An}$ important issue in the historiography of nineteenth-century German science is the nature and role of Naturphilosophie. I have elsewhere argued that it must be distinguished from the mainstream physics of the early decades of the century (i.e., concretizing science) and that it in no way set the tone for the physics of the period. Not only did the younger generation not represent a conscious reaction against it, but several of them drew inspiration from it to look for unity where others had been satisfied with diversity. The electrodynamics of Fechner, Weber, Neumann, and Grassmann all bear an unmistakable stamp due to the direct or (with Weber) indirect influence of Naturphilosophie. See Caneva, op. cit. (note 2), pp. 99-103, 132-157, and 364-413.

'Letter of 27 September 1828 to his wife, quoted in Wilhelm Haberling, Johannes Müller. Das Leben des rheinischen Naturforschers (Leipzig, 1924), p. 93. Müller's impression is substantiated by the data. I have been able to identify twenty-six of the twenty-nine eigentliche Physiker present, a category including Müller and the Naturphilosoph Henrich Steffens (1773-1845). With the exception of Ernst Gottfried Fischer (1754-1831), who was by ten years the oldest, the rest fall into three quite distinct groups: ten were born within the period 1764-1778, five within the period 1786-1790, and ten within the period 1795-1804. (See Isis von Oken, 22 [1829], col. 246.) With respect to the possibility of there having been a similar generational discontinuity in chemistry, see Erwin Hiebert, rev. of Deutsche Chemiker in der ersten Hälfte des neunzehnten Jahrhunderts (Weinheim, 1956) by Wilhelm Prandtl, Isis, 50 (1959), 79-81, on 80.
} 
tional grouping takes on added significance from the fact that it corresponds very closely to a division of the sample according to scientific paradigm, and I shall often speak simply of "the older generation of concretizing scientists" and "the younger generation of abstracting scientists." The close association between generational membership and adherence to a particular paradigm will be elaborated in Section 4 , which seeks to explain this episode of rapid and profound scientific change in terms of the professional-institutional and socialpsychological context within which individuals did a particular kind of science. Of importance there will be not only the sharpness of the generational split but also the historical situation of the younger generation in a period of disruption and social reform.

My conception of the role of generations in the history of science is different from the one recently advanced by Lewis S. Feuer. ${ }^{7}$ Feuer defined his generations primarily in personal and psychological terms, in particular with respect to the relationship between child and parent. My generations are groups defined conceptually and sociologicohistorically, and it is the nature of the relationship between these two modes of definition that this paper attempts to explain on the basis of a detailed analysis of the scientific work done by the two groups and the society to which they belonged. An essential aspect of my approach, which is sorely lacking in Feuer's book, is the identification of those particular aspects of scientific change that seem not to be explicable simply in terms of borrowing or of some kind of internal scientific dynamic. Feuer's preoccupation with personal "generational revolt" and his desire to avoid any kind of "generational relativism" with respect to what constitutes scientific knowledge have led him to underestimate the force of community-defined standards and to overestimate the extent to which scientists are capable of resolving disputes on the basis of their supposed "common allegiance to verification." In this paper, on the contrary, I attempt to demonstrate the explanatory strength of paradigms as more or less incommensurable expectations of acceptable science.

\section{THE SCIENCE OF THE CONCRETE}

The dominant feature of the science of the concrete was a particular conception of the nature of knowledge and its relationship to experience, a conception reflected in the essentially qualitative character of most of the experimental work done by the members of the older

'Lewis S. Feuer, Einstein and the Generations of Science (New York, 1974). 
generation. In part their experimental standards reflected the ideal of the experimentum crucis, whereby researchers sought one simple experiment whose results would tell directly and decisively either for or against a particular point without any need for quantitative data. Experiments done in that mode were typically either null-effect or those showing only the presence or absence of some substance or phenomenon. The reliance on supposedly decisive, nonquantitative experiments was one of the most significant features of the long and heated controversy between the chemical and contact theories of the voltaic pile. In part the experiments of the older generation reflected the vague ideal of a purely atheoretical physics, of facts and experiments without any hypothetical interpretation. This attitude can be seen in the titlc given to many of the papers of the period, "Versuche und Bemerkungen über...," according to which model experiments were done, sometimes without much direction or clear expectation, and the results obtained were then commented upon.

The most important general aspect of the older generation's view of the relationship between knowledge and experience was the belief that experiment was supposed to come-logically and, ideally, also temporally-before any conceptualization. This meant that experiment tended to be regarded as a source rather than as a control of whatever theory there might be. Not only was scientific knowledge supposed to derive from experiment, but it was often supposed to be a direct expression of some basic, experimentally demonstrable phenomenon, some Zentralphänomen, Hauptphänomen, or Fundamentalversuch. It was strongly felt that a theory should capture and express the phenomena directly in something like pictorial representation. One repeatedly encounters the demand that a theory should be anschaulich, and this desire for Anschaulichkeit was one of the most distinguishing features of concretizing science. Indeed, since the usual English translation of Anschauung as "intuition" suggests an internal-mental source of knowledge, it is well to keep in mind that the basic meaning of anschauen is "to look at" and that the Anschaulichkeit demanded of theory implied an element of perceptual immediacy.

The other side of this empiricism was an explicit rejection of the use of hypotheses in science. When hypotheses were used at all it was generally with the attitude that they were only provisional substitutes for sure knowledge. Hypothesizing prior to experimenting was regarded as almost dishonest and certainly liable to lead to distortion. Although an experimentum crucis might in principle have been part of a hypothetico-deductively elaborated theory, it was in practice not so conceived by the older physicists. Such an experiment tended rather 
to be associated with a particular Fundamentalversuch and not with a tightly structured but perforce merely "hypothetical" theory. It is important to recognize that whereas the empiricism of the "classical" Baconian inductive method was primarily a method of discovery, the empiricism of German concretizing scientists was rather a method of presentation and proof. Furthermore, since by "theory" the latter characteristically understood a nonmathematical representation of the experimentally given, one could say that their empirical-experimental method aimed at demonstrating "theories" rather than at discovering facts, though again one of the aims of their methodology was to bridge, if not to eliminate entirely, the gap between fact and theory.

This qualitative experimental bias and the demand that physical knowledge be anschaulich were naturally accompanied by a deemphasis of mathematics. Numerical data would have been of little relevance to a nonquantitative theory, and it was agreed that a theory could not be anschaulich if it were couched in the language of mathematics, which was incapable of capturing the essentially "physical" aspects of phenomena. The very lively contemporary discussion of the relative merits of mathematical versus physical theories demonstrated how the desire to avoid the over-mathematization of physics was a self-conscious position that reflected the prevailing view of what a physical theory was supposed to do.

To these three strongly characteristic traits of the physics of the older generation may be added a fourth, which, although expressive of the same underlying attitude toward science, was not as prevalent in as much of their work. Because of their experimental, frequently antitheoretical bias, it is often difficult to infer any precise notion of scientific explanation from the books and articles they wrote. Nevertheless, one often encounters the notion that the explanation of a particular phenomenon should be sought in terms of its association with other known phenomena. What was desired was a schematization or classification according to conceptual or analogical relationships within the framework of the existing body of knowledge. The older generation was at the same time in general agreement that physical explanation was not to be equated with mathematical description or with the hypothetico-deductive confirmation of predictions made on the basis of a precise theory.

These characteristics of the physics of the older generation make up what I call "the science of the concrete," or "concretizing science." 
The rest of this section will illustrate the extent to which these traits defined a coherent style of physics practiced by a temporally and geographically localized group of scientists.

\section{The Qualitative Nature of Experiment}

A typical example of the concretizing scientists' qualitative approach to experimentation is the electromagnetic research of the Berlin academician T. J. Seebeck. In keeping with much of the work done in immediate response to the discovery of electromagnetism in 1820 , Seebeck investigated the nature of the magnetic force exerted by a current-carrying wire or rod by noting the orientation assumed by magnetic needles held in different positions around it. On the basis of a number of such observations he threw out the conclusion that "the intensity of the magnetism is inversely proportional to the distance of the circle of action from the rod, and the magnetic middle of this circle of action is the axis of the rod." 9 He further noted that the declination of the magnetic needle due to the effect of the current depended on the length of the needle, and he cited results obtained for needles of different length. However, his data only showed that the declination was greater for shorter needles. He did not attempt to derive any mathematical law, nor did he give any information on such factors as the distance of the needle from the wire or the relative strength of the needles. This work was typical of Seebeck's contentment with qualitative or crudely quantitative results and of his failure to provide a detailed description of the conditions of his experiments.

physique expérimentale. See Robert E. Schofield, Mechanism and Materialism: British Natural Philosophy in an Age of Reason (Princeton, 1970); I. Bernard Cohen, Franklin and Newton. An Inquiry into Speculative Newtonian Experimental Science and Franklin's Work in Electricity as an Example Thereof (Philadelphia, 1956); and Jean Torlais, "La physique expérimentale," Enseignement et diffusion des sciences en France au XVIII ${ }^{\mathrm{e}}$ siècle, ed. René Taton (Paris, 1964), pp. 619-645. On the application of mathematics to the experimental sciences in France see Eugene Frankel, Jean-Baptiste Biot: The Career of a Physicist in Nineteenth Century France (diss., Princeton Univ., 1972). On scientific method see Laurens Laudan, "Theories of Scientific Method from Plato to Mach: A Bibliographical Review," History of Science, 7 (1968), 1-63. On the place of these experimental traditions in the history of science see Thomas S. Kuhn, "Mathematical vs. Experimental Traditions in the Development of Physical Science," Journal of Interdisciplinary History, 7 (1976), 1-31. For a more detailed exposition and further references see also Caneva, op. cit. (note 2), pp. 29-42 and 159-163.

'Thomas Johann Seebeck, “Ueber den Magnetismus der galvanischen Kette," Abhandlungen der Königlichen Akademie der Wissenschaften zu Berlin, 1820-1821 (pub. 1822), Abhandlungen der physikalischen Klasse, pp. 289-346, on p. 299. For comparison see the careful quantitative measurements of Jean-Baptiste Biot and Félix Savart, "Sur l'aimantation imprimée aux métaux par l'électricité en mouvement," Journal des savans (Avril 1821), pp. 221-235, and in much more expanded form in Biot's Précis élémentaire de physique expérimentale, 3rd ed., 2 vols. (Paris, 1824), 2, 704-774. 
In another series of incompletely reported experiments Seebeck investigated the relationship between the chemical activity in the pile and the "magnetic tension" exerted by the current-carrying wire. He placed a magnetic needle near the connecting wire of a copper-zinc cell whose liquid was made increasingly acidic, and he tabulated for each concentration the final rest position of the needle and the number of oscillations it made before coming to rest after the circuit had been closed. Although he made no attempt to analyze his data mathematically and had no measure at all of chemical activity (different from concentration), he stated his conclusion as if he had discovered a precise relationship between electromagnetism and chemical activity: "From these experiments it therefore follows that the magnetic tension of a galvanic circuit is proportional to its chemical activity, and hence the magnetic needle will be able to be used to determine the energy [Energie] of the chemical process in the galvanic circuit."10 In these and other experiments Seebeck recorded quantities of data, but in every case the data allow only qualitative or general order-of-magnitude conclusions. Never did he derive a precise functional relationship between two variables, not did he seem interested in the possibility of doing so. Although he wondered how the dimensions of a spirally wound conductor affected the magnetic tension it exerted, he never tried to determine exactly how that tension depended on the individual measurable factors such as thickness of wire or number of turns.

The existence of a dispute between the Heidelberg physicist G. W. Muncke and the St. Petersburg academician H. F. E. Lenz affords an excellent opportunity for contrasting the experimental techniques of members of the older and younger generations. The interchange began with the publication of a paper of Muncke's in 1830 describing a torsion balance he had built to study faint electrical attractions and repulsions. The balance consisted of a beam made of a long thin glass rod with a small pith ball on one end and a gold-leaf counterbalance on the other, the whole suspended by means of a silk thread and enclosed in a hemispherical glass case. By chance Muncke noticed "an automatic rotation of the beam" when the balance was set up near a window. ${ }^{11}$ After eliminating terrestrial magnetism and light as possible causes, he decided to test whether the motion of the beam was due to heat. Placing a container of hot water near the glass

10Seebeck, op. cit. (note 9), p. 311.

${ }^{11}$ Georg. Wilhelm Muncke, "Thermoelektrische Beobachtungen, mitgetheilt in der Versammlung der Naturforscher und Aerzte zu Hamburg 1830," Annalen der Physik und Chemie, 20 (1830), 417-431, on 418. 
hemisphere in which the balance was housed, he noticed that not just the pith ball but the entire beam moved against the glass wall and stayed there, sometimes for several seconds, only to fall back and then return again with "precisely such motions... as such balls are wont to make when one approaches them with an electrically charged conductor."12 On the basis of this similarity Muncke jumped to the conclusion that the motions he had observed were also due somehow to electricity, for, as he wrote, "the motions of light bodies attracted by electricity are, under somewhat greater electrical tension, of such peculiar character that a trained observer can easily distinguish them from others." 13 In support of his explanation Muncke repeatedly emphasized the peculiar and distinctive motions of electrically charged bodies and the testimony of others that these motions "looked electrical." In a subsequent paper he reported that "various physicists [including Captain Henry Kater] have since then seen the phenomenon in my laboratory, and all have pronounced it to be decidedly electric." 14 Muncke seems to have had the notion that questions in physics are decided on the same basis as in law, by agreement among honest witnesses. Lenz ridiculed him on this point by paraphrasing his statement above as "I, Captain Kater, and other friends found that the motions look thoroughly like electrical," " and he had only contempt for Muncke's argument, "which is derived from the appearance of the motions and can have complete power of proof for at best eyewitnesses."15

Having surmised from the supposed peculiar nature of the motions that the phenomenon was electrical, Muncke concluded that a difference in temperature on opposite sides of the balance had "thermoelectrically" excited the electricity. Nevertheless he did not try to detect this electric charge by means of an electroscope, nor did he determine how large a charge of static electricity produced by other

\footnotetext{
12Ibid., pp. 419-420.

13Ibid., p. 420.

${ }^{14}$ Muncke, "Bemerkungen über die Versuche des Hrn. Lenz in Betreff der Drehungen des Coulombschen Wagebalkens, und Nachricht von den akustischen Versuchen des Hrn. Scheibler," Annalen der Physik und Chemie, 29 (1833), 381-397 and 398-403 ("Nachschrift"), on 386. Cf.: "When one justly appreciates all the reasons given, in particular the fact attested to unanimously by three credible observers, that the rotations in a significantly evaculated space were similarly unchanged, when one [considers] the peculiar character of the oscillations, which one of course must have seen in order to declare them to be unquestionably electrical..., then I do not in fact understand how there can remain any doubt as to the correctness of the explanation given" (ibid., p. 389). For yet another example of this attitude, see Muncke, op. cit. (note 11), p. 422.

15 Heinrich Friedrich Emil Lenz, "Bemerkungen gegen den in diesen Annalen (Bd. XXIX S. 381) enthaltenen, wider mich gerichteten Aufsatz des Hrn. Muncke über Thermoelektricität des Glases," Annalen der Physik und Chemie, 35 (1835), 72-81, on 74 and 80.
} 
means would be necessary to cause similar motions. Although he quite gratuitously asserted that the slight temperature difference at the surface of the glass hemisphere would not be great enough to produce air currents strong enough to move the balance beam, he accepted without hesitation or corroboration "the remarkable fact of the phenomena" that such a slight temperature difference was sufficient to produce an electric charge great enough to cause the observed deflection. ${ }^{16}$ To test whether the air contributed to the motion, Muncke repeated the experiment with his balance in an evacuated bell jar. He found that the apparatus exhibited the same phenomena and with equal strength "as far as can be decided by simple estimation without actual measurement." 17 Not only did Muncke make no attempt to measure the magnitude of the force, as Coulomb had shown how to do forty-five years earlier, but he could make no theoretical prediction as to whether increased rarity of the air should diminish the effect if it were due to air currents. The inability to make meaningful measurements led him to desire the decisiveness (entscheidender Beweis) of a nonquantitative, all-or-nothing experiment carried out in an (unfortunately unobtainable) perfect vacuum. ${ }^{18}$ Muncke felt no need to control, vary, and measure the different variables in his experiment so that his results would decide clearly either for or against his proposed explanation.

Lenz responded to Muncke's claims in one of his earliest scientific papers. He had originally accepted Muncke's explanation but began to doubt it when he observed that the apparent attraction or repulsion of the balance beam depended on whether the hot body was held above or below the level of the beam. If the motion were due to thermoelectricity the beam should always be attracted, whatever the temperature of the body. If the motions were due to air currents, however, a hot body brought against the glass would cause the air adjacent to that side to rise, producing circular convection currents within the container. Hence, if the beam were hung toward the heated side near the top of the container it should move away from that side. Lenz performed a series of twenty-four experiments in

16Muncke, op. cit. (note 11), p. 424.

${ }^{17}$ Ibid., p. 420.

18Ibid., p. 423. Lenz pointed out that since we do not know how the velocity of air molecules depends on density, Muncke was not entitled to use the results of an experiment in a partially evacuated container as proof of the unimportance of air currents, especially in the absence of quantitative measurements. Such experiments, uncontrolled by precise theory, cannot support firm conclusions. See Lenz, "Ueber die Bewegungen des Balkens einer Drehwage, wenn demselben andere Körper von verschiedener Temperatur genähert werden," Annalen der Physik und Chemie, 25 (1832), 241-265, on 263-264. 
which he observed the deflection of the beam by a hot or a cold body placed alongside the glass container when the beam was hung either near the top or near the bottom. He found that the results of his experiments "correspond exactly to what I had already concluded beforehand on the basis of the theory of air currents." $19 \mathrm{He}$ then confirmed this explanation in additional series of experiments under varying conditions. Although his experiments were not always strictly quantitative, Lenz did seek to estimate the relative importance of several possible factors by controlling them one at a time. To detect the presence of free electricity on the cylindrical glass housing of his apparatus he performed twenty trials with a sensitive electroscope. Only two revealed very weak traces of negative electricity. He sought to demonstrate the nullity of the supposed thermoelectric effect directly, by using a torsion balance, the beam of which consisted of a copper wire with a gilded pith ball on one end and a mercury-filled thermometer bulb on the other. The entire beam was then suspended by a thin silver wire, enabling him to communicate positive or negative electricity to the gilded pith ball. He found that the motion of the beam was the same whatever the charge given to the pith ball, whereas if the thermoelectricity of the glass were positive and the electricity conveyed to the pith ball were also positive, then the beam should always have indicated repulsion. To be sure that the pith ball did in fact carry a charge he checked to see that it responded to the presence of a charged glass rod brought near the glass housing. He concluded that heat could not have produced the observed motions through the stimulation of electricity in the glass.

Compared to the standards of their younger successors like Lenz, the experimental technique of older physicists like Seebeck and Muncke seemed to lack precision and control. Yet it cannot be said that they were simply poor experimenters. Rather their work reflected the striking absence of any interest in finding quantitative relationships between variables characteristic of concretizing scientists. This tendency is further illustrated by the early investigations of the electroscopic phenomena of the pile carried out by the Berlin physicist P. Erman and the Stuttgart physician C. C. F. Jäger. The experiments they performed on the phenomena we now identify as showing a progressive voltage drop across an increasingly long resistance were carefully and thoughtfully done, but neither man showed any interest in making precise measurements in order to discover exactly how the phenomena depended on the several identifiable vari-

${ }^{19}$ Lenz, op. cit. (note 18), pp. 252-253. 
ables. ${ }^{20}$ Nor can it be maintained that this omission was solely due to the state of experimental technique, especially after Coulomb had shown how to measure exact quantities of static electricity. It was rather that a conviction of the importance of such measurements had not yet become the standard of German experimental physics. Erman, for one, who lived well into the era of modern physics in Germany, never adopted the quantitative approach. In a paper of 1832 he proposed to investigate "the mechanism of permanent, fixed magnetic polarity" in order to decide between the "Cartesian-Ampèrian" and the "AepinusCoulombian" theories of magnetism, based respectively on the assumption of molecular currents and discrete magnetic fluids. ${ }^{21}$ To this end he performed a number of experiments in which a magnetoelectric current was induced by altering the magnetic state of a fixed magnet by bringing the magnet into contact with either a piece of soft iron or another magnet. Erman's experiments were entirely qualitative, and he did not explain how his experiments were relevant to the question of the nature of magnetism. Certainly he did not come close to providing a decision between competing theories based on the confirmation of a quantitative prediction.

The first published paper of the Berlin physicist J. C. Poggendorff exemplifies concretizing science's closest approach to a quantitative procedure, but although he recorded some numerical data, the only conclusions he was able to draw were strictly nonquantitative and general. Poggendorff proposed to investigate how the deflection of the magnetic needle varied according to its position relative to the current-carrying wire "and thereby to reduce the phenomena to a general expression." 22 This was the first task that many scientists set themselves after the announcement of Oersted's discovery of electromagnetism. However, Poggendorff's "general expression" was not a precise statement but a set of two schemas and two figures which pictorially indicated the motion of the magnetic needle with respect to the current-carrying connecting wire.

\footnotetext{
20Paul Erman, "Ueber die electroskopischen Phänomene der Voltaischen Säule," Annalen der Physik, 8 (1801), 197-209; "Ueber die electroskopischen Phänomene des Gasapparats an der Voltaischen Säule," Annalen der Physik, 10 (1802), 1-23; and Carl C. F. Jäger, "Ueber die electroskopischen Aeusserungen der Voltaischen Ketten und Säulen," Annalen der Physik, 13 (1803), 399-433.

${ }^{21}$ Erman, "Ueber Erzeugung von Electromagnetismus durch blosse Modification der Vertheilung der Polarität in einem unbewegten Magnet," Abhandlungen der Königlichen Akademie der Wissenschaften zu Berlin, 1832, Pt. 1 (pub. 1834), Physikalische Abhandlungen, pp. 17-32, on p. 18.

${ }^{22}$ Johann Christian Poggendorff, "Physisch-chemische Untersuchungen zur nähern Kenntniss des Magnetismus der voltaischen Säule," Isis von Oken, 1821, Bd. 2 [des Jahres = Bd. 9 der ganzen Reihe], cols. 687-710, in col. 688 .
} 
The first relationship Poggendorff investigated was that between the deviation of the multiplier needle and the number of turns in the coil. He recognized that it was first necessary to determine "whether the angle of deflection is to be taken as the direct expression for the measure of the magnetic forces." ${ }^{23} \mathrm{His}$ experiment consisted of connecting in turn one, two, or three simple piles with a multiplier of eight turns and observing the deflection of the needle for each case. From three resulting pairs of readings he concluded that the angle of deflection was not a direct measure of the electromagnetic force exerted by the wire. Although he recognized that one could not measure the magnetic activity without calculating the dependence of the angle on the force exerted by the wire, he apparently had no idea how to carry out this analysis. Poggendorff next tabulated the deflection of the needle as the number of turns was increased by hundreds, from 100 to 1300 . He noted that the maximum magnifying effect of the multiplier was reached somewhere between 800 and 900 turns. In other experiments he compared the effect of two batteries of widely differing plate size. This time he connected together the ends of all the coils to form a continuous wire but used only a particular number of turns at any one time. His readings, for both large and small batteries, were taken for 1, 5, 10, 25, 50, and 75 turns and by hundreds of turns from 100 to 1000 . For the large battery the maximum effect was reached before 75 turns and for the small battery somewhere between 200 and 300, though the value of the maximum deflection was the same in both cases, a fact for which Poggendorff had no explanation. Except for one other similar but much less extensive experiment using coils made of thicker wire, he made no attempt to control successively his variables in order to discover the exact relationship between them, contenting himself with the conclusion that "the action of the circuit does not increase without limit with the number of turns." 24 Despite his early and promising start toward discovering the laws governing the behavior of the multiplier when connected with variously constructed piles, Poggendorff abandoned the subject after 1821 . He never showed any interest in finding mathematical laws.

Although the multiplier has come to be thought of as a measuring device, it was not immediately so conceived or used by the members of the older generation. It was not used in that way by Poggendorff or by its coinventor, the Halle professor of physics and chemistry J. S. C. Schweigger. Nor did Oersted use the multiplier in the first instance as a measuring device but rather as a qualitative indicator of the direc-

24Ibid., col. 697; cf. the fourth of his fourteen conclusions, col. 709. 
tion of the current produced by piles composed of different metals and acids. ${ }^{25}$ Oersted was interested not in the quantitative relations of the multiplier for their own sake but in defending the contact theory and in arranging the different metals in the traditional electromotive series.

\section{The Role of Experiment: The Inductivist Ideal and the Rejection of the Hypothetico-Deductive Method}

Concretizing scientists' qualitative approach to experiment was closely related to their conception of its role vis-à-vis scientific knowledge, a fact especially evident in their explanation of electromagnetism in terms of the theory of transversal magnetism, some form of which was accepted by most of the older generation. This theory held that a current-carrying wire becomes magnetically polarized transversally, with several lines of north and south poles running along its length, the exact number and position of them varying according to the particular version of the theory. ${ }^{26}$ This was regarded as a physically more plausible alternative to Ampère's theory, which was criticized in the following typical fashion by Muncke:

The thing that has made the more exact knowledge and grasp [Uebersicht] of Ampère's theory so exceptionally difficult for me and certainly for many others, too, is the circumstance that its famous discoverer leaves completely unexplained the original principal fact, namely, the peculiar magnetic action of the simple electric conductor on the magnetic needle, while he with great cleverness derives the formation of a steel magnet out of electromagnetic, wound conductors and with remarkable skill develops the mutual influence of both on each other under the most varied modifications. Even his geometrical construction of all electromagnetic phenomena, carried out with great skill in calculation and the application of the cleverest combinations, is based on the mutual action of two electric currents on each other and thereby passes over the action of the simple conductor on the

\footnotetext{
${ }^{25}$ Hans Christian Oersted, "Sur le Multiplicateur électro-magnétique de $\mathrm{M}$. Schweigger, et sur quelques applications qu'on en a faites," Annales de chimie et de physique, 22 (1823), 358-365; reprinted in his Naturvidenskabelige Skrifter, ed. Kirstine Meyer, 3 vols. (Copenhagen, 1920), 2, 266-272. Poggendorff used the multiplier for exactly the same purpose: op. cit. (note 22), cols. 703-704.

${ }^{26}$ For a non-German variant see Jöns Jacob Berzelius, "Lettre à M. Berthollet sur l'état magnétique des corps qui transmettent un courant d'électricité," Annales de chimie et de physique, 16 (1821), 113-119.
} 
magnetic needle, which Ampère, to be sure, does not fail to report as a fact. ${ }^{27}$

Although Muncke recognized that Ampère's theory had withstood every attempt to bring it into contradiction with the phenomena, he refused to accept it because it was not based on what he regarded as "the original principal fact," the action of a current-carrying wire on a magnetic needle. That he regarded this as the fundamental phenomenon and not, with Amperre, the action between current elements stemmed in part from its historical priority with Oersted and in part from his dislike of the violation of the analogy from electrostatic forces that Ampère's law entailed. The fact that like-directed current elements attract in Ampère's theory, whereas like charges of static electricity repel, seemed unsatisfactory to Muncke. In addition, Muncke insisted on seeing transversal magnetism as directly given by the observable phenomena, especially by a certain "fundamental experiment":

A great number of physicists see in the wire conducting electricity nothing other that a transversal magnet with north and south polarities running parallel to its axis. It reveals itself in reality so clearly as such... that this simplest of all modes of explanation had to find many supporters, all the more as it had significant support from the bipolarity of all known magnetic phenomena. Accordingly, each cross section of the electrical conductor forms a surface in which the opposed magnetic poles lie around the center of the electric current, the number of poles varying considerably among the supporters of this viewpoint. All these diversely modified theories have, with Oersted and Faraday, the common advantage that their explanations proceed from the first fundamental experiment. ${ }^{28}$

The primary role that Muncke assigned to experiment as the direct source of his theory of transversal magnetism corresponded to his general views on the character of physics. He insisted that physics was an Erfahrungswissenschaft based upon observations and experiments and that it was built "solely upon experiences and the conclusions derived therefrom." 29

\footnotetext{
${ }^{27}$ Muncke, "Elektromagnetismus," Johann Samuel Traugott Gehler's Physikalisches Wörterbuch, eds. Heinrich Wilhelm Brandes, Leopold Gmelin, Johann Caspar Horner, Joseph Johann von Littrow, Georg Wilhelm Muncke, and Christoph Heinrich Pfaff, 11 vols. (Leipzig, 1825-1845), 3 (1827), 473-647, on 616-617.

28Ibid., pp. 621-622.

${ }^{29}$ Muncke, "Physik," Gehler's Physikalisches Wörterbuch, (note 27), 7, Pt. 1 (1833), 493-573, on 501 and 505; see also 497.
} 
When Muncke published his own theory of transversal magnetism in 1822, he noted that two similar theories had already been proposed to explain electromagnetism. ${ }^{30}$ Both of these theories had opposed the identity of electricity and magnetism postulated by Amperre, and they did not, as did Ampère's theory, apparently contradict the established laws of electrostatics by assuming that the homogeneous electricities of two conducting wires attract each other. Muncke argued that one should stick to the long-known and observable facts which clearly attest to the existence of four symmetrically situated lines of magnetic polarity running parallel to the length of the electric conductor. ${ }^{31}$ Muncke's theory was supposed to be directly demonstrable by means of simple experiments, and he began its proof by observing the attractions and repulsions of a small magnetic needle held in various positions around a current-carrying wire. His initial results were often obscure or even contradictory, but he found a way out of this confusion by investigating the behavior of the needle with respect to bar magnets substituted for the wire, quite ignoring the objections that might be made to this substitution. He regarded these experiments with magnets as the direct source and justification of his theory of transversal magnetism, insisting that his conclusions were "not asserted hypothetically but derived immediately from the phenomena" and that they could not fail to be accepted by anyone who would simply observe the experiments he described, in particular the "peculiar character" of the oscillations of the needle. ${ }^{32}$ In Muncke's opinion his own theory avoided the structural defects of Ampère's theory that even its complete success in practice could not outweigh, namely, its arbitrariness and its presuppositions not drawn from the essence of the phenomenon. ${ }^{33}$

Muncke subscribed to the belief that hypotheses are only provisional substitutes for sure knowledge. ${ }^{34}$ When concretizing scientists like Muncke did use them, hypotheses had more the character of

30These were Berzelius, op. cit. (note 26) and August Heinrich Jacob von Althaus, Versuche über den Electromagnetismus, nebst einer kurzen Prüfung der Theorie des Herrn Ampère. Mit einer Vorrede vom Hofrath Muncke (Heidelberg, 1821). Althaus (1791-?) was a nobleman who dabbled in science and whose contribution to electricity was this book of thirty-seven pages.

${ }^{31}$ Muncke, "Versuche über den Electro-Magnetismus zur Begründung einer genügenden Erklärung desselben," Annalen der Physik, 70 (1822), 141-174, on 145-146. See his final formulation of this Hauptgrundsatz on p. 169.

32Ibid., p. 167. See also his "Fortgesetzte Versuche über den Electro-Magnetismus zur Begründung einer genügenden Erklärung desselben," Annalen der Physik, 71 (1822), 20-38, on 36 .

${ }^{33}$ Muncke, op. cit. (note 27), p. 615.

${ }^{34}$ Muncke, op. cit. (note 29), pp. 503-504. 


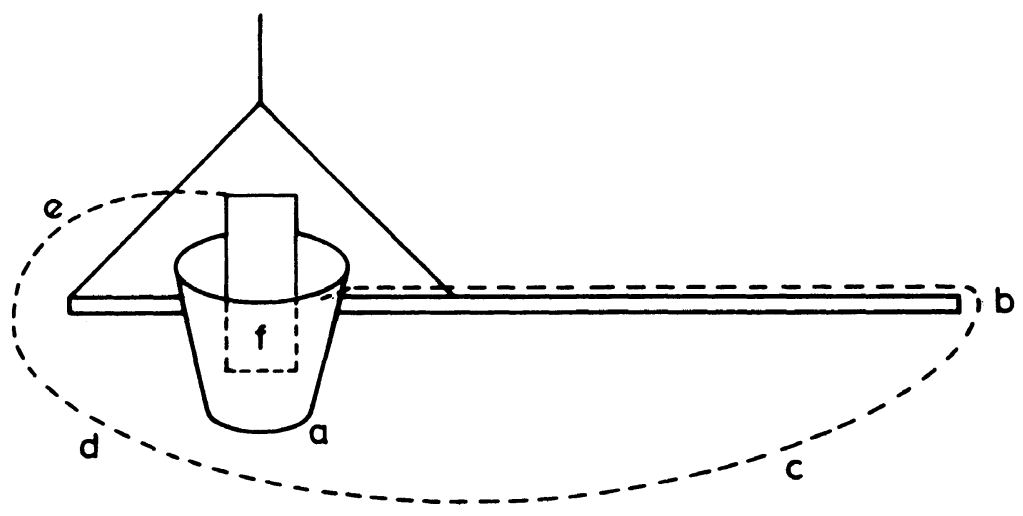

Figure 1. Erman's Rotations-Kette.

a-silver or copper cup, filled with dilute acid. bcde-narrow strip of zinc or tin foil or wire. $f$-piece of zinc.

The "arm" of the Rotations-Kette was a 7"-8" strip of cardboard.

after-the-fact possible explanations for puzzling phenomena than of sharply formulated statements to be tested by subsequent, controlled experiment. ${ }^{35}$ Muncke's protestation that his conclusions were not advanced hypothetically but deduced immediately from the phenomena reflects the common belief that it was somehow dishonest to try to prove a personal opinion with experiments contrived after the fact. ${ }^{36}$

That Paul Erman, too, was wedded to the antihypothetical inductivist and representationalist standpoint of concretizing science was vividly shown in his only published book in which he proposed his own theory of transversal magnetism. His method, essentially the same as Muncke's, was to present his theory as the direct expression of a series of easily repeated and wholly qualitative experiments. His primary piece of apparatus was his Rotations-Kette, a freely suspended galvanic circuit which he believed would clearly reveal the nature of what he called "electric-chemical magnetism" (see Figure 1). His procedure was to observe the motion of the Rotations-Kette as a hand-held bar magnet was brought up to it from different directions. For example, when the cup end of the Rotations-Kette was toward the

${ }^{35} \mathrm{Cf}$. Muncke, "Hypothesen zur Erklärung einiger räthselhafter Naturphänomene," Journal für Chemie und Physik, 25 (1819), 17-28; and "Einige Bemerkungen zur Electricitäts- und Wärmelehre," Journal für Chemie und Physik, 30 (1820), 193-217.

${ }^{36} \mathrm{Cf}$. Althaus, op. cit. (note 30 ), p. 3. 


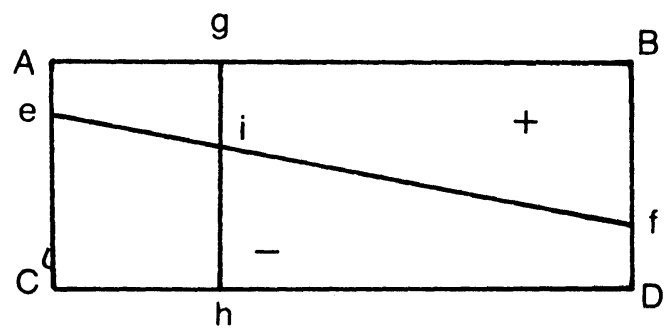

Figure 2. The transversal magnetism of a current-carrying conductor, according to Erman.

south, he found that the north pole of a magnet approaching the north end of the Kette from the east repelled that end, but approaching that same end from the west attracted it. In an easy leap to the conclusion he wanted to draw, Erman likened this behavior to that of an iron bar magnetized transversally such that the magnetic poles stretched along the entire length of the bar's opposite sides. On the basis of this and a few other experiments, Erman concluded that a current-carrying conductor becomes magnetically polarized along a diagonal plane cutting it transversally, as in Figure 2 (his Figure 9). Here $A B C D$ is a cross section of the wire or metal strip and ef is the imaginary plane separating the positively and negatively magnetized portions of the conductor. In his experiments and especially in his diagrams, Erman preferred rectangular to circular conductors as more clearly exhibiting the supposed transversal magnetism. He was especially concerned that his pictorial theory of diagonal polarization provide "a sufficient physical basis" for the most essential and characteristic phenomena so that it would seem worthwhile to pursue it further. He recognized that his theory needed refinement "before it is adequate to reproduce exactly all the details of the phenomena in all particulars." 37 His use here of the word nachkonstruiren-to copy, to reproduce-betrays the essentially physical-pictorial nature of his theory, and indeed it was of great importance to him that one could actually produce a bar magnet having the distribution of poles he assigned to the "electric-chemical" magnetism of the conducting wire. The further support he adduced for his theory was also of an explicitly concretely pictorial nature: "In order now finally to test graphically [mit Anschaulichkeit zu prüfen] the possibly already attained cogency of our conception and the extent of its agreement with the phenomena in this and all other cases, let one prepare according to

\footnotetext{
${ }^{37}$ Erman, Umrisse zu den physischen Verhältnissen des von Herrn Professor Örsted entdeckten elektro-chemischen Magnetismus (Berlin, 1821), p. 76.
} 
Figure 9 the picture of a suitably long and wide diagonally colored conductor, and, if one desires, also the picture of a compass needle enlarged in the same proportion." 38 Using actual models in this literal manner, he described how a magnetic needle should move when brought into different positions with respect to such a diagonally transverse distribution of magnetism.

Erman's theory of transversal magnetism is fully representative of concretizing science: it was totally qualitative and nonmathematical; its force was in the Anschaulichkeit with which it enabled one to conceive and reproduce certain fundamental phenomena; and it was presented as if it had arisen naturally from a sequence of simple experiments. ${ }^{39}$ Another subtle but important aspect of Erman's style of physics was his preoccupation with a narrow conception of straightforward honesty that discouraged use of the hypotheticodeductive method: "Since the view sketched here of the physical phenomena of chemical magnetism, as far as they are now known, really arose with me in the order of the investigations as expressed in the three sections [of this work], I considered myself, as it were, obliged to maintain the same order of presentation, for it is far easier to uncover the paralogisms of a theory when one knows precisely the thought process that led or misled its author."40 Erman's words imply that it would have been a violation of scientific propriety to have reorganized one's evidence after having devised a theory. Concretizing scientists consistently sought to guarantee the truth of their theories by showing their unforced, direct relationship to experiment. Erman in effect apologized for having introduced the concept of transversal magnetism as early in his book as he did when he wrote of having ordered his facts "on the basis of a hypothetical guide, as a necessary evil toward a better overview." 41

The general character of concretizing science had a great influence on the tenor of the long and heated controversy over whether the electricity of the voltaic pile was due to the mere contact of heterogeneous metals, as Volta had taught, or to some original chemical action, as maintained by Berzelius and later and with greater

\footnotetext{
38Ibid., pp. 99-100. On pp. 103-104 he again called his procedure anschaulich.

39These qualities also marked Schweigger's theory of a "double magnetic polarity" of the current-carrying wire and his "theory" (a pictorial schema) of the operation of the multiplier. See Caneva, op. cit. (note 2), pp. 80-84, and Schweigger, "Zusätze zu Oersteds elektromagnetischen Versuchen," Journal für Chemie und Physik, 31 (1821), 1-17 and 35-41. Schweigger referred to his hypothesis as one "that may be regarded as simply an expression of the fact" (ibid., p. 10).

${ }^{40}$ Erman, op. cit. (note 37), p. 36.

41 lbid., p. 35.
} 
fervor by Auguste de la Rive. ${ }^{42}$ Neither side had a theory that permitted exact predictions to be made and then tested against experiment, nor could either side decisively disprove the evidence advanced by the other. Rather each side found its favorite argument in one or two supposedly clinching experiments, while ignoring or explaining away the opponents' counter-experiments. The contact theorists thus often cited the sorcalled fundamental experiment of Volta, in which traces of static electricity were detected when two heterogeneous metals were placed in contact with each other and with a suitable electroscope, as proving conclusively that the mere contact between metals was capable of producing electricity. In reply the chemical theorists would claim that those results were really due to traces of moisture, friction, or some other complicating cause, and they would counterattack by citing a crucial experiment of their own. Each side relied on experiments of a generally qualitative, or at best crudely quantitative, all-or-nothing character. To be sure, the dispute could hardly have been resolved at a time when the relationship between static and current electricity was obscure and when there could be no recourse to arguments based on conservation of energy; but the manner in which the dispute was conducted attests eloquently to the methodological standpoint shared by both sides.

C. H. Pfaff, professor of chemistry at Kiel, was probably the most vocal and indefatigable advocate of the contact theory in Germany, and he devoted a major part of his scientific output toward its defense. ${ }^{43}$ The predominance of this one theme across more than forty years' work, as well as the polemical tone in which the inconclusive feud was carried out, distinguished Pfaff's work from that of the other representatives of concretizing science. Although he, too, believed

\footnotetext{
${ }^{42}$ On this controversy see Wilhelm Ostwald, Elektrochemie, ihre Geschichte und Lehre (Leipzig, 1896) and Wilhelm Beetz, "Die Fortschritte des Galvanismus in den Jahren 1837-1847," Repertorium der Physik, 8 (1849), 1-351.

43See, for example, his "Grundzüge von Volta's electrischer Theorie der Erscheinungen seiner Säule," Annalen der Physik, 10 (1802), 219-238; an unfinished critical article (he never got past Berzelius), "Revision und Kritik der bisher zur Erklärung der galvanischen Erscheinungen aufgestellten Theorien, und der Erfahrungen, auf welche sie sich stützen. Rechtfertigung derVoltaischen Theorie gegen die Einwendungen von Berzelius, Davy, Erman, Jäger, Ritter, Schweigger u. a.," Journal für Chemie und Physik, 10 (1814), 179-200; Der Elektro-Magnetismus, eine historisch-kritische Darstellung der bisherigen Entdeckungen auf dem Gebiete desselben, nebst eigenthümlichen Versuchen (Hamburg, 1824); "Défense de la théorie de Volta, relative à la production de l'électricité par le simple contact, contre les objections de M. le professeur A. de La Rive," Annales de chimie et de physique, 41 (1829), 236-247; and Revision der Lehre vom Galvano-Voltaismus, mit besonderer Rücksicht auf Faraday's, de la Rive's, Becquerels, Karstens u. a. neueste Arbeiten über diesen Gegenstand (Altona, 1837).
} 
that the contact theory was a direct expression of a simple demonstrable fact-Volta's fundamental experiment-he chose rather to emphasize its relationship to one or two other wholly qualitative crucial experiments. Insofar as the experimentum crucis was for Pfaff more of a test than a source of theory, it played a slightly different role for him than it did for others of the older generation. On the other hand, Pfaff's science never exhibited the kind of close correlation between theoretically deduced implications and subsequent experimental verification characteristic of the hypothetico-deductive method. In addition to the supposed cogency of Volta's fundamental experiment, Pfaff and other contact theorists made much of the absence of chemical action in an open pile, when closing the circuit (that is, establishing metallic contact) led to the production of an electric current. ${ }^{44}$ When dealing with the contact theory of the pile, not even those scientists who otherwise made use of the hypothetico-deductive method could break with the desire to find a single decisive experiment; and the certainty and sufficiency of Volta's fundamental experiment, regardless of any contradictory evidence, remained the basic issue for both Schmidt and Fechner. ${ }^{45}$ G. G. Schmidt, professor of mathematics and physics at Giessen, was in fact the only older generation scientist to make explicit and consistent use of the hypothetico-deductive method and hence is an exceptional case within the sample. His work, which tended to be much more mathematical than the contemporary norm, was devoted primarily to the physical properties of gases and liquids. ${ }^{46}$

\footnotetext{
${ }^{44}$ That was the thrust of Pfaff's paper, "Ein Experimentum crucis für die Richtigkeit der Contacttheorie der galvanischen Kette, und für die ökonomische Anwendbarkeit der Kette als bewegendes Princip durch Elektromagnetismus," Annalen der Physik und Chemie, 53 (1841), 303-309. See also Poggendorff, "Ueber die Frage, ob es wirksame galvanische Ketten ohne primitive chemische Action gebe, und über die Bildung der Eisensäure auf galvanischem Wege," Annalen der Physik und Chemie, 54 (1842), 353-377, which contains a good discussion of the points at issue.

${ }^{45}$ Georg Gottlieb Schmidt, "Einige electrisch-magnetische Versuche $u$. Wiederholung von Volta's Fundamental-Versuchen," Annalen der Physik, 70 (1822), 229-233; Gustav Theodor Fechner, "Rechtfertigung der Contact-Theorie des Galvanismus," Annalen der Physik und Chemie, 42 (1837), 481-516. See also Fechner's "Beiträge zur Lehre des Galvanismus," Journal für Chemie und Physik, 57 (1829), 1-16.

${ }^{46}$ Although I cannot satisfactorily explain why Schmidt was the exception that he was, it is perhaps significant that he was very interested in the construction and operation of instruments. Such a concern, involving control and prediction, is often associated with use of some form of hypothetico-deductive method. For a typical example of Schmidt's use of the hypothetico-deductive method see his "Versuche über die Gesetze, wonach gasartige Flüssigkeiten aus engen Oeffnungen von verschiedener Gestalt und durch Röhren unter einem gegebenen Druck ausströmen," Annalen der Physik, 66 (1820), 39-83. For further references see Caneva, op. cit. (note 2), p. 176.
} 


\section{Mathematical versus Physical Theories}

The constellation of attitudes that characterized concretizing science included a strongly felt distinction between the concretely physical and the abstractly mathematical. Only theories of the former kind were thought capable of capturing the essence of the phenomena. Concretizing science was not simply unmathematical, a deficiency of learning, as it were, which might be remedied by reading a book. Its practitioners self-consciously defended an ideal of science that held mathematical description in no great esteem on the grounds that mathematics tended to mislead the physicist from his proper field of study. Pfaff clearly expressed concretizing scientists' sense of a distinction between mathematical and physical explanations, according to which only the latter could get at the essence of the phenomena:

A mathematical explanation or construction of the phenomena is in certain respects to be distinguished from a physical one, and the former can, despite all its internal coherence and the logical consistency of its propositions, nevertheless still leave out of account the essential nature [das eigentliche Wesen] of the phenomena, which is the subject matter of the physical [mode]. The mathematician conceives the phenomena of electromagnetism in the first instance only as diverse modifications of motions; if he succeeds in setting up a fundamental equation into which all the factors that influence the kind and magnitude of the motion enter as elements, whose particular values, exactly determinable by the formula itself, exactly specify the motion itself, then he has incontestably satisfied the demands placed on the so-called mathematical physics.... By means of such a mathematical law all phenomena are as it were resolved into pure Anschauungen, divested of everything particularly qualitative, and even the opposites in the motions, the attractions and repulsions, appear in relationship to each other merely as positive and negative quantities. Such a mathematical law need not concern itself any further with the secret source out of which the effects proceed. A physical explanation penetrates further than a soto-speak mathematical explanation, which gives only a formula for the quantitative determination of the phenomena. It seeks to represent the phenomena in their larger general connections with the whole of nature and to connect the fact with which the mathematical construction starts still higher with the essence of the forces of nature themselves and thus to give an account of the qualitative [aspects] of the phenomena. Nevertheless every 
genuine physical explanation must at the same time be mathematical. ${ }^{47}$

This sentiment was echoed by Schweigger in a paper written in 1825 for the fourth Naturforscherversammlung. Always skeptical of the propriety of the mathematical method, he complained that too many inadequate theories had been hastily proposed to explain Oersted's discovery: "In fact, however, the matter does not yet seem ripe for a strict physical theory. All the easier is it, therefore, to produce an abundance of mathematical formulas, with which one customarily merely calculates out what one has [already] inserted into the phenomenon. But even that, like all intellectual games, is to be appropriately esteemed insofar as it stimulates new investigations." 48 Schweigger objected to the fact that the wide applicability of Ampère's theory was based on extended chains of mathematical reasoning. He cited with favor Biot's criticism of the lack of analogy between Ampère's fundamental law and other laws of attraction, and he endorsed Biot's claim that Biot's own theory, although not yet calculable, was easy to conceive. ${ }^{49}$ The kind of mathematics Schweigger favored was not analysis but geometry, whose virtue lay in its Anschaulichkeit, for the mind has the ability to grasp geometrical truths immediately, and geometry expresses the essences of things directly. ${ }^{50}$

Muncke, too, believed that the use of mathematics in physics had recently gotten out of hand:

Since the time [of Descartes and Newton] the value of mathematics has been set very high, and one cannot fail to recognize that this has recently occurred to an exaggerated extent especially with the French and is still occurring now with many Germans, in part to avoid the charge of wishing to excuse their ignorance of this science by depreciating it. Nevertheless if one is sincere about promoting science and considers the present state of

47Pfaff, Der Elektro-Magnetismus, (note 43), pp. 200-201.

${ }^{48}$ Schweigger, "Ueber Elektromagnetismus," Journal für Chemie und Physik, 46 (1826), $1-72$, on 15 . He regarded mathematical analysis as easier than, hence in some vague sense not as honest as, real physical understanding. Note also the implicit association and rejection of the use of mathematics and the hypothetico-deductive method: by means of the latter one artificially assigns to nature what one wanted to prove was there all the time.

49lbid., pp. 16-18. Schweigger cited Biot from Fechner's translation of the Précis; for the original, which is of great interest, see Biot's book, op. cit. (note 9), 2, 771-772.

50Schweigger, "Ueber Daltons Messkunst der chemischen Elemente, als Anhang zur vorhergehenden Abhandlung [von John Davy über die Verbindung verschiedener Metalle mit Halogen]," Journal für Chemie und Physik, 10 (1814), 355-381, on 356-358. 
physics just as accurately as completely, one cannot for a moment fail to recognize that we now require observations and experiments much more than calculations and geometrical formulas. The principal cause of this [state of affairs] is that one can much more easily calculate at one's desk than experiment with ingeniously contrived and difficult-to-operate apparatus. ${ }^{51}$

Note here not only Muncke's implied identification of the role of experiment as discovery, not as test, but also his attitude, precisely Schweigger's, that it is easier to manipulate mathematical formulas than to carry out difficult experiments, almost as if a higher morality attached to experimental than to theoretical physics.

The first substantial mathematical treatment of electricity by a German was Die galvanische Kette, mathematisch bearbeitet (1827) by G. S. Ohm, who from 1813 to 1849 taught mathematics and physics in various secondary schools. In his book Ohm derived a law for the voltaic pile and circuit that related current strength to resistance and electromotive force, and on that basis he developed an elaborate mathematical theory which he successfully applied to a host of hitherto poorly understood electrical phenomena. Ohm was not a concretizing scientist, but an early representative of a wholly new style of physics that would become dominant in Germany in the 1830 's and 1840's. He had the misfortune of falling between two generations and of being judged at first by men who represented an older and different kind of physics. The nature of their criticism of his work throws into especially clear focus the distinction made by concretizing scientists between mathematical and physical knowledge.

The most virulent example of this antagonism was the review of Ohm's book written by G. F. Pohl, later professor of physics at Breslau. Pohl maintained that mathematics was an abstraction whose use in physics necessarily entailed the exclusion of essential aspects of the real physical world, and he had only contempt for the sterility of a physics that would be essentially mathematical. ${ }^{52} \mathrm{He}$ asked rhetorically years later: "What cannot be measured and subjected to the mathematical schematism without one's thereby being either prop-

\footnotetext{
${ }^{51}$ Muncke, op. cit. (note 29), pp. 510-511. For a more considered discussion of Muncke's attitude toward mathematics see Caneva, op. cit. (note 2), pp. 110-112.

52Pohl, rev. of Die galvanische Kette, mathematisch bearbeitet (Berlin, 1827), by G. S. Ohm, Jahrbücher für wissenschaftliche Kritik, 1828, Bd. 1 [des Jahres], cols. 85-103, in col. 102. This well-known Berlin literary journal counted Pohl, Johannes Schulze, and G. W. F. Hegel among its editors. Cf. Pohl's Ueber das Wesen der Elektricität und Schwere. Offener Brief an Herrn Professor Dr. H. W. Dove (Breslau, 1848), where he said that he rejected Ohm's theory "weil sie... nicht concret genug ist" (p. 10), and where he criticized the inability of a mathematical theory to capture "die innere Anschauung" (p. 26).
} 
erly acquainted with the superficially conceived object of the imagination or secured against the most absurd misconception [Begriffsvertauschung] of it?"'53 As far as Pohl was concerned, Ohm's mathematical theory, whose essence was embodied in two formulas, was simply not a contribution to physical knowledge. In his opinion $\mathrm{Ohm}$ had wrongly isolated the electrical manifestations of the galvanic circuit from a fuller context that included chemical and magnetic phenomena. Pohl's criticism of Ohm was to be sure excessive even by the standards of the day, and it reflected the fact that his adherence to Naturphilosophie set him apart from nearly all other contemporary physicists. Nevertheless his basic dissatisfaction with Ohm's theory touched upon a distinction between physical explanation and mathematical description widely held by concretizing scientists. ${ }^{54}$

\section{Explanation as Schematization}

It is often difficult to extract any specific notion of scientific explanation from the individual published works of concretizing scientists. True to their anti-hypothetical, empiricist bias, they frequently favored the unembellished recounting of experimental findings, and they certainly did not identify physical explanation with mathematical description or with the hypothetico-deductive confirmation of precise predictions. ${ }^{55}$ Nonetheless, a reasonably common mode of explanation was the association of one phenomenon with other known phenomena in terms of either reductionism (for example, of electromagnetism to common magnetism) or classification (for example, of metals according to electric or magnetic tension). I have chosen the term "schematization" to capture these two aspects of concretizing scientists' implicit attitude toward explanation. This term also recalls the attachment to the ideal of Anschaulichkeit exemplified by the schematic representationalism of the conceptually reductionist theories of transversal magnetism.

Although it would otherwise have been consistent with this view of explanation as schematization, concretizing scientists did not make

${ }^{53}$ Pohl, rev. of Ueber die Elektricität der galvanischen Kette (Göttingen, 1840), by Friedrich Christoph Henrici, Jahrbücher für wissenschaftliche Kritik, 1840, Bd. 2 [des Jahres], cols. $382-390$, in col. 390 (question mark supplied). On the amateur Henrici (1795-1885) see Caneva, op. cit. (note 2), p. 183.

${ }^{54}$ For Ohm's reception by other concretizing scientists see Caneva, op. cit. (note 2), pp. 114-115.

${ }^{55}$ Of Erman's 1806 paper on the electrical conductivity of different substances we are told by his biographer that he was, "as always," very cautious in the explanation of the facts and scarcely indicated his own views (Wilhelm Erman, Paul Erman. Ein Berliner Gelehrtenleben, No. 53 of Schriften des Vereins für die Geschichte Berlins [Berlin, 1927], p. 113). 
particular explanatory use of analogies. On the contrary, facile analogizing was consciously avoided because it had become associated with a discredited Naturphilosophie. Muncke, for example, objected in the following terms to one author's attempt to draw parallels between gravity, light, and heat: "To be sure, one cannot fail to recognize great similarity in the behavior of light and heat, but since finding analogies has been so damaging to the progress of science, the prudent scientist will do well to stress the differences." 56

The issues involved are best seen in an example such as the theory of transversal magnetism, which found great favor with virtually every representative of concretizing science. In addition to being directly constructable in terms of known quantities, this theory stayed within the existing framework of familiar magnetic forces. As Erman argued in 1821, "an attempt to keep even the most paradoxical novelty in the first instance within earlier existing analogies is always to be approved." 57 The best procedure for discovering possible peculiarities in the new phenomena would be "to begin with presently known laws and the heretofore acknowledged analogies between magnetism and galvanism in order to find physically based constructions which correspond as much as possible to the new phenomena." $58 \mathrm{He}$ reasoned that his book "may therefore not unfittingly contain, alongside the presentation of several of the principal factual features of electrochemical magnetism, a few preliminary attempts at parallelization of the newly discovered with the already known." 59

Erman's words reflect the conservative tendency of concretizing scientists not to go beyond the framework of existing knowledge in the explanation of a new phenomenon. This attitude of explaining the new by relating it to the old was shared by Muncke, whose own explanation of electromagnetism also stayed within traditional conceptual bounds. In an afterword to his series of papers on transversal

\footnotetext{
${ }^{56}$ Muncke, rev. of Die Naturlehre nach ihrem gegenwärtigen Zustande mit Rücksicht auf mathematische Begründung (Wien, 1824), by Andreas Baumgartner, Heidelberger Jahrbücher der Literatur, Jg. 18 (1825), 1st half, pp. 179-194, on p. 187. Baumgartner (1793-1865) was professor of mathematics and physics at the University of Vienna from 1823.

${ }^{57}$ Erman, op. cit. (note 37), p. 3; quoted in "Des Professors Erman in Berlin Untersuchungen über den Magnetismus des geschlossenen Voltaischen Kreises, frei und prüfend dargestellt, von Gilbert," Annalen der Physik, 67 (1821), 382-426, on 385.

s8Ibid.

59lbid., pp. 4 and 386. Schweigger's judgment echoed this characterization: "The purpose of this book ... is to join the newly discovered electrochemical phenomena onto those already known" ("Auszüge aus der Schrift: 'Umrisse zu den physischen Verhältnissen des vom Herrn Professor Oersted entdeckten elektrochemischen Magnetismus skizzirt von P. Erman. Berlin 1821.' nebst einigen Zusätzen von Dr. J. S. C. Schweigger," Journal für Chemie und Physik, 32 [1821], 38-50, on 38).
} 
magnetism, Muncke observed: "In general it seems to me that the same thing is happening with the explanation of electromagnetism that was earlier the case after the discovery of the Leyden jar, the electrophore, and galvanism. Moved by the newness of the matter, people made an incredible to-do about it, but in the end all the phenomena fit very simply into the known natural laws."60

Concretizing scientists believed that the essence of Amperre's theory was an assertion of the identity of electricity and magnetism. One of the chief advantages of the theory of transversal magnetism was that it kept electricity and magnetism distinct and noninteracting, although the theory was based on the phenomenological analogy between the behavior of current-carrying wires and transversally magnetized iron bars. Electromagnetism was thus subsumed under normal magnetic action while preserving the qualitative distinction between electricity and magnetism.

An early example of the interest concretizing scientists showed in the classification of phenomena was Erman's reevaluation of a finding made in 1797 by Alexander von Humboldt (1769-1859). Humboldt had argued against the electrical nature of galvanism by claiming that the galvanic action was blocked by some things (e.g., dry bones, flames, and empty space) which let common electricity pass. Erman demonstrated that both forces behave in the same way with respect to these three nonconductors and to ice. ${ }^{61}$ These experiments led Erman to the discovery of "unipolarity," the supposed property of certain flames to conduct off only positive or only negative galvanic electricity. This phenomenon was based on the observation that an alcohol flame held between the poles of a voltaic pile failed to conduct electricity across it, but while the negative pole remained isolated (charged), the positive pole was discharged. The reverse occurred with a phosphorous flame. His findings were published in a paper of 1806 in which he identified five classes of conductors: nonconductors, complete conductors, bipolar incomplete conductors, and positive and negative unipolar conductors. ${ }^{62}$ His intention was to identify examples of each kind of conductor experimentally in order to illus-

${ }^{60}$ Muncke, "Nachtrag zu dieser Vorlesung [über Electro-Magnetismus]," Annalen der Physik, 71 (1822), 425-435, on 426.

${ }^{61}$ Erman, "Ueber die Fähigkeit der Flamme, der Knochen und des luftleeren Raumes, die Wirkungen der Voltaischen Säule zu leiten," Annalen der Physik, 11 (1802), 143-168, on 147. See also Wilhelm Erman, op. cit. (note 55), p. 106. Humboldt's claim was made in Versuche über die gereizte Muskel- und Nervenfaser, nebst Vermuthungen über den chemischen Process des Lebens in der Thier- und Pflanzenwelt, 2 vols. (Posen \& Berlin, 1797), 1, 433.

${ }^{62}$ Erman, "Ueber die fünffache Verschiedenheit der Körper in Rücksicht auf galvani'sches Leitungsvermögen," Annalen der Physik, 22 (1806), 14-50. 
trate the justness of a classificatory schema, based on qualitative differences, which would embrace all substances. This was a typical undertaking of concretizing scientists, who, to be sure, more commonly limited themselves to the threefold distinction between nonconductors and complete and incomplete conductors. The tendency of the physics of the next generation would be to try to quantify such qualitative, essential disjunctions.

Seebeck's work in electromagnetism illustrates not only the qualitative nature of experimentation practiced by concretizing scientists, but also their preoccupation with schematization as a favored mode of explanation. His chief concerns were the identity of electricity and magnetism (which he denied), the schematic orientation of what he identified as the magnetic poles of a pile with respect to its electric poles, and the drawing up of a linear table of metals according to their thermomagnetic activity, analogous to the electromotive series. ${ }^{63}$ Typical of his approach is the paper in which he announced his discovery of thermoelectricity, or rather thermomagnetism as he called it, since phenomenologically what one observes is not the current but the electromagnetic action manifested by a magnetic needle. In order to discover the interrelationship between electrical, magnetic, and chemical activities, he first established that a "magnetic polarization" - not an electric current-is produced in a bimetallic ring if the junctions are kept at different temperatures. He performed a great many qualitative experiments on the behavior of different metals and ores and tabulated his results in an array which gave the direction (not strength) of the magnetism produced when his twenty-eight samples were connected together pairwise. There followed an extended list of thirty-five metals and ores in a single "magnetic series," such that a metal connected with one above it produced an "easterly" declination of a magnetic needle, with one below it a "westerly" declination. Thus his series had both an "eastern" end (bismuth) and a "western" end (antimony and tellurium). Seebeck never experimented with one combination in order to find out exactly how the strength of the magnetic action might depend on the temperature difference, but contented himself with the general observation that they increased together. He used the radical lack of correspondence between the sequence of metals in his magnetic series and the traditional electromotive series as proof of the dissimilar nature of magnetism and electricity, and he interpreted this finding as

\footnotetext{
${ }^{63}$ On the second of these concerns see Caneva, op. cit. (note 2), pp. 123-125, or Seebeck, op. cit. (note 9), esp. p. 345.
} 
a refutation of Ampère's electrodynamic explanation of magnetism in terms of current loops. ${ }^{64}$

Schweigger used his version of transversal magnetism-his hypothesis of a "double magnetic polarity" - as the basis of a peculiar theory of the operation of the multiplier which underscores the occasionally pronounced graphic element of explanation by schematization. He employed not a simple loop but a figure-eight shaped coil of wire so that the magnetic needle could be placed alternately in either half of the "eight," thereby more dramatically showing the opposite effect on the needle as its position was reversed relative to the direction of current. The schematic-pictorial nature of theory as conceived by concretizing scientists is illustrated in the schema by which Schweigger represented his theory of the multiplier. Refering to the diagram reproduced here as Figure 3 (his Figure 11) he concluded: "All phenomena will take place just as one is entitled to expect according to the theory represented in Figure 11. And to that extent the theory may be allowed to pass as an expression suited at least to an overview [Ueberblicken] $(\theta \epsilon \omega \rho \epsilon \iota)$ of all known electromagnetic phenomena." 65 In Figure 3 the circles represent cross sections of the current-carrying wire forming Schweigger's figure-eight-shaped multiplier, the smaller arrows indicating the direction of the transversal magnetism of each portion of the wire, the two larger arrows indicating the direction a magnetic needle would assume in the middle of each half of the "eight." When Schweigger elsewhere asserted that "every theory is indeed only a picture," he gave expression to the tendency of concretizing scientists to regard a theory as a simple and direct representation of the phenomena. ${ }^{66}$ In an extreme case such as

\footnotetext{
${ }^{64}$ Seebeck, "Magnetische Polarisation der Metalle und Erze durch TemperaturDifferenz," Abhandlungen der Königlichen Akademie der Wissenschaften zu Berlin, 1822-1823 (pub. 1825), Abhandlungen der physikalischen Klasse, pp. 265-373, on pp. 292-293. Cf. Poggendorff's use of his Condensator (i.e., multiplier) not as a measuring instrument but to determine the order of twenty-nine substances in an electromotive series (op. cit. [note 22], cols. 703-707).

65Schweigger, op. cit. (note 39), p. 38. In the accompanying Figure 3 (from ibid., Tafel I, Figur 11), the direction of the larger left-hand arrow has been reversed from the original. In another characterization of physical theory Schweigger used " $\Theta \epsilon \omega \rho \in \iota$ " to gloss Beschauen, again underscoring the anschaulich quality of theory ("Einige Bemerkungen zu Davy's Abhandlung: über die Verhältnisse zwischen elektrischer und chemischer Wirksamkeit," Journal für Chemie und Physik, 52 [1828], 33-74, on 65).

66"The quotation is from a footnote signed "Die Redaction" in a "Schreiben des Herrn Professor Oersted an die Redaction vom 9. Sept. 1821," Journal für Chemie und Physik, 33 (1821), 123-131, on 125; reprinted in Oersted, Naturvidenskabelige Skrifter, (note 25), 2, 246-251, on 247. Schweigger's coeditor from 1819 to 1823 was Johann Ludwig Georg Meinecke (1781-1823), though the sentiment was certainly Schweigger's.
} 

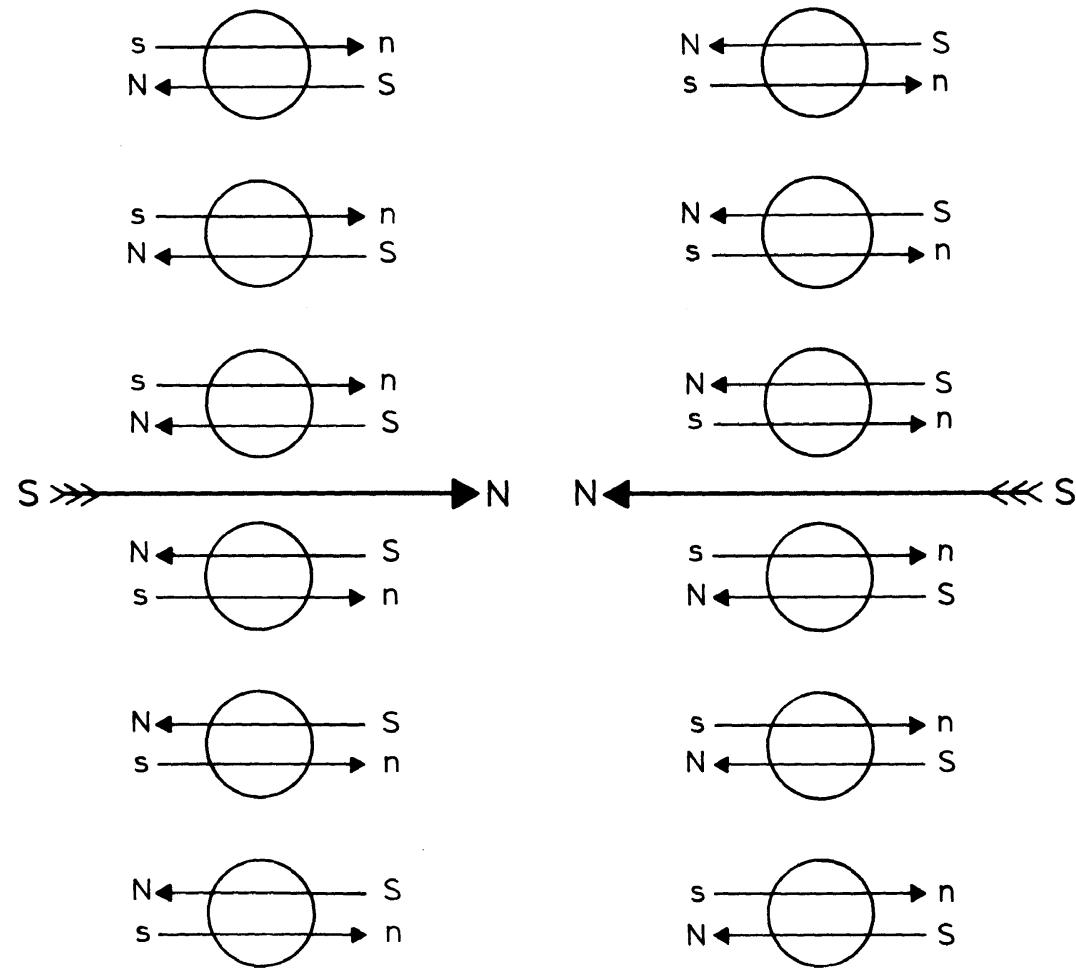

Figure 3. Schweigger's explanation of the multiplier.

this one it was not even necessary that the theory be expressed in words, much less in testable statements or mathematical formulas. Although this schematic aspect of Schweigger's notion of explanation played a more important role in his work than the kind of classification sought be Seebeck or Erman, Schweigger, too, stressed the need for the proper arrangement of facts in the construction of a theory. Indeed, these two were ideally one and the same: "An appropriate grouping of a series of phenomena, in order to apprehend the individual in its natural connection with the whole, is indeed basically that which we are alone accustomed to call a physical theory." 67

${ }^{67}$ Schweigger, "Nachschreiben des Herausgebers [zu den vorstehenden Aufsätzen über Döbereiner's neues Feuerprincip]," Journal für Chemie und Physik, 39 (1823), 211-230, on 214. 


\section{THE SCIENCE OF THE ABSTRACT}

The abstractness of the physics of the younger generation contrasts sharply with the qualitative Anschaulichkeit of concretizing science. Against the former notion that one of the tasks of science was to capture the essence of the phenomena, the new physics dropped the requirement that a theory should provide a true representation of physical reality. Among the younger physicists this abstract approach became so much the norm that some, such as Neumann, never concerned themselves with models or physical mechanisms as long as their mathematical theories were coherent and testable. The explanation of a physical phenomenon came to be so inextricably associated with its mathematical description that the latter could be taken for the former to an extent the older generation would have pronounced entirely unacceptable. The new physics was also characterized by an unprecedented increase in the precision of its experiments and in the ambitiousness of its exhaustively conducted research programs. The relative laxness and contentment with qualitative or crudely quantitative results which marked concretizing science gave way to a preoccupation with exact measurement and an attention to technique which were part of a self-conscious emphasis on correct methodology. There came into general acceptance nothing less than a completely new standard of scientific method in the performance of research.

A third fundamental characteristic of the new physics was the explicit adoption of the hypothetico-deductive method, representing a profound change from concretizing scientists' empiricist avoidance of anything "hypothetical." Abstracting scientists tended to present their concepts and theories explicitly as hypotheses whose acceptability depended on their subsequent experimental confirmation. Concepts were not expected to be naturally entailed by experience, nor were empirically confirmed laws presented as convenient mathematical reexpressions of the data. The intrinsically hypothetical character of this methodology was reflected by the fact that abstracting scientists largely ignored the question of whether their theories were "true" in any sense other than agreement with experience. By contrast, many French mathematical physicists of the same period still wished to attain certainty, and their model of scientific knowledge resembled deductive mathematics, which secures its premises directly and not on the basis of conclusions drawn from them. Although the hypothetico-deductive method was occasionally used by some French physicists, theirs was not the dominant tradition in 
France and German abstracting scientists did not simply import their new methodology from abroad. ${ }^{68}$ The strong rationalist tradition in French science seems to have contributed to the notion that scientific truth could speak for itself. German abstracting scientists, who represented no such tradition, felt a greater responsibility to experience, and arguments based on theoretical simplicity tend to be absent or unstressed even where they might be expected, such as in Weber's and Neumann's electrodynamics.

The reasons for these developments in mathematization, experimentation, and methodology are complex. Adoption of the hypothetico-deductive method in a sense required experiments to be quantitative if they were to be capable of deciding the validity of precise statements drawn from mathematical theories. However, science does not consist solely of testing theories, and diligent, quantitative experimentation became a general trait of much of nineteenthcentury German science independently of whether any theory was being tested. Again, if it might seem that use of the hypotheticodeductive method is a natural consequence of the mathematization of physical theory, the example of French mathematical physics indicates that there is in fact no intrinsic connection between the two. Although an interest in instrumentation may have encouraged some abstracting scientists to use the hypothetico-deductive method, any strictly internal account of its widespread acceptance must be insufficient. Later I argue that its adoption was due to changes in society and in scientists' perception of their role which not only encouraged the practical testing of ideas but also led to a reversal in the conception of the relationship between knowledge and experience.

The work in electrodynamics of an important subgroup of abstracting scientists represented an approach to physics different from that of either their French or German predecessors. In contrast to the French, they did not content themselves with merely applying mathematical analysis to one particular class of phenomena but rather sought to construct a mathematical theory that would bring together conceptually a number of such classes. It is characteristic of the French attachment to established paradigms that Poisson's theory of magnetism of 1824 did not even make provision for an explanation of

\footnotetext{
${ }^{68}$ On the metholodology of French mathematical physics see Caneva, op. cit. (note 2), pp. 331-363, which amplifies and substantiates the claims made here. Robert Kargon has implied that the "hypothetico-deductive approach" was characteristic of the French "mechanico-molecular school" of Laplace, Cauchy, Navier, and Poisson ("Model and Analogy in Victorian Science: Maxwell's Critique of the French Physicists," Journal of the History of Ideas, 30 [1969], 423-436, esp. 423 and 426). This is not true with respect to the Laplacians' favored mode of presentation.
} 
electromagnetic interaction, discovered four years earlier. Despite the dominance of French physics at that time, it remained for the Germans to seek the theoretical unification of electrostatics, electrodynamics, and electromagnetic induction. This concern for synthesis was the most fruitful legacy of German Naturphilosophie. ${ }^{69}$

\section{Mathematics and Abstraction}

That the physics of the younger generation was consistently mathematical is a point as basic as it is unproblematic. This section will deal with some implications of the mathematization and abstractness that completely replaced the Anschaulichkeit of concretizing science. Some of the younger generation felt that the use of mathematics in physics still had to be defended. The Berlin physicist P. T. Riess, a pioneer in the quantification of static electricity who consistently expressed his findings algebraically, found himself faced with the charge that his use of mathematics had hindered the understanding and dissemination of his work. ${ }^{70}$ Muncke's thousand-page article on heat in Gehler's Physikalisches Wörterbuch did not, he lamented, even "correctly and understandably" reproduce his basic formula for the static-electric generation of heat. ${ }^{71}$ Königsberg professor of physics L. F. Moser complained in the preface to his 1839 book on actuarial statistics that there were still many people "who placed the least possible weight on numbers and on all conclusions based on them, considering them to be insubstantial shadows, nests from which truth has flown. ${ }^{\prime 72}$ He suggested that people had difficulty following and accepting a mathematical argument because of the "small measure of immediate perception [Anschauung]" which characterizes our relationship to mathematics. ${ }^{73}$ Applied to individuals, as in statistics, mathematics requires abstracting from all qualities belonging only to the individual; we are interested only in the fictitious "average man" representing the regularity of the apparently lawless phenomena. ${ }^{74}$ To Moser this abstractness of the mathematical handling of phenomena was a virtue, even if science found itself "in a

\footnotetext{
${ }^{69}$ For reasons of space this conclusion cannot be further developed here; see Caneva, op. cit. (note 2), pp. 364-413, where I discuss the work of Fechner, Weber, Neumann, and Grassmann.

70Peter Theophil Riess, "Die Lehre von der Elektricität (Zweiter Bericht)," Repertorium der Physik, 6 (1842), 109-314, on 189.

71 Ibid. Muncke's article, "Wärme," appeared in Gehler's Physikalisches Wörterbuch, (note 27), 10, Pt. 1 (1841), 52-1179.

${ }^{72}$ Ludwig Ferdinand Moser, Die Gesetze der Lebensdauer (Berlin, 1839), pp. xviii-xix.

73Ibid., p. xix, and cf. pp. $x x-x \times i$.

${ }^{74}$ Ibid., p. 3.
} 
certain, more or less definite, distorted relationship [Missverhältniss] to reality" because of its one-sided attention to the "quantitative relationships" of objects. ${ }^{75}$

One implication of the mathematical approach to science was the deemphasis of qualitative distinctions. An early example of this tendency was Ohm's work on the electric current, which was the focus of some debate over the distinction between mathematical and physical knowledge. Ohm's originality lay in explicating the precise relationship between tension and current and in associating a varying electric tension, or electroscopic force, with each point of a current-carrying wire. Previously there had been only confused notions of the relationship between these two classes of phenomena, some even considering them to be mutually exclusive. This was not surprising, since measurement of the electric tension of a pile had in general only been possible when no current flowed. On the other hand, the early experiments of Erman, Ritter, and Jäger had demonstrated not only the presence of an electroscopic force at the poles of a pile closed by means of a poor conductor, such as water, but also the progressive decrease in this force from the poles toward the center of the connecting conductor. ${ }^{76}$ To the extent that these experiments had not simply been forgotten, they were thought inapplicable to the case of metallic conduction because of the traditional classification of substances into perfect and imperfect conductors and nonconductors, each with its own peculiar characteristics. To Ohm, who had the mathematical physicist's tendency to regard properties less as an "either-or" of some quality than as a "more-or-less" of some quantity, such distinctions could have no intrinsic validity; and he did not hesitate to apply to metals findings originally restricted to imperfect conductors.

The disposition to play down the significance of qualitative distinctions, or to interpret them as quantitative differences in the values of certain coefficients, was also a feature of one of the major optics papers of F. E. Neumann, professor of physics and mineralogy at Königsberg. Neumann reasoned that theory must treat uncrystallized bodies as special cases of crystallized ones because there could be no

75Ibid., p. 5. Moser explicitly generalized his judgement to all of science.

76Johann Wilhelm Ritter, "Versuche und Bemerkungen über den Galvanismus der Voltaischen Batterie. . . Dritter Brief," Annalen der Physik, 8 (1801), 385-473; for Erman's and Jäger's papers see note 20. For Ohm's knowledge of these see his "Versuch einer Theorie der durch galvanische Kräfte hervorgebrachten elektroskopischen Erscheinungen," Annalen der Physik und Chemie, 6 (1826), 459-469 and 7 (1826), 45-54 and 117-118 ("Nachtrag"), on 53-54; reprinted in Gesammelte Abhandlungen von G. S. Ohm, ed. Eugen Lommel (Leipzig, 1892), pp. 37-54, on pp. 51-52. On the largely romantically inspired work of J. W. Ritter, see Caneva, op. cit. (note 2), pp. 99-102, 140-145, and the references cited there. 
qualitative difference between the two. ${ }^{77}$ It is also possible that the unification of electrostatics and electrodynamics achieved by W. E. Weber, professor of physics at Leipzig, owed something to the consideration that Coulomb's law must be only a special case for particles at rest of a more general velocity-dependent electrical law. Despite the fact that Weber seems to have required Fechner's stimulation to occupy himself with the unification of electrostatics, electrodynamics, and electromagnetic induction, it reflects the character of thought of the mathematical physicist that this consideration was first made explicit by Weber and not by Fechner, who was not particularly adept at mathematics and who ignored electrostatics in his unification of electrodynamics and induction.

Neumann's was the epitome of a kind of abstract physics which placed greatest emphasis on the mathematical development of theory. His student Woldemar Voigt contrasted Neumann's "less graphic [anschaulich] but always certain method" to "the use of such graphic pictures" that had characterized an earlier style of science. ${ }^{78}$ Neumann had occasionally used the latter approach as an aid in constructing a theory, Voigt noted, "but he nevertheless always sharply distinguished between the results of that pictorial [bildlich] treatment, which are susceptible to test by means of observation, and the auxilliary ideas themselves, which had shown the way to them and which do not permit being tested other than by means of the end attained."79 The most important example of Neumann's ability to deal with abstract concepts was his explanation of electromagnetic induction in terms of change in potential, a mathematically defined quantity not easily given a direct empirical basis. For Neumann to generalize change in potential as the cause of induction marked a significant departure from the kinds of explanatory concepts favored by concretizing scientists.

Wilhelm Weber's approach to mathematical physics is often contrasted to Neumann's. The work of the latter, all commentators have

\footnotetext{
77Franz Ernst Neumann, "Theoretische Untersuchung der Gesetze, nach welchen das Licht an der Grenze zweier vollkommen durchsichtigen Medien reflectirt und gebrochen wird," Abhandlungen der Königlichen Akademie der Wissenschaften zu Berlin, 1835 (pub. 1837), Mathematische Abhandlungen, pp. 1-160, on p. 4; reprinted in Franz Neumanns Gesammelte Werke, eds. Carl Neumann, Woldemar Voigt, and Albert Wangerin, 3 vols. (Leipzig, 1906-1928), 2 (1906), 359-574, on 364.

${ }^{78}$ Woldemar Voigt, "Zur Erinnerung an F. E. Neumann, gestorben am 23. Mai $1895 \mathrm{zu}$ Königsberg i./Pr.,' Nachrichten von der Königl. Gesellschaft der Wissenschaften zu Göttingen, 1895, Mathematisch-physikalische Klasse, pp. 248-265, on p. 259; reprinted as "Gedächtnissrede auf Franz Neumann" in Newmann, Werke, 1 (1928), 1-19, on 13-14.

79 bid., p. 259 and Werke, 1, 14. Note here the implied reliance on the hypotheticodeductive method as the touchstone for the acceptance of a theory.
} 
agreed, exemplified abstract mathematical theory that made no attempt to provide a picture of reality or even to construct hypothetical mechanisms. ${ }^{80}$ Weber, in contrast, made extensive use of models and hypothetical mechanisms, especially in his 1846 electrodynamics paper. Emphasizing this difference between the two men, however, neglects the conceptual component in Neumann's work, misinterprets the role of physical models in Weber's science as naive representationalism, and promotes a misconception of the use of models in abstracting science. Abstracting scientists' employment of models might appear at first glance similar to concretizing scientists' desire to have physics express the nature of the phenomena, but in fact the difference between them is fundamental. When Weber made use of a physical model, he did so solely in virtue of its ability to be expressed in mathematical form, and no claim was made that it corresponded to the actual structure of the world. Its fruitfulness as a heuristic aid in the derivation of a theory and the degree of correspondence between theory and observation were the decisive factors in its use.

Weber's attitude toward abstraction and the use of physical models in mathematical physics was characteristic of the transformation taking place in German physics. He himself was not uninterested in the actual structure of the physical world, but he kept such considerations out of his physics unless they could be made an integral part of theory. At the end of his first electrodynamics paper he discussed the possibility that the form of his electrodynamic force law was due to the dependence of the propagation of the force on an intervening medium; he compared this electric medium to the luminiferous ether; he noted Faraday's recent discovery of the influence of electricity on light; and he referred favorably to Ampère's discussion of the plausibility that the electrodynamic influence was transmitted by an ether. ${ }^{81}$ In a letter to C. F. Gauss, professor of mathematics and astronomy at Göttingen, he expressed the opinion that "the nicest solution to the puzzle [of electrodynamic action-at-a-distance] would be its explanation on the basis of a gradual propagation of the force." 82 Despite

80"Vorwort zum dritten Bande," Neumann, Werke, 3 (1912), viii; Hoppe, op. cit. (note 2), p. 465, quoted in Karl Heinrich Wiederkehr, Wilhelm Eduard Weber, Erforscher der Wellenbewegung und der Elektrizität (Stuttgart, 1967), pp. 101-102; and Wilbur Morris Stine, The Contributions of H. F. E. Lenz to Electromagnetism (Philadelphia, 1923), p. 114.

${ }^{81}$ Wilhelm Weber, Elektrodynamische Maassbestimmungen (Leipzig, 1846), pp. 168-170; reprinted in Wilhelm Weber's Werke, 6 vols. (Berlin, 1892-1894), 3 (1893), 25-214, on 212-214. The 1846 book was a separate printing of "Elektrodynamische Maassbestimmungen," Abhandlungen bei Begründung der Königlich Sächsischen Gesellschaft der Wissenschaften am Tage der zweihundertjährigen Geburtsfeier Leibnizens herausgegeben von der Fürstlich Jablonowskischen Gesellschaft (Leipzig, 1846), pp. 209-378.

${ }^{82}$ Letter of 31 March 1845, quoted in Karl Heinrich Wiederkehr, Wilhelm Webers Stellung in der Entwicklung der Elektrizitätslehre (diss., University of Hamburg, 1961), p. 68. 
these sentiments favorable to the physical existence of an ether, he was content in practice to derive his fundamental formula on the assumption of simple action-at-a-distance between electrical particles. Weber used an atomistic representation of the current because it was a mathematically analyzable model that allowed the electrodynamic action-at-a-distance phenomena to be calculated. ${ }^{83} \mathrm{He}$ regarded it as perfectly acceptable to base a theory on a model that he himself did not believe corresponded to reality. He later assigned the real cause of electrical resistance to the "alternate union and separation" of the two electricities, a type of double current, to be sure, but not one of discrete electric masses. ${ }^{84}$

Weber's desiderata were clarity and susceptibility to exact measurement. He knew that his velocity-dependent force law represented a break with tradition, and he tried to anticipate criticism of his abandonment of past norms by seeking refuge in the external unassailability of his mathematical theory:

The question [of whether there are velocity-dependent forces] cannot be decided a priori because the assumption of such forces does not contain, formally, either a contradiction or anything unclear or indeterminate.

The laws of the dependence of forces on given physical relationships are called fundamental physical laws and serve, according to the aim of physics, not to give an explanation of the forces in terms of their true bases [Gründe], but only a clearly presented and usable general method for the quantitative determination of the forces in terms of the fundamental units of space and time established in physics. From a physical standpoint there can therefore be no objection to a force being made a function of a timedependent relationship, just as little as its being made a function of a distance, since a time-dependent relationship is just as measurable a quantity as a distance: both, that is, [are] by nature suited to precise quantitative determination, even if unsuited to the search for the internal basis [innerer Grund] of a force. ${ }^{85}$

${ }^{83}$ Weber, op. cit. (note 81), Art. 19, p. 11 and Werke, 3, 136.

${ }^{84}$ Wiederkehr, op. cit. (note 82), p. 183; also cited in Wiederkehr, op. cit. (note 80), p. 153. The reference there is to Weber's "Elektrodynamische Maassbestimmungen insbesondere Widerstandsmessungen" of 1852.

${ }^{85}$ Weber, op. cit. (note 81), Art 20, pp. 112-113 and Werke, 3, 149-150. Even where Weber discussed a possible physical analog of the potential he recognized that it was not less acceptable to physics by being purely ideal, since it was useful for the theoretical interpretation of experience; see the section he contributed to his and Gauss's Atlas des Erdmagnetismus nach den Elementen der Theorie entworfen (Leipzig, 1840), Sect. 25, pp. 18-19; reprinted in Carl Friedrich Gauss Werke, 12 vols. (Göttingen, etc., 1863-1933), 12 (1929), 335-408, on 374-377. 
Weber's physics, in order not to be deprived of the successes of its mathematization, had to give up any claim to providing a representation of reality. Weber believed that this change was a general characteristic of contemporary physics, and he noted that there existed a tendency (Bestreben) "to determine all natural phenomena in terms of number and measure, and thereby to secure for theory a foundation independent of sensual representation [sinnliche Anschauung] or mere approximation." 86

Gauss's famous desire to have a "constructible representation" (construirbare Vorstellung) of the way in which the electrodynamic force might be propagated across space was of a piece with Weber's use of physical models as a heuristic picture susceptible to mathematical analysis. ${ }^{87}$ The desire to have a "precise physical principle" on which to base the mathematical theory of a physical phenomenon also underlay Gauss's judgement of the theoretical significance of Weber's experimental proof of the unequal distribution of electricity on a sphere composed of zinc and copper hemispheres. ${ }^{88}$ Gauss doubted whether the "physical foundation" underlying Poisson's theory of the distribution of electricity on the surface of conducting bodies could explain the phenomenon demonstrated by Weber. He suspected that one would have to devise a physical model according to which the molecular forces acted other than according to the inverse-square law. ${ }^{89}$ That Gauss realized it might be possible to base a correct (that is, verifiable) theory on more than one model, hence that mathematical physics did not necessarily provide insight into the physical nature of a phenomenon, is clear from his work on terrestrial magnetism. In fact, for Gauss part of the beauty of a mathematical theory was that it could survive changes in physical conception. ${ }^{\mathbf{9 0}}$

Fechner might appear to be an exception to the hypothetical use of models that characterized abstracting science, for the author of the Atomenlehre seems to have believed in the fundamental atomicity of all physical phenomena rather than to have regarded atomism as only

${ }^{86}$ Weber, op. cit. (note 81), p. 9 and Werke, 3, 34.

${ }^{87}$ Letter of 19 March 1845 to Weber, in Gauss, Werke (note 85), 5 (1867), 629.

${ }^{88}$ Letter of 27 January 1844 to Weber, in Gauss, Werke, 11, Pt. 1 (1927), 175.

89lbid., p. 177 .

${ }^{90}$ Gauss, "Die Intensität der erdmagnetischen Kraft, zurückgeführt auf absolutes Maass," Annalen der Physik und Chemie, 28 (1833), 241-273 and 591-615, on 614-615 ("Intensitas vis magneticae terrestris ad mensuram absolutam revocata," Commentationes societatis regiae scientiarum gottingensis recentiores, 8 [1832-1837; pub. 1841], Classis mathematicae, pp. 3-44, on p. 44; reprinted in his Werke [note 85], 5, 79-118, on 118). See also Gauss, "Allgemeine Theorie des Erdmagnetismus," Resultate aus den Beobachtungen des magnetischen Vereins im Jahre 1838, 3 (1839), 1-57 and 146-148 ("Nachtrag"), on 6; reprinted in his Werke, 5, 119-193, on 126. 
a convenient picture. On closer examination, however, Fechner's attitude toward scientific knowledge is entirely consonant with the "public positivism" of abstracting science. The key to understanding Fechner is to realize that he could consistently take both positions with respect to the reality of atoms, depending on whether he was speaking "scientifically" or not. That was a crucial distinction reflected in the title and structure of his Ueber die physikalische und philosophische Atomenlehre: the first half dealt with the physical foundations of atomism, the second with the philosophical possibilities it allowed. ${ }^{91}$ As far as science was concerned, atomism was a hypothesis, albeit to Fechner an extremely probable one, which had to be judged solely on the basis of its success in accounting for the individual phenomena and in providing a unified picture of their interconnections. ${ }^{92}$ Physics is not a source of certainty, nor does it have anything to say about essences or underlying reality. ${ }^{93}$ Although Fechner believed in atoms and assumed an atomistic model of electricity in his electrodynamics, he did not maintain that their existence was proved by science. Similarly, he did not believe that the physicist's use of the concept of the luminiferous ether entailed any belief in its actual existence: "The quality of the luminiferous ether is, for the physicist, completely immaterial. He says nothing about it, he knows nothing about it, and even the existence of a substrate serves him merely as the basis for clear conceptions [Vorstellungen] of the motion [of light], as the formal nucleus of a play of phenomena, forces, and laws."94 If Fechner's use of such Vorstellungen was more conceptual and discursive than Gauss's and Weber's mathematically elaborated construirbare Vorstellungen, the difference lies in the fact that Fechner was not a mathematical physicist rather than in any fundamental difference in their conception of the nature of scientific knowledge. ${ }^{95}$

\footnotetext{
${ }^{91}$ For the sharpness of this distinction see Fechner, Ueber die physikalische und philosophische Atomenlehre (Leipzig, 1855), esp. p. ix. His electrodynamics paper of 1845 was mute on these questions; hence one can only assume that what was explicit in 1855 was implicit a decade earlier. The failure to appreciate the distinction between personal belief in atomism and its use as a scientific model is a critical flaw in Arthur Philip Molella, Philosophy and Nineteenth-Century German Electrodynamics: The Problem of Atomic Action at a Distance (diss., Cornell Univ., 1972); see esp. pp. 44, 103, and 111.

${ }^{92}$ Fechner, op. cit. (note 91), pp. viii, 30, and 50.

93lbid., pp. 26, 93, and 113.

${ }^{94}$ Ibid., pp. 15-16.

${ }^{95}$ For Fechner's heuristic use of an atomistic model of the electric current see his "Ueber die Verknüpfung der Faraday'schen Inductions-Erscheinungen mit den Ampère'schen elektro-dynamischen Erscheinungen," Annalen der Physik und Chemie, 64 (1845), 337-345. Compare also his Elemente der Psychophysik, 2 vols. (Leipzig, 1860), which was a masterful example of exact scientific method in which the search for quantitative and experimentally demonstrable functional relationships between var-
} 
Although H. G. Grassmann was primarily a mathematician and not a physicist, the character of his work also demonstrates the increased abstraction shown by physics. In the first edition of his Ausdehnungslehre he announced that his aim was to abstract and generalize the formal relationships of geometry in order to eliminate all principles based on spatial intuitions (Raumanschauungen). ${ }^{96} \mathrm{He}$ wished to replace an intuitive system by one that was purely conceptual and abstract. Grassmann's approach was criticized as an unwarranted break with the mathematical tradition of Anschaulichkeit. The professor of philosophy at Jena, Ernst Friedrich Apelt (1812-1859), asked the mathematician and professor of astronomy at Leipzig, August Ferdinand Möbius (1790-1868): “Have you read Grassmann's remarkable Ausdehnungslehre? I know it only from Grunert's Archiv but it seems to me to rest on a false philosophy of mathematics. The essential character of mathematical knowledge, the Anschaulichkeit, seems to have been totally banished from it. Such an abstract theory of extensive quantities as he attempts could only be derived on the basis of concepts. But the source of mathematical knowledge lies not in concepts but in Anschauung." In his reply Möbius agreed with Apelt that Grassmann "distances himself too much from all Anschaulichkeit, the essential character of mathematical knowledge."97 A similar abstraction from imaginable physical models in favor of systematic conceptual unity was an important feature of Grassmann's electrodynamics paper of $1845 .{ }^{98}$

\section{Experiment and Measurement}

The most significant developments in the experimental study of electricity in Germany during the second quarter of the nineteenth century were a greater concern with quantitative measurement and a

\footnotetext{
iables was carried out with conscious exclusion of all questions having to do with possible underlying psychological entities. Fechner was passionately concerned with things otherwordly and nonprovable, but he was acutely aware of what belonged to science and what did not.

${ }^{96}$ Hermann Günther Grassmann, Die lineale Ausdehnungslehre, ein neuer Zweig der Mathematik dargestellt und durch Anwendungen auf die übrigen Zweige der Mathematik, wie auch auf die Statik, Mechanik, die Lehre vom Magnetismus und die Krystallonomie erläutert (Leipzig, 1844), "Vorrede," pp. ix-x; reprinted in Hermann Grassmanns gesammelte mathematische und physikalische Werke, ed. Friedrich Engel, 3 vols. (Leipzig, 1894-1911), 1, Pt. 1 (1894), 1-319, on 10. See also Victor Schlegel, Hermann Grassmann. Sein Leben und seine Werke (Leipzig, 1878), pp. 17-18.

${ }^{97}$ Letters of 3 September 1845 and 5 January 1846, in Grassmann, Werke (note 96), 3, Pt. 2 (1911), "Grassmanns Leben, geschildert von Friedrich Engel," p. 101.

${ }^{98}$ Grassmann, "Neue Theorie der Elektrodynamik," Annalen der Physik und Chemie, 64 (1845), 1-18; reprinted in his Werke 2, Pt. 2 (1902), 147-160.
} 
dramatic increase in the ambitiousness of scientists' research programs. The modest efforts of Pfaff, Muncke, and Erman are just not comparable to the pains taken by Fechner, Weber, Lenz, or Riess. These changes were especially evident in the relatively sophisticated instrumentation routinely used by virtually all members of the younger generation. When Schweigger, Poggendorff, and Schmidt measured the electric current-when they measured it at all-they used a multiplier and noted the equilibrium position of its needle. In contrast, Ohm used a precise Coulomb torsion balance; Fechner adapted Biot's method of counting the oscillations of a magnetic needle; and Weber (following Gauss's example) employed an extremely sensitive galvanometer making use of the mirror-and-telescope reading of the deflection of a suspended magnetic needle. Fechner expressed amazement in 1831 that his contemporaries (which at that date in electricity meant concretizing scientists) had not enthusiastically adopted the more precise measuring procedures available:

As far as the measuring procedure I used is concerned, to my knowledge it has up to now been applied only once to galvanic phenomena, by Biot. It is difficult for me to explain how one could have forgotten this method of measurement in favor of others which are in part downright inadmissible, in part very uncertain or of only limited applicability, and how in particular one could have clung so stubbornly to the method of deviations [of the multiplier needle], while the method of the torsion balance offered a so much more certain procedure, even if one did not wish to make use of the method of oscillations I used. ${ }^{99}$

The experimental standards that Fechner took for granted had not been deemed necessary by the older generation, who neither exploited the techniques available to them nor tried to develop new ones.

Gauss's influential paper of 1832 on the intensity of terrestrial magnetism provides a noteworthy example of the instrumental precision he sought. Gauss described a method of measuring the intensity of the earth's magnetism in terms of standard units of length, time, and mass, thereby making possible the comparison of measurements made at different times and places. The sensitive instrument that he and Weber devised for this purpose incorporated two important innovations: the suspension of the magnet from a wire (instead of its being supported from below), and the use of a mirror and telescope in

$$
\text { iv. }
$$

99Fechner, Massbestimmungen über die galvanische Kette (Leipzig, 1831), "Vorwort," p. 
reading the deflection of the magnet. ${ }^{100}$ Gauss and Weber's magnetometer was adequate for measuring the magnetic declination but not the horizontal component of the terrestrial magnetic force. The latter measurement was normally carried out by calculating the period of oscillation of the suspended magnetic needle, but the considerable length of time required to get an accurate reading made the magnetometer insensitive to short-term variations in the magnetic intensity. To remedy this defect Gauss devised his bifilar magnetometer, which in its original form consisted of a twenty-five pound magnet suspended from two seventeen-foot long steel wires, the bifilar suspension serving to damp the magnet's oscillations. ${ }^{101}$ The placement of the telescope and scale at a distance of sixteen feet from the magnetometer and mirror meant that even extremely minute deflections could be measured. Gauss noted later that his magnetometer was capable of measuring the magnetism of a needle and the intensity of the terrestrial magnetic force "with an exactitude... equal to the precision of the most accurate astronomical observations." 102 Indeed, it was from astronomy that Gauss derived the standards of experimental precision that he applied to physics. Weber knew that his and Gauss's instrumental study of magnetism marked a break with the previously dominant mode of science. "It is our conviction," he wrote, "that the traditional way of doing physics is obsolete and in need of reform and that our way of handling the magnetic problem is a first sample. It goes against many deep-seated habits and causes many to wish that such a thing had never been started. But if it is carried through it will soon develop further and have a beneficial effect on all areas of science."103

The keynotes of Weber's physics were measure (Maass) and measurement (Messung, Maassbestimmung). Repeatedly concerned with

\footnotetext{
${ }^{100}$ Felix Klein, Vorlesungen über die Entwicklung der Mathematik im 19. Jahrhundert, Pt. 1, ed. R. Courant and O. Neugebauer, Vol. 24 of Die Grundlehren der mathematischen Wissenschaften in Einzeldarstellungen mit besonderer Berücksichtigung der Anwendungsgebiete (Berlin, 1926), p. 20. On the historical importance of these innovations see the editor's comments in Gauss, Die Intensität der erdmagnetischen Kraft auf absolutes Maass zurückgeführt, ed. E. Dorn, No. 53 of Ostwald's Klassiker der exakten Wissenschaften (Leipzig, 1894), p. 54.

${ }^{101}$ Gauss, "Ueber ein neues, zunächst zur unmittelbaren Beobachtung der Veränderungen in der Intensität des horizontalen Theils des Erdmagnetismus bestimmtes Instrument," Resultate aus den Beobachtungen des magnetischen Vereins im Jahre 1837, 2 (1838), 1-19; reprinted in his Werke (note 85), 5, 357-373.

${ }^{102}$ Gauss, "Erdmagnetismus und Magnetometer," Jahrbuch für 1836, ed. Heinrich Christian Schumacher, pp. 1-47, on p. 28; reprinted in Gauss, Werke, 5, 315-344, on 332. See also ibid., pp. $42-43$ and Werke, 5, 341.

${ }^{103}$ Letter of 9 April 1841 to the historian of law Karl von Richthoven, quoted in Wiederkehr, op. cit. (note 80), pp. 147-148.
} 
questions of international standards and absolute units, he was deeply committed to a quantitative physics whose typical object of investigation was an instrument or a measuring device. In one paper, for example, he described a modification of organ pipes which kept their frequency constant at all pressures, and he outlined the analysis he had undertaken "in order to be able to subject this means of compensation to calculation and to apply it reliably" to the definition of a "normal tone" against which others could be compared. ${ }^{104}$ In another paper he described an instrument, his Monochord or Tonmesser, which consisted of a vertical wire capable of producing a desired series of tones when its length or tension was suitably varied. This device could be used to measure very small time intervals and the speed of sound in solids as well as to define a "normal measure" in terms of which other tones could be measured precisely and internationally. ${ }^{105}$ Weber's preoccupation with problems of measurement dominated his work for most of the fifteen years following his initial collaboration with Gauss in 1831. In one two-year period alone (1837-1838) he published or wrote seven papers devoted to the combined theoretical and experimental analysis of a variety of measuring devices. ${ }^{106}$ Typical of Weber's approach was his synopsis of the contents of his paper on the bifilar magnetometer:

We shall consider in order the following:

1. the parts of the small measuring instrument,

2. the observations to be made with it,

3. the rules for the utilization of the observations,

4. the calculation of the observations according to these rules,

5. the results of the calculation,

${ }^{104}$ Weber, "Compensation der Orgelpfeifen, ein Vortrag des Prof. Wilhelm Weber zu Halle, bei der Versammlung der deutschen Naturforscher zu Berlin, den 19. Sept. 1828," Annalen der Physik und Chemie, 14 (1828), 397-408, on 400-401; reprinted in his Werke (note 81), 1 (1892), 257-265, on 259-260.

${ }^{105}$ Weber, "Ueber die zweckmässige Einrichtung eines Monochords oder Tonmessers und den Gebrauch desselben, zum Nutzen der Physik und Musik," Annalen der Physik und Chemie, 15 (1829), 1-19, on 1-2; reprinted in his Werke, 1, 346-359, on 346-348.

${ }^{106}$ Weber, "De tribus novis librarum construendarum methodis," Commentationes societatis regiae scientiarum gottingensis recentiores, 8 (1832-1837; pub. 1841), Classis physicae, pp. 81-101; "Ueber Barometer- und Thermometerskalen," Annalen der Physik und Chemie, 40 (1837), 27-39; "Beschreibung eines kleinen Apparats zur Messung des Erdmagnetismus nach absolutem Maass für Reisende," Resultate aus den Beobachtungen des magnetischen Vereins im Jahre 1836, 1 (1837), 63-89; "Bemerkungen über die Einrichtung und dem Gebrauch des Bifilar-Magnetometers," Resultate... [von] 1837, 2 (1838), 20-37; “Das Inductions-Inclinatorium," Resultate .. . [von] 1837, 2 (1838), 81-96, reprinted in Annalen der Physik und Chemie, 43 (1838), 493-511; "Das transportable Magnetometer," Resultate ... [von] 1838, 3 (1839), 68-85; and "Der Inductor zum Magnetometer," Resultate .. . [von] 1838, 3 (1839), 86-101; reprinted in his Werke, 1, 497-515, $516-525,2$ (1892), 20-42, 43-57, 75-88, 89-104, and 105-118, respectively. 
6. the advantage of the chosen dimensions of the apparatus for the sharpening of the results. ${ }^{107}$

The section of Weber's electrodynamics paper of 1846 dealing with the validity of Amperre's law contained an extended criticism of the methods and accuracy of the experiments of his French predecessor. Weber argued that Ampère had not described his experiments in enough detail and that his apparatus did not allow the kind of precise measurement on which everything depended. Ampère had claimed that his law was derived uniquely from experiment and had discussed the theoretical implications of his apparatus, but Weber objected that

there is lacking a precise description of the experiments themselves. With such fundamental experiments it is, however, not sufficient to indicate their purpose and to describe the instruments with which they are made and in general merely to add the assurance that they were accompanied by the expected results; rather it is also necessary to enter more precisely into the details of the experiments themselves and to indicate how often each experiment was repeated, which modifications were made, and what influence these had-in short to give a complete and accurate record of all facts [protocollmässig alle Data mitzutheilen] which contribute to the basis of a judgement on the degree of certainty or definiteness of the result. Ampère has not given such a detailed account of his experiments, and they still require for their completion an actual direct proof of the fundamental electrodynamic laws. The fact of the interaction of conducting wires has, to be sure, been placed beyond doubt by means of frequently repeated experiments, but only with such means and under such circumstances where there could be no question of quantitative determinations, let alone that these determinations had attained the precision necessary for the law of those phenomena to be regarded as experimentally proven. ${ }^{108}$

After discussing in detail one of Ampère's null-effect, nonquantitative experiments, Weber underscored Ampère's failure to provide any indication of the limits within which the observed results could be expected to hold:

One misses in this Ampère's mentioning the obvious hindrance of that fourfold friction, and he does not even say explicitly that

\footnotetext{
${ }^{107}$ From the third of the papers listed in note 106, quoted from Weber, Werke, 2, 20-21. For an especially good statement of Weber's method, see the last paper of note 106, ibid., p. 109.

${ }^{108}$ Weber, op. cit. (note 81), pp. 6-7 and Werke, 3, 31.
} 
he himself saw and observed the motion of the eccentric arc. Aside from any doubts that might thereby arise as to the actual observation of the fact, and assuming that Amperre himself saw and also assured himself of the displacement of the arc under the conditions described, and assuming that this was really the effect of electrodynamic forces which were strong enough to overcome all opposing hindrances, even then it has in no way been said at what eccentricity of arc these motions first occurred and within what limits they did not take place. However, without the determination of such limits this experiment cannot be granted complete power of proof....

By means of these remarks on Ampère's experiments I have only wished to show that the electrodynamic laws have received no sufficient proof from these experiments reported without more detailed information and that such proof cannot be obtained by means of observations with Ampère's instruments, but that for that [proof] observations with precise measuring instruments are required, which have heretofore been lacking. ${ }^{109}$

Weber's attitude is that of the scientist for whom correct methodology is the sine qua non of scientific proof. Without quantitative measurements one can have no appreciation of either the correctness or the range of validity of what purports to be knowledge. These were the considerations behind his conviction of the necessity to verify Ampère's law. Weber's extraordinarily extensive and careful experiments represented a refinement of technique far beyond anything ever employed by concretizing scientists. Of his electrical papers the editor of his works correctly observed that "alongside their theoretical importance they constitute a model for experimental research." $110 \mathrm{His}$ work was nothing if not exemplary.

$\mathrm{Ohm}$, a forerunner of the new generation of mathematical physicists, was also a careful experimenter who appreciated the necessity of basing quantitative conclusions on precisely controlled experiments, and in his first paper he indicated how he had fit a mathematical formula to quantitative experimental results. ${ }^{111}$ A more refined

\footnotetext{
109bid., p. 9 and Werke, 3, 34.

110Heinrich Weber, "Vorwort zum dritten Bande," Wilhelm Webers Werke (note 81), 3 , iv-v.

${ }^{111}$ Ohm, "Vorläufige Anzeige des Gesetzes, nach welchem Metalle die ContactElectricität leiten," Journal für Chemie und Physik, 44 (1825), 110-116 and 116-118 ("Nachschreiben"); also in Annalen der Physik und Chemie, 4 (1825), 79-86, 86-87 (a "Nachschrift" not in Schweigger's Journal or Ohm's Gesammelte Abhandlungen), and 87-88 ("Späterer Nachtrag," the same as the original "Nachschreiben"); reprinted in Ohm, Gesammelte Abhandlungen (note 76), pp. 1-8.
} 
version of this technique was a feature of his second major paper, in which he derived his fundamental formula for the electric circuit. ${ }^{112}$ Ohm's current source was a copper-bismuth thermocouple whose ends were carefully kept at the temperature of boiling and freezing water, and he used a Coulomb torsion balance to measure the electromagnetic action of the resulting current through a series of eight copper wires of uniform thickness and varying length. The description of his apparatus and experimental technique was detailed enough to permit his method to be reproduced or intelligently criticized. He took great care to obtain consistent results, which he tabulated and then rechecked in order to establish the validity of his proposed mathematical law.

Ohm noted that his theory was in general agreement with the experimental results reported by Poggendorff in 1821.113 Both showed that a given multiplier had a certain maximum effect, that this maximum was the same for plates of all sizes, that the number of turns needed to produce this effect was greater for smaller plates, and that a greater maximum effect was achieved with thicker wire in the multiplier. Nevertheless, Ohm noted that Poggendorff's data were often too variable to permit sure conclusions to be drawn and that their general usefulness was limited by their author's failure to make them susceptible to quantitative interpretation. ${ }^{114}$ Although Poggendorff did record numbers, he had no feeling for precision, sought to derive no mathematical laws, and contented himself with qualitative or only roughly quantitative conclusions. It is indicative of his approach to physics that he never refined this early work that fairly begged for the kind of treatment it received in Ohm's hands.

Fechner's Massbestimmungen über die galvanische Kette (1831) devoted over two hundred pages to the description of 135 meticulously executed series of experiments testing the validity and applicability of Ohm's mathematical laws by varying and controlling the different quantities that appeared in them. Fechner's painstaking experimentation stood in bold contrast to most other contemporary researches on the pile. With dogged conscientiousness he overcame the host of obstacles to obtaining consistent and meaningful results with wet

\footnotetext{
${ }^{112} \mathrm{Ohm}$, "Bestimmung des Gesetzes, nach welchem Metalle die Contaktelektricität leiten, nebst einem Entwurfe zu einer Theorie des Voltaischen Apparates und des Schweiggerschen Multiplicators," Journal für Chemie und Physik, 46 (1826), 137-166, on 151; reprinted in his Gesammelte Abhandlungen, pp. 14-36, on p. 25. His formula was $X=a$ $I(b+x)$, where $X$ is the strength of the magnetic effect (later taken explicitly to be directly proportional to the current), $x$ is the length of the conductor, and $a$ and $b$ are constants depending on the electromotive force and resistance.

113 See note 22.

${ }^{114} \mathrm{Ohm}$, op. cit. (note 112), p. 164 and Gesammelte Abhandlungen, p. 34.
} 
cells. His data were copious and were made to decide clearly either for or against the particular formula under scrutiny. Concerning the agreement he found among his different results, Fechner stated: "I have shunned any attempt to bring about such an agreement by means of falsification or adjustment of the observed to the calculated numbers, and no fraction of any number that I once recorded as observed has been changed. Where the experiment gave anomalous results, I have sought this in the circumstances of the experiment and either succeeded in disposing of them by modifying and repeating the latter (in which I spared no pains) or convinced myself that these apparent anomalies have some constant basis in the nature of the circuit [Kette], even though up to now not explained by any theory." 115 That Fechner thought it appropriate to state explicitly that he had not manipulated his results suggests that that was not something to be taken for granted at the time. He expressed the hope that his labor might serve "to make available to others the techniques of measurement and thereby guarantee a further treatment of galvanic phenomena in terms of quantitative determinations along the path of experimentation."116

Fechner's feeling that physics was in a state of flux and that previously acceptable standards of experimentation would no longer suffice was echoed by Riess and Moser in a joint paper that was the former's first and the latter's second publication. Their purpose was to settle the inconclusively debated question of the influence of sunlight on magnetism by reviewing and redoing the experiments reported by others. It was their opinion that "the present age [die neuere Zeit] ... cannot content itself with the affirmation that a needle has become magnetic; it may justly require measurements, even if they only serve to eliminate the suspicion of an easily possible deception." 117 Their experiments failed to discover any regular effect of sunlight on magnetism. Although Moser's physics was predominantly theoretical, Riess devoted many years to the quantitative analysis of static electricity, in particular to the heating of wires by the discharge of electricity through them. In the first of a series of five papers on this problem, Riess stated that his purpose was to provide physics with easily reproducible "quantitative [messend] electrical experiments."118 In these papers he investigated the precise functional

\footnotetext{
115Fechner, op. cit. (note 99), p. v.

116lbid., p. iv.

${ }^{117}$ Riess and Moser, "Ueber die magnetisirende Eigenschaft des Sonnenlichts," Annalen der Physik und Chemie, 16 (1829), 563-592, on 564.

${ }^{118}$ Riess, "Ueber einige Wirkungen der Reibungselektricität im Verhältnisse zu ihrer Anhäufung," Annalen der Physik und Chemie, 40 (1837), 321-355, on 322.
} 
dependence of that heating on factors such as the charge and surface area of battery and the length and radius of connecting wires of a variety of substances. ${ }^{119} \mathrm{His}$ work showed skillful reasoning back and forth between carefully controlled experiments and their possible mathematical description, and he repeatedly compared observed and calculated values to test the validity of his formulas. For example, he found that the expression for the rise in temperature $T$ of a wire of length $l$ and radius $r$ is

$$
T=\frac{a}{r^{4}} \cdot \frac{1}{\left(1+\frac{b \lambda}{\rho^{2}}\right)} \cdot \frac{q^{2}}{s},
$$

where $\lambda$ and $\rho$ are the length and radius of the rest of the connecting wire, $q$ and $s$ are the charge and the surface area of the battery, and $a$ and $b$ are experimental constants. His ambitious program embraced the inductive effect of a circuit parallel to that through which the electricity was discharged and the dependence of spark length on quantity of electricity and composition of the circuit. ${ }^{120}$ Although Riess's work was in the main innocent of theory, he nevertheless showed the extent to which this realm of phenomena could be quantified on the basis of precise experiments.

Lenz's work further illustrates the extent to which quantitative experimentation characterized the work of abstracting scientists even when no theory was being tested. His first significant paper applied the quantitative approach to Michael Faraday's discovery of induction. ${ }^{121}$ His next paper applied the same procedure to Humphry Davy's discovery of 1821 that "the conducting power of metallic bodies [for electricity] varied with temperature, and was lower in

\footnotetext{
119 Riess, "Ueber die Erwärmung im Schliessungsbogen der elektrischen Batterie," Annalen der Physik und Chemie, 43 (1838), 47-88; "Ueber die elektrische Verzögerungskraft und das elektrische Erwärmungsvermögen der Metalle," Annalen der Physik und Chemie, 45 (1838), 1-24; "Ueber die Wärmeerregung in einem verzweigten Schliessungsbogen der elektrischen Batterie," Annalen der Physik und Chemie, 63 (1844), 481-505; and "Ueber das Glühen und Schmelzen von Metalldrähten durch Elektricität," Abhandlungen der Königlichen Akademie der Wissenschaften zu Berlin, 1845 (pub. 1847), Physikalische Abhandlungen, pp. 89-140.

${ }^{120}$ Riess, "Ueber das Maximum der Wirkung eines Nebendrahtes auf die Entladung der elektrischen Batterie," Annalen der Physik und Chemie, 51 (1840), 177-196; and "Ueber die Schlagweite der elektrischen Batterie," Annalen der Physik und Chemie, 53 (1841), 1-20.

${ }^{121}$ See note 138. Moser reported at length on this and the subsequent paper of Lenz's in his review article, "Magneto-Electricität oder induzirter Magnetismus," Repertorium der Physik, 1 (1837), 282-342. Of Lenz's experiments he said: "They have led to very important conclusions and have at the same time shown the kind of certainty that numerical determinations by means of induced currents allow. The method Lenz followed in these experiments will be able to supply a norm for other similar investigations" (p. 314).
} 
some inverse ratio as the temperature was higher."122 Lenz noted that following Davy, all textbooks contained the statement that the electrical conductivity of metals decreased with increasing temperature, "without to my knowledge anyone having attempted to determine numerically the magnitude of the decrease in conductivity with the increase in temperature."123 The determination of that relationship was the task he set himself. An indication of the precision of his carefully executed and mathematically interpreted experiments is afforded by his results, five empirical formulas, for silver, copper, brass, iron, and platinum, showing the dependence of conductivity $\gamma_{n}$ on temperature $n$ in degrees Réaumur. For example he found that $\gamma_{n}=136.250-0.49838 n+0.00080378 n^{2}$, where the conductivity of copper at $0^{\circ} \mathrm{R}$ was set equal to 100 . Lenz's painstaking experiments and the quantitative results derived from them should be contrasted with Davy's original paper, which had contented itself with the above-quoted general statement of the same phenomenon. ${ }^{124}$

\section{The Hypothetico-Deductive Method}

Adoption of the hypothetico-deductive method by German abstracting scientists marked a fundamental change in the conception

\footnotetext{
${ }^{122}$ Humphry Davy, "Farther researches on the magnetic phaenomena produced by electricity; with some new experiments on the properties of electrified bodies in their relations to conducting powers and temperature," Philosophical Transactions of the Royal Society of London, 111 (1821), Pt. 2, 425-439, on 431 (original in italics). This paper appeared in German translation in Annalen der Physik, 71 (1822), 241-261.

${ }^{123}$ Lenz, "Ueber die Leitungsfähigkeit der Metalle für die Electricität, bei verschiedenen Temperaturen," Mémoires de l'Académie impériale des sciences de St.-Pétersbourg, 6th series, Sciences mathématiques, physiques et naturelles, 2 (1833), 631-655, on 632; reprinted in Annalen der Physik und Chemie, 34 (1835), 418-437, on 419.

${ }^{124}$ Davy had determined the "conducting power" of a given connecting wire by noting at what point it was just able to completely discharge a given battery, that is, at what point a parallel circuit showed no further decomposition of water. This procedure is a classic example of the all-or-nothing, nonmeasuring, semiquantitative type of experiment also characteristic of German concretizing science. Davy did not describe his procedure in detail, and he knowingly accepted sources of error that a more meticulous experimenter would have sought to eliminate. Although he knew that his results were only approximate and not always repeatable, he quoted numbers as if he had found perfect agreement between experiment and his law, suggesting that he did not distinguish clearly between experimental results and ideal exemplifications of the discovered relationship. Cf. Davy, op. cit. (note 122), p. 431. To be sure, Davy and Lenz were not dealing with precisely the same quantity. Davy's notion of "conducting power" was based upon an imprecisely conceived theory of conduction, according to which the power of conduction of a given body had a certain limit, and upon a lack of appreciation for the difference between intensity and quantity of electricity. Lenz's "conductivity" was a quantity precisely defined in terms of Ohm's mathematical theory of the electric current. This does not, I believe, vitiate the significance of the marked contrast in the general character of their experimental technique.
} 
of the relationship between theory and experiment, according to which experimentation followed the elaboration of theory and served as a check on the acceptability of the assumptions from which it was derived. Physics was thereby freed from the requirement that, at least ideally, its basic explanatory principles be immediately demonstrable in experience. This section will illustrate the extent to which the new methodology became standard practice among abstracting scientists.

Gauss's use of the hypothetico-deductive method is exemplified by his work on terrestrial magnetism. In a paper of 1836 he gave a nonmathematical exposition of the principles behind the determination of the terrestrial magnetic force, considered from both a theoretical and a practical, instrumental standpoint. His general discussion of how physics treats the various forces it identifies in the world contained a clear statement of the hypothetical (postulational) character of scientific knowledge. "All material things," Gauss wrote, "are subject to gravity, with the exception perhaps-and only perhaps-of a few substances we call imponderables and which we assume hypothetically, because with their assumption we are able to explain a vast number of phenomena and without them we cannot. By explanation, however, the scientist understands nothing other than reduction to the fewest and simplest possible fundamental laws, beyond which he cannot go, but on the basis of which he derives the phenomena with exhaustive completeness as necessary." 125

Weber's earliest significant use of the hypothetico-deductive method came in his first major theoretical paper, the "Elektrodynamische Maassbestimmungen" of 1846, in which he criticized Ampère's attempt to derive the basic law of electrodynamics directly from a set of four equilibrium experiments. Weber rejected those experiments because they did not allow measurements capable of indicating quantitatively how closely theory agreed with experiment let alone allow any determination of an absolute unit of electrodynamic force. ${ }^{126}$ Only exact measurement, compared with the predictions of theory, could provide the kind of proof Weber required. In his experimental verification of Ampère's law, its origin or supposed direct derivation from experiment was of no consequence; what mattered was its subsequent confirmation in hypotheticodeductive fashion. Although Weber based his new law on three fundamental "facts," he made no attempt to prove them directly by

\footnotetext{
${ }^{125}$ Gauss, op. cit. (note 102), pp. 1-2 and Werke, 5, 315-316. Cf. also his monumental "Allgemeine Theorie des Erdmagnetismus" (note 90).

${ }^{126}$ Weber, op. cit. (note 81), pp. 5-9 and Werke, 3, 29-34.
} 
experiment but let their justification follow from the testable truth of the law derived from them.

Weber began the section entitled "Proof of the Fundamental Electrodynamic Law from Measurements" with an explicit consideration of these questions of methodology, quoting long passages from Ampère's memoir of 1826 in which Ampère discussed two ways of discovering the law of electrodynamic action. ${ }^{127}$ The first involved measuring the force between current-carrying wires, making a hypothesis about the infinitesimal force law, applying it to the experimental situation, comparing calculated against observed values, and modifying the hypothesis until agreement between them was reached. The second involved looking for experimental arrangements in which the current-carrying wires remain in equilibrium when subjected to certain modifications, then concluding directly what form the force law must have. Ampère believed that the directness of the second method made it preferable and followed it in his own work. Weber denied that Ampère's method had any experimental advantage over the first and conceded only that it might have had some theoretical advantage in the discovery of the law. ${ }^{128}$ Just as Weber rejected Ampère's experiments as imprecise, he rejected his methodology as inappropriate. Weber insisted that it was the close agreement between calculated and observed values that warranted the acceptance of the assumptions or laws he tested. For example, he used his data to check the applicability to electromagnetic spirals of Gauss's deductions concerning the interaction of magnets. Finding less than one percent disagreement, he concluded that "one could not wish for better agreement between the observed and calculated values, and Ampère's fundamental law is thus confirmed by experience in one of its most general and important consequences."129 And from the agreement he obtained between his laboriously observed and calculated values of the electrodynamic force he concluded that "this complete agreement between the values calculated according to Ampère's formula and the observed values - differences never exceeding the possible size of the unavoidable observational errors-is, considering the different relationships on which this agreement is based, a complete proof of the truth of Ampère's fundamental law."130

Just as Weber's use of the hypothetico-deductive method is especially striking when contrasted to Ampère's approach to the verifica-

\footnotetext{
127Ibid., Art. 5, pp. 25-26 and Werke, 3, 52.

${ }^{128}$ Ibid., p. 26 and Werke, 3, 53.

129lbid., Art. 7, p. 41 and Werke, 3, 69.

130Ibid., Art. 8, p. 50 and Werke, 3, 79.
} 
tion of the same mathematical law, so is Fechner's use of the method in his Massbestimmungen über die galvanische Kette (1831) even more striking when contrasted to Ohm's original work, for Ohm had taken Fourier as his model and had thereby been led to deemphasize the experimental basis of his theory. Fechner's treatment of Ohm's theory was explicitly hypothetico-deductive. He noted that "in presenting the circumstances on which the quantitative relationships of the activity of galvanic circuits depend, I have not so much followed Ohm's theory as I have proved by experience that its most essential conclusions are confirmed in reality."131 Fechner's book omitted all mention of Ohm's attempt, inspired by Fourier, at a deductive proof of his laws from a few basic facts given by experiment. The experimental portion of Fechner's work was organized into the proof of fifteen major propositions expressing different applications of Ohm's law. In each case experimental evidence was adduced in confirmation of the previously stated proposition, usually in the form of a tabular comparison between calculated and observed values. There was no attempt to present the formulas as summaries of experimental data. Fechner expressed his conception of the probative role of experiment several times in his concluding synopsis. He wrote that "a precise verification of this law can only take place by tracing it into the details of the phenomena...; suffice it here to consider a few of its general consequences and to indicate their agreement with experience." 132 Fechner then discussed the more important consequences of Ohm's law, referring to his experiments for confirmation. The structure of the book and its consistent mode of presentation was an extended example of the self-conscious use of the hypothetico-deductive method.

Fechner's Atomenlehre defended the view that atomism was only an especially clear example of the hypothetical character of all scientific knowledge. He contended that atomism was adopted by physicists because it was more successful than any competitor, such as dynamism. ${ }^{133}$ He even went so far as to say that "in science as in life, might makes right." 134 Against some scientists' dissatisfaction with certain aspects of atomism, Fechner asserted that what science needs is not "words" but "assumptions which lead to the experientially

\footnotetext{
${ }^{131}$ Fechner, Lehrbuch des Galvanismus und der Elektro-Chemie. Nach den Originalquellen bearbeitet (Leipzig, 1829), "Vorwort," p. x. This book also appeared under the title Lehrbuch der Experimental-Physik oder Erfahrungs-Naturlehre von Jean Baptiste Biot.... Zweite Auflage der deutschen Bearbeitung. Mit Hinzufügung der neuern und einheimischen Entdeckungen. Dritter Band; it was, however, virtually an independent work of Fechner's.

${ }^{132}$ Fechner, op. cit. (note 99), p. 227.

${ }^{133}$ Fechner, op. cit. (note 91); e.g., pp. 1-2, 24, and 52.

${ }^{134}$ Ibid., p. 34.
} 
confirmed facts."135 Although he doubted that existing methods of the "mathematical and mechanical sciences" could in practice discover the finer properties of atoms, he believed that the only sure way of proceeding was either "to infer the closer relationships of atoms outward from the phenomena or to test hypothetical relationships of them against experience on the basis of the calculation of their consequences."136 The methodology that Fechner had earlier used was in the same spirit as that which he here defended with respect to science in general.

The work of Lenz and to a lesser extent of M. H. Jacobi, with whom Lenz collaborated at the St. Petersburg Academy after 1838, also exhibited the habitual use of the hypothetico-deductive method characteristic of the younger generation. ${ }^{137}$ The aim of Lenz's first paper in electromagnetism was to set up precise criteria for the production of the largest possible electromagnetically induced current given a particular magnet, length of wire, etc. ${ }^{138}$ He generated the induced current by rapidly pulling a wire-wound iron bar from a position of rest across the poles of a horseshoe magnet and measured the resulting current by means of a Nobili double-needle multiplier. His first set of data consisted of the number of turns of wire in the coil versus the average deflection of the multiplier needle; from the deflection he determined the velocity given ballistically to the needle by the momentary induced current. His expression for this velocity, which he took as a direct measure of the induced current, was $A=p \sin 1 / 2 \alpha$, where $\alpha$ is the angle of deflection and $p$ is a constant. Using Ohm's law (and Lenz was among the first to do so), he derived another expression for the induced current equal to the unknown induced electromotive force $(x)$ divided by the sum of the reduced lengths of the multiplier, connecting wire, and coil ( $L, l$, and $\lambda$, respectively). These considerations gave him the equation

$$
\frac{x}{L+l+\lambda}=p \sin 1 / 2 \alpha
$$

135İbid., p. 24; cf. also pp. 6 and 27.

136lbid., p. 77.

${ }^{137} \mathrm{~A}$ simple but telling example of Lenz's use of that method was visible in his response to Muncke's "thermoelectric" experiments: he predicted the consequences of his explanation of the new pheneomena and then verified them experimentally.

${ }^{138}$ Lenz, "Ueber die Gesetze nach welchen der Magnet auf eine Spirale einwirkt wenn er plötzlich genähert oder von ihr entfernt wird und über die vortheilhafteste Construction der Spiralen zu magneto-electrischem Behufe," Mémoires de l'Académie impériale des sciences de St.-Pétersbourg, 6th series, Sciences mathématiques, physiques et naturelles, 2 (1833), 427-457, on 428; reprinted in Annalen der Physik und Chemie, 34 (1835), 385-418, on 386. 
From his data and this equation Lenz did not attempt directly to derive an expression for the dependence of the induced electromagnetic force on the number of turns in the coil, as he might have. Rather, he explicitly employed the hypothetico-deductive method by assuming direct proportionality between these two quantities, developing the implications of this assumption into a formula, and testing this formula against his experimental results. He thus derived the following equation to be tested (his "equation $C^{\prime \prime}$ ): $\sin 1 / 2 \alpha$ $=n \sin 1 / 2 \xi$, where $\xi$ is the assumed deflection due to one turn and $n$ is the number of turns in the induction coil, the electromotive force of one turn having been set equal to one. Lenz remarked: "If we substitute for $1 / 2 \alpha$ the values from the last column of our table of experiments we obtain eleven equations from which $\xi$ can be determined according to the method of least squares. If we substitute this value of $\xi$ into equation $C$ we then obtain the deflections $\alpha$ belonging to the number of turns $n$; the differences between these values and those observed will inform us whether the assumed hypothesis of the proportionality of the number of turns to the electromotive force is in fact confirmed by observation." 139 A tabulated comparison between calculated and observed values of $\alpha$ confirmed his original hypothesis, which he then reconfirmed in similar hypothetico-deductive fashion in two series of experiments in which certain variables were changed. He followed the same procedure in showing that the induced electromagnetic force was independent of the diameter of the coil, the thickness of the wire in it, and the substance of which it was made.

Lenz and Jacobi's first joint paper began with the observation that although many researchers had succeeded in building strong electromagnets, none had had any exact knowledge of the relative role played by the many different factors: "It was therefore a requirement of science to determine their true laws by means of a series of precise experiments. However, there was also an overriding practical necessity for them as soon as it became a question of using the magnetism excited in soft iron as a motive power, since in that case everything depends on producing the largest possible useful effect with the materials available." 140 The topic of this paper fell clearly into the pattern of Lenz's earlier work; namely, by means of controlled measurements to find the mathematical law governing the behavior of some already

139lbid., p. 435 and Annalen, pp. 393-394.

${ }^{140}$ Lenz and Jacobi, "Ueber die Gesetze der Electromagnete," Bulletin scientifique publié par l'Académie impériale des sciences de Saint-Pétersbourg, 4 (1838), cols. 337-367, in cols. 337-338; reprinted in Annalen der Physik und Chemie, 47 (1839), 225-266 and 266-270 (a "Nachtrag" by Lenz), on 225-226. 
known device or phenomenon. The authors' main task was to devise means to control and measure two electric currents, one primary and one magnetically induced, as well as the strength of the electromagnet used to produce the secondary current. Their procedure was to pass a known current through the coil of an electromagnet, with and without an iron core, and then measure the momentary current induced in another, coaxial coil when the primary circuit was broken. Again their method was explicitly hypothetico-deductive: "That this induced current arising upon the disappearance of the magnetism in the iron core is proportional to that magnetism is the presupposition upon which our entire procedure is based."141 They used the same method of quantitative experimental control over hypothetically derived mathematical predictions to determine that the magnetism created in iron cores by helical galvanic currents is independent of the thickness and shape of the wires making up the galvanic coil, that the diameter of the coils is thereby a matter of indifference, and that the total effect of all the turns of wire around an iron core is equal to the sum of the effects of the individual turns. ${ }^{142}$,

Neumann's attitude toward the hypothetico-deductive method is more difficult to assess than that of other abstracting scientists. One of his students, after noting the methodological difference between assigning experiment a role either before or after the elaboration of a theory, placed Neumann among those who exemplified the latter practice:

In general one can express the relationship between observation and theory to the effect that observation precedes theory in the exploration [Recognoscirung] of the phenomena and then again follows it in order to test the theoretically obtained results and thereby to guide the correction or further development of the theory.

Such exploratory [recognoscirend] observations, upon which the popular fame of a scientist is wont principally to be based, have never significantly attracted Neumann. For him observation, in the form of exact measurement, always begins after the theory, namely, in that for him the method of observation itself is also always an object of the theory.

Doubtlessly influenced by the exemplary work of Bessel on the length of the seconds pendulum, he required that every part of

141lbid., cols. 341-342 and Annalen, p. 230.

${ }^{142} \mathrm{Cf}$. their later paper, "Ueber die Anziehung der Electromagnete," Bulletin scientifique publié par l'Académie impériale des sciences de Saint-Pétersbourg, 5 (1839), cols. 257-272, in cols. 257-258; reprinted in Annalen der Physik und Chemie, 47 (1839), 401-418, on $401-402$. 
the experiment involved with measurement be accessible to the theory; he incorporated the sources of error into the actual calculations and so arranged the observations as to permit their influence to be determined quantitatively. Attachment to these principles placed him to some extent in opposition to those masterly experimenters-especially the French-who contented themselves with so contriving the conditions of the experiment that the influence of the sources of error was as small as possible, or who at most determined their order of magnitude by repeating the observations under varying conditions and who increased their precision by taking the averages of numerous measurements. ${ }^{143}$

The first half of this passage suggests that Neumann made conscious use of the hypothetico-deductive method. The second half, though not inconsistent with the first, places the burden of his methodology on the theoretical analysis of experimental variables, especially sources of error. Although not primarily an experimentalist, Neumann was always sensitive to the requirement that theory take into consideration the possibilities and limitations of actual experimentation. His seminars in particular stressed the importance of making physical phenomena amenable to mathematization on the basis of precise experimental control. ${ }^{144}$

The extent to which Neumann made use of the hypotheticodeductive method in his published work is illustrated by his 1845 paper on the general laws of induced electric currents, in which he several times justified making a particular assumption in terms of the subsequent verification of the theory based upon it, rather than in terms of intrinsic reasonableness or simplicity. In that spirit he based his theory of induction on two principles, the first being Lenz's empirical law for determining the direction of an induced current and the second the assumption "that the intensity of the momentary induction is proportional to the speed with which the conductor is moved."145

\footnotetext{
${ }^{143}$ Voigt, op. cit. (note 78), pp. 256-257 and Neumann, Werke (note 77), 1, 11-12.

${ }^{144}$ See the passages from his seminar reports of 1839-1840 and 1847-1849 quoted in Albert Wangerin, Franz Neumann und sein Wirken als Forscher und Lehrer (Braunschweig, 1907), pp. 171 and 156. Cf. Voigt, op. cit. (note 78), p. 258 and Neumann, Werke, 1, 13; and Stanley Goldberg's article on Voigt in Dictionary of Scientific Biography, ed. Charles C. Gillispie, 14 vols. (New York, 1970-1976), 14 (1976), 61-63, on 61. For an early example of Neumann's concern with having theory realistically reflect the possibilities of experimental confirmation see his "Untersuchung über die specifische Wärme der Mineralien," Annalen der Physik und Chemie, 23 (1831), 1-39; reprinted in his Werke, 2, 1-36.

${ }^{145}$ Neumann, "Allgemeine Gesetze der inducirten elektrischen Ströme," Abhandlungen der Königlichen Akademie der Wissenschaften zu Berlin, 1845 (pub. 1847), Physikalische Abhandlungen, pp. 1-87, on p. 13; reprinted in his Werke, 3, 257-344, on 271.
} 
These principles had led him to a simple and general law of induction "which, as far as my own and others' observations are available, has been confirmed in all its consequences."146 In other words Neumann staked the validity of his basic law of induction on its hypotheticodeductive confirmation by experiment. To derive this law he imagined a closed conductor to be moved with velocity $v$ in the neighborhood of a fixed inducing current. He then assumed that the component of force of the inducing current in the direction of motion of the induced circuit was the same on each element $D s$ of the induced circuit and set this force equal to $C \cdot D s$ for the case when the induced circuit was imagined to carry a unit current, the component of force $C$ being calculable on the basis of Ampère's law. If $\lambda$ is the entire length of the induced circuit, $C \lambda=C^{\prime}$ is the entire force of the inducing current on the induced circuit. If the induced circuit carries not a unit current but one of intensity $k$, then the force on it is $k C^{\prime}$. If now $k$ is the actual induced current, it must by hypothesis be proportional to the momentary velocity of the induced circuit, or $k=L v$, hence also $k C^{\prime}=$ $L C^{\prime} v$. Neumann then reasoned as follows: “According to Lenz's law, $L C^{\prime} v$ is always a negative quantity. From this it follows that since $C^{\prime}$ changes its sign with the direction of motion, $L$ must be a function of $C^{\prime}$, one, moreover, that changes its sign simultaneously with $C^{\prime}$. The simplest assumption one can make in this regard and which proves by its consequences to be sufficient is that $L$ be set equal to $-e C^{\prime}$, where $e$ is a constant coefficient." 147 His method here was again essentially hypothetico-deductive in that he justified making a basic and necessary assumption in terms of the validity of its implications. Although Neumann's paper did not contain the kind of extended quantitative comparison between theory and experiment that characterized many of the papers of abstracting scientists, he regarded his theory as a formal structure, based on a few hypotheses, the validity of which could be determined only after the fact by agreement with experience.

Moser and Riess also assigned particular importance to the adaptation of one's mathematical theory to the possibilities of experimental realization. ${ }^{148}$ Unlike Neumann, however, they made much more

\footnotetext{
146Ibid.

${ }^{147}$ Ibid., p. 14 and Werke, 3, 271.

${ }^{148}$ Moser and Riess, "Ueber die Messung der Intensität des tellurischen Magnetismus," Annalen der Physik und Chemie, 18 (1830), 226-239; Riess and Moser, "Ueber die tägliche Veränderung der magnetischen Kraft und weitere Ausführung der Poissonschen Methode, die Intensität des Erdmagnetismus zu messen," Annalen der Physik und Chemie, 19 (1830), 161-179; Moser, "Ueber eine Methode die Variationen in der Richtung der tellurisch-magnetischen Kraft zu messen, und über einige Anwendungen derselben,"
} 
consistent and explicit use of the hypothetico-deductive method, and they repeatedly subjected to quantitative experimental control conclusions based on explicit assumptions or at least recognized that their hypotheses were in principle dependent on such after-the-fact testing. ${ }^{149}$ Moser in particular was quite comfortable with the idea that physics required such assumptions: "Nature always follows simple laws in her phenomena, and where these are nevertheless complicated, there disturbing causes have hidden the underlying lawfulness. We obtain them by means of experiment, or, where that is not possible, by means of an assumption whose consequences can be compared with the facts. It is in this latter circumstance that we find ourselves with respect to the phenomena of terrestrial magnetism." 150 Riess, on the other hand, independent of Moser's collaboration, often expressed an empiricist's cautious desire to have his formulas appear to be direct expressions of observation. ${ }^{151} \mathrm{He}$ may have been influenced in this regard by the strong empiricist school in Berlin represented by Erman, Poggendorff, Dove, and Magnus. ${ }^{152}$

Annalen der Physik und Chemie, 20 (1830), 431-450; Riess, "Zur Bestimmung der magnetischen Inclination eines Orts," Annalen der Physik und Chemie, 24 (1832), 193-204; and Moser, "Magnetismus und einige Nachträge zum Galvanismus und zum induzierten Magnetismus," Repertorium der Physik, 2 (1838), 100-284, esp. 169-170. The occasion for their programmatic pronouncements in this regard was in most cases the critique of some French mathematical theory (as of Poisson or Biot) or experimental procedure (as of Biot or Arago).

${ }^{14}$ 9Moser and Riess, "Ueber den Einfluss der Wärme auf den Magnetismus," Annalen der Physik und Chemie, 17 (1829), 403-434, on 426; Moser, "Ueber eine Methode" (note 148), pp. 435, 444, and 448-450; Moser, "Ueber den Magnetismus der Erde," Annalen der Physik und Chemie, 34 (1835), 63-84 and 271-292, on 64-65 and 79; Riess, op. cit. (note 118), pp. 326 and 345-346; Riess, op. cit. (note 70), p. 231; and Moser, op. cit. (note 72), pp. $125-126,129,167-168$, and 328.

${ }^{150}$ Moser, "Ueber den Magnetismus der Erde" (note 149), pp. 64-65. According to Moser, corroboration of the numerical implications of a hypothesis does not establish its "physical" truth (p. 68). After noting in another context that probabilities are not simply empirically given numbers but are underlain by some theoretical assumption, he added: "But in no science do we have to do with so-called pure facts; they take us no step further" (op. cit. [note 72], p. 11).

${ }^{151}$ Riess, op. cit. (note 118), p. 322; "Ueber Hrn. V. de Heer's Bearbeitung meiner Wärmeuntersuchungen an der elektrischen Batterie," Annalen der Physik und Chemie, 48 (1839), 320-326, on 325; "Fortgesetzte Untersuchungen über den Nebenstrom der elektrischen Batterie," Annalen der Physik und Chemie, 50 (1840), 1-24, on 2; op. cit. (note 70), p. 189; "Ueber die Ablenkung der Magnetnadel durch die elektrische Batterie," Annalen der Physik und Chemie, 67 (1846), 535-540, on 539; and "Ueber die Entladungszeit der elektrischen Batterie," Annalen der Physik und Chemie, 69 (1846), 426-428, on 426.

${ }^{152} \mathrm{Cf}$. Carl Gustav Adolf von Harnack, Geschichte der königlich preussischen Akademie der Wissenschaften zu Berlin, 3 vols. (Berlin, 1900; rpt. Hildesheim \& New York, 1970), 1, Pt. 2, 808 and 812; John Theodore Merz, A History of European Thought in the Nineteenth Century, 4 vols. (Edinburgh, 1896-1914; rpt. New York, 1965), 1 (1896), 205; and Hermann von Helmholtz, "Zum Gedächtniss an Gustav Magnus," Vorträge und Reden, 5th ed., 2 vols. (Braunschweig, 1903), 2, 33-51, esp. 44 and 48. Heinrich Gustav Magnus (1802-1870), 


\section{EXTERNAL FACTORS IN THE TRANSITION FROM CONCRETIZING TO ABSTRACTING SCIENCE}

Until now I have dealt solely with the actual scientific work of two distinct groups of nineteenth-century German scientists. In this section I intend to show that the character of their work must be understood in terms of both its narrower institutional and its broader social context. Granting the validity of my description of the replacement of concretizing by abstracting science as paradigms belonging to two distinct and for the most part temporally separated groups, the question remains how that historical development is to be explained. Experimental discoveries such as Oersted's of electromagnetism (1820), Seebeck's of thermoelectricity (1821-1822), and Faraday's of induction (1831) were clearly prerequisites for much of the work of abstracting scientists; but particular discoveries could not by themselves have brought about such a thorough transformation of electrical science. Concretizing scientists continued to treat new discoveries within the old paradigm and were not induced to change the kind of science they did. Nor was their antimathematical bent simply a reflection of the state of electrical science during the early decades of the century: the French found certain aspects of electricity amenable to mathematization, and concretizing scientists advanced a philosophical justification for their avoidance of mathematics which extended to all areas of physics. The new paradigm was not simply taken over from another branch of science, nor was German abstracting science merely imported from elsewhere. Despite the fact that the younger Germans derived their basic knowledge of mathematical physics from French sources, German abstracting scientists had a different appreciation of the role of experiment and of the hypothetico-deductive method, and an indigenous philosophical tradition gave some of them a synthetic perspective quite unlike the narrowly focused analytical investigations of the French. ${ }^{153}$

professor of physics at Berlin from 1834, did experimental work in chemistry, the expansion of gases, and the mechanics of rotation. On Dove see the references cited in note 185 . Dove espoused a strongly empiricist line and did not quantify his electrical experiments as, for example, Riess had done; among many examples see his "Versuche über Anziehungen und Abstossungen des galvanischen Schliessungsdrahtes und der Magnetnadel," Annalen der Physik und Chemie, 28 (1833), 586 591; "Magneto-elektrische Elektromagnete," Annalen der Physik und Chemie, 29 (1833), 461-464; and his grand summary article, "Ueber Induction durch elektromagnetisirtes Eisen," Abhandlungen der Königlichen Akademie der Wissenschaften zu Berlin, 1841, Pt. 1 (pub. 1843), Physikalische Abhandlungen, pp. 85-176.

${ }^{153}$ On these two points see notes 5 and 68 . 
Since what changed in Germany was the very character of science, there must have been a reason why the members of the younger generation were dissatisfied with their predecessors' way of doing science and why they were receptive to a different set of standards. If the case of a contemporary chemist may be cited, the language Justus Liebig (1803-1873) used in his autobiography suggests that he was intellectually predisposed toward the kind of science he found in France before he had acquired any firsthand knowledge of it. Of his studies in Erlangen he recounted how "Schelling's lectures attracted me for a while, but Schelling did not possess a thorough knowledge of the branches of natural science, and the dressing up of natural phenomena with analogies and in pictures, which was called explanation, did not appeal to me [sagte mir nicht $z u$ ]."154 By contrast, the lectures of Gay-Lussac, Thenard, and Dulong "had for me an indescribable fascination [Reiz]," and the experiments they performed "spoke to me in a language I understood."155 This is more the language of preexisting intellectual disposition than of simple influence. The fact that the younger Germans were not trained to do the kind of physics they did, as their French contemporaries were, also suggests that their approach to science would have been more susceptible to influences coming from outside physics.

These considerations imply that a complete explanation of the changes described in this paper must go beyond the internal history of science. Of first importance is the recognition that the two opposing paradigms belonged for the most part to two different generations and that this generational split coincided with the transformation of German society occasioned by the Napoleonic Wars. The fact that the younger generation grew up in a period of disruption and reform heightened their awareness of belonging to a new order of things and facilitated their break with past modes of science as the intellectual property of a superseded generation. Liebig recognized the intrinsic connection between the Wars of Liberation, the general destruction of faith in authority, and the questioning of previously dominant ideas and theories. He wrote: "Exhausting wars which undermined the wellbeing of the population and external political pressure had resulted in the devastation of our universities and for many years caused people agonizing distress and directed their desires and efforts in completely different directions; the national spirit had found refuge for its freedom and independence in ideal areas, which in many respects had a

\footnotetext{
${ }^{154}$ Justus von Liebig, "Eigenhändige biographische Aufzeichnungen," Deutsche Rundschau, 66 (1891), 30-39, on 35.

155Ibid., pp. 35 and 36.
} 
beneficial effect through the destruction of faith in authority, especially in medicine and philosophy."156 Although Liebig mentioned only medicine and philosophy, I believe that the same thing happened in physics.

This historical setting accounts at most for the timing and perhaps the thoroughness of the generational-conceptual change in German physics. It fails to explain why the new science took the particular form it did. For this one must look more closely at the changing institutional and social setting within which science was pursued. I will argue that the younger generation's attachment to the new ideology of Wissenschaft, together with their disillusionment with the dominant mode of university instruction, not only reinforced their feeling of belonging to a new generation but also accentuated the methodological aspects of scientific activity and knowledge. I will describe the ways in which physics was becoming a more professionalized activity with respect to education, employment, teaching, research, and publications; and I will underscore the profound effect these changes had on the scope and quality of the scientific work produced by the younger generation. However, the study of electricity and magnetism was influenced by more than its institutional and professional context, and I will show how some of the changes it underwent reflected larger scale social developments. These two realms are linked in part by the assumption that science is an activity that must be socially and psychologically legitimated to its practitioners, especially if it is a new activity without established institutional definition. I will argue that social disruption and reform, by changing the ways in which an individual defined his place in society, encouraged the intensive pursuit of a new kind of science. The strongest evidence for this connection comes from the individual biographies of several of the younger scientists, whose letters and diaries reveal how science was used to meet acute personal and religious problems. Although such psychological factors can operate in any society, one would expect their frequency and impact to be greatest during a period of extreme social unrest, when the relationship between the individual and society was undergoing profound change. Thus Erman's turning from religion to science was not only a rarer occurrence for someone of the older generation, but the nature and intensity of his work was also radically different from that of certain members of the younger

\footnotetext{
156Ibid., p. 34. For further evidence that the Napoleonic Wars fostered a feeling among German youth of belonging to a new generation, see Konrad $H$. Jarausch, "The Sources of German Student Unrest 1815-1848," The University in Society, ed. Lawrence Stone, 2 vols. (Princeton, 1974), 2, 533-569, on 535-540 and 564-565.
} 
generation, soon to be discussed, who sought in science the certainty they had failed to find in religion. ${ }^{157}$

At a more general level one still has to explain why people's basic conception of scientific explanation changed, why they assigned experience a new role with respect to their theoretical knowledge, and why they were satisfied with an unprecedented degree of abstractness. Here the nature of the new society is of crucial importance, and it is necessary to distinguish between psychological and sociological modes of explanation. Explanation in terms of legitimation, which looks at the individual in his direct biographical relationship to his surroundings, cannot deal adequately with factors belonging to the general structure of the social system, whose implications may not be perceived by the individual. Pursuing an idea of Durkheim's, David Bloor has argued that people's image of the way society is organized determines their conception of the nature of knowledge. ${ }^{158}$ According to Bloor, metaphorical application of social ideologies provides the mediating link between people's social experience and their conception of knowledge. The possibility of such a metaphorical transference of structural patterns finds support in the parallels between the two paradigms of science that I have characterized and the societies to which their respective representatives belonged. Indeed, either some such mechanism exists or the extent and close fit of those parallels must be explained away as coincidences or historical artifacts. It is my hope that this case study will demonstrate the practical applicability of the sociology of knowledge to the history of science.

\section{The Institutional and Social Context of Scientific Change}

\section{Toward the Professionalization of Science}

The first quarter of the nineteenth century saw a profound reformation of the German university system. Between 1798 and 1818 nine universities were closed, two were absorbed by stronger neighbors, and three were founded, not to mention numerous important reforms. ${ }^{159}$ After a decade-long crisis of low prestige and poor enroll-

\footnotetext{
${ }^{157}$ Erman had a more empirical conception of knowledge and devoted less of himself to scientific research and publication. His son Adolf wrote that "the conviction that there is no science independent of experience drew him away from theology and won him for physics," quoted in Wilhelm Erman, op. cit. (note 55), p. 30.

${ }^{158}$ David Bloor, Knowledge and Social Imagery (London, 1976), pp. 44-47 and 65-66; see also his essay review, "Popper's Mystification of Objective Knowledge," Science Studies, 4 (1974), 65-76.

${ }^{159}$ Johannes Conrad, The German Universities for the Last Fifty Years (Glasgow, 1885), pp. 290-291.
} 
ment, the final defeat of the French in 1815 and the reestablishment of control by the German states was followed by a surge of youth into the revitalized universities, resulting in a steep rise in university attendance between 1815 and $1830 . .^{160}$ One manifestation of the heightened self-consciousness of many German students during this period was the idealistic Burschenschaft movement, which began at the University of Jena in 1815 and spread to other universities, though suppressed in Prussia after 1819. The pan-German sentiments of these fraternities and their willingness to admit students of all backgrounds undercut prior regional and class distinctions among students and contributed to the general spirit of rejection of past norms. ${ }^{161}$

The sweeping reorganization of the Prussian school system began under the impetus and direction of Wilhelm von Humboldt (17671835) during his short tenure as Minister of Education from February 1809 to June 1810 . Measures then instituted, such as compulsory testing of university applicants, introduced a new competitive rigor and standardization into university affairs and saw the state become virtually the sole authority in educational matters. In 1810 the government ban preventing Prussian students from studying outside Prussia was rescinded (although it was later reinstated between 1833 and 1838), resulting in "the century-long competition between institutions for students, status, and professors." 162 To the renovated philosophical faculties of the reformed universities fell the job of train-

\footnotetext{
${ }^{160}$ Franz Eulenburg, Die Frequenz der deutschen Universitäten von ihrer Gründung bis zur Gegenwart, Vol. 24, No. 2 of Abhandlungen der philologisch-historischen Klasse der königlich sächsischen Gesellschaft der Wissenschaften (Leipzig, 1904), pp. 165, 184, and 303. For a comparison between Prussian enrollments and those for Germany as a whole during the period 1800-1870, see Jarausch's graph in Stone, op. cit. (note 156), p. 557. The depressed state of the German universities between 1785 and 1815 probably discouraged many from entering academic careers and would help account for the dearth of individuals in my sample born between 1780 and 1795 . Be that as it may, the virtual nonexistence of intermediate figures accentuated the dichotomy between the older and younger generations.

${ }^{161}$ Heinz Degen, "Geschichte der Gesellschaft Deutscher Naturforscher und Aerzte IV: Lorenz Oken und seine Isis um die Gründungszeit der Gesellschaft Deutscher Naturforscher und Aerzte," Naturwissenschaftliche Rundschau, 8 (1955), 145-150 and $180-189$, on 150 . Neumann was a member of such a student society, as was Liebig.

162Roy Steven Turner, The Prussian Universities and the Research Imperative, 1806 to 1848 (diss., Princeton Univ., 1972), p. 359. Although the best-known and best-documented reforms of both society and the universities were in Prussia, they were by no means limited to there. In any event most of the younger generation of abstracting scientists in my group-Neumann, Weber, Grassmann, Riess, Moser, and Jacobi-were raised and educated in Prussia. Fechner was brought up in Saxony; Lenz, a Baltic German, in Dorpat, Estonian Russia. The Kaiserliche Universität zu Dorpat was refounded by Alexander $I$ in 1802 and was a bastion of German culture in the Baltic until it was Russianized in 1893.
} 
ing a new corps of Gymnasiallehrer, who as of 1810 were required as civil servants to pass a competitive state qualifying examination. In a similar spirit the Habilitation, now granting the right to teach only specific subjects, became obligatory in 1816 for all privatdocents at the University of Berlin. The precedent for making the rigorous Habilitation a prerequisite to university teaching was followed by Bonn, Breslau, and other German universities during the Vormärz period. ${ }^{163}$ The new status of the privatdocent "signaled a transition from the older, corporate conception of the professorate to a new conception of the professorate as an independent career, separate from the other service professions and defined through scholarly expertise. ${ }^{164}$ Despite the increased difficulty of the required Habilitation, the number of privatdocents increased astoundingly in the expanding Prussian universities, from 11 percent of the 195 teachers in 1800, to 23 percent of the 482 in 1834, to 28 percent of the 531 in 1853. In the philosophical faculties alone their number grew from 61 in 1834 to 90 in 1853, their increase making up 74.5 percent of the net faculty growth in those faculties. ${ }^{165}$ These and related changes fostered within the teaching ranks the same increased competitiveness that marked so many of the individual reform measures. ${ }^{166}$

Among the liberal measures which further altered the character of the professorate was the systematic breakdown of its special corporate privileges, which had come to be identified with academic mediocrity, shortsightedness, and resistance to innovation. ${ }^{167}$ The weakening of corporate identity was only one instance of how socially based modes of personal and professional identity were giving way to more individualistic, disciplinary, and abstract modes of identity. The qualitative change from subjective to objective criteria of personal worth was an important element in the rise and ultimate success of a new kind of science. A similar spirit infused the reform of the procedures and criteria of professorial appointment in the Prussian universities, where the passing of control over appointments from the local faculties to the ministry in Berlin led to a shift in emphasis from

\footnotetext{
163lbid., pp. 363-364. One writer has attempted to link the office of the privatdocent to the growth of the middle class and its need for state-guaranteed institutional security; see Alexander Busch, Die Geschichte des Privatdozenten. Eine soziologische Studie zur grossbetrieblichen Entwicklung der deutschen Universitäten, Vol. 5 of Göttinger Abhandlungen zur Soziologie unter Einschluss ihrer Grenzgebiete (Stuttgart, 1959), p. 2.

${ }^{164}$ Turner, op. cit. (note 162), p. 369. Turner has given a useful characterization of these general changes in "The Growth of Professorial Research in Prussia, 1818 to 1848 Causes and Context," Historical Studies in the Physical Sciences, 3 (1971), 137-182, on 138. ${ }^{165}$ Turner, op. cit. (note 162), p. 366.

${ }^{166}$ Turner, op. cit. (note 164), p. 143. Cf. also Turner, op. cit. (note 162), p. 461.

${ }^{167}$ Turner, op. cit. (note 162), pp. 361-362.
} 
"corporate" to "disciplinary" values and fostered a new "research imperative" among increasingly professionalized academics. ${ }^{168} \mathrm{~A}$ letter written by Paul Erman to his son in 1827 testifies not only to the existence of this new state of affairs but also to the elder Erman's cynical attitude toward it. He instructed his son to give Dove the advice that he should write something in the interest of his advancement: "The gentlemen in the Ministry [of Education] set great store by that, they love tangible literary merit. As soon as he has published something or only intended to, it's in the bag for him. It wouldn't hurt if the work were at the same time good, too, but it wouldn't help much. But he must write, there are just far too few books."169

Another consequential aspect of the educational reform movement, pertaining less to institutions than to ideology, was the popularization of new ideals of Bildung and Wissenschaft, according to which the defining activity of the scholar was the pursuit of new knowledge and not simply the mastery of the already known. The Forscher was to replace the Gelehrter, and the purpose of the university was to promote the sciences, both humanistic and natural, for their own sake. Brotstudium, the acquisition of merely practical knowledge, was scorned. The ideology of Wissenschaft condemned the collection of isolated facts and stressed the unity of all knowledge. ${ }^{170}$ Since this unity was often conceived in terms of methodology, it was through common methods of investigation that the various disciplines earned the right to be called Wissenschaften. ${ }^{171}$ Grassmann explicitly noted that method was the unifying characteristic of scientific activity: "Since both mathematics and philosophy are sciences in the strictest sense, the method in each must have something in common which makes them scientific. Now we ascribe Wissenschaftlichkeit to a mode of treatment when the reader is, on the one hand, led by it with necessity to the recognition of each individual truth and on the other hand enabled at every point in the development to perceive [übersehen] the direction of further progress." $172 \mathrm{He}$ attributed this general

${ }^{168} \mathrm{Ibid}$. pp. 166 and 170-171 and his Chapter 7, "The Prussian State and the Professorial Career," pp. 426-485, esp. pp. 449-450 and 455-456.

${ }^{169}$ Letter of 24 April 1827 to Adolf Erman (1806-1877), in Wilhelm Erman, op. cit. (note 55), p. 247.

170Turner, op. cit. (note 162), p. 247. Turner has distinguished between the speculative-synthetic and the critical-analytic strains which coalesced into the popular Wissenschaftsideologie (ibid., pp. 250-253). On this subject see also Merz, op. cit. (note 152), $1,168-172$.

${ }^{171}$ The common home of all the Wissenschaften was the burgeoning and increasingly prestigious philosophical faculties; see Joseph Ben-David, The Scientist's Role in Society: A Comparative Study (Englewood Cliffs, N.J., 1971), p. 113.

${ }^{172}$ Grassmann, op. cit. (note 96), pp. xxix-xxx and Werke, 1, Pt. 1, 30. 
methodological conception of science to the influence of Schleiermacher. ${ }^{173}$ Indeed, since the ideology of Wissenschaft was espoused especially by men of romantic spirit such as Schleiermacher, Fichte, and Wilhem von Humboldt, it was important that the younger generation did not reject Naturphilosophie out of hand.

A concern with methodology was intrinsic to the role definition of the new professor, who was expected to be both teacher and researcher. Since research was to be pursued according to an explicit methodology, it was reasonable to try to train others to become scientists. The tendency of this development was to democratize scientific work by externalizing and standardizing its procedures. Whereas in the eighteenth century scientific or scholarly discovery was regarded as the rare product of special genius, in the nineteenth century it was seen as the natural consequence of using the right method of research. ${ }^{174}$

These changes in the definition of science exerted tremendous influence on the generation of German scientists and scholars coming of age between 1815 and 1830 . Having taken to heart lofty ideals of science and education, they found their own university instruction in the hands of an older generation relatively untouched by the new developments, whose lecturing tended toward the dry, anecdotal, encyclopedic presentation of "facts." The contradiction between their ideals and reality contributed to their disenchantment with, and rejection of, the old order.

Neumann's case is a clear example of idealism disillusioned by the existing state of affairs. He was an enthusiastic follower of Fichte's "Reden an die deutsche Nation," delivered in Berlin during the winter of 1807-1808, in which Fichte urged that the student be stimulated "above all to individual intellectual activity."175 In 1813 he was confirmed by Schleiermacher, who was dean of the Berlin theological faculty when Neumann matriculated in 1817. Schleiermacher, like Fichte, believed that the universities "should train the critical faculties, awaken the scientific spirit, and encourage originality."176 On 19 January 1818 the Protestant theologian Philipp Konrad Marheineke (1780-1846) delivered a rectoral address exhorting the student to devote himself to the cultivation of pure knowledge and demanding

${ }^{173}$ See his Lebenslauf of 1834 in Grassmann, Werke, 3, Pt. 2, 21-22, and cf. 28.

${ }^{174}$ Turner, op. cit. (note 162), pp. 206-207. This point is further elaborated in Turner, "University Reformers and Professorial Scholarship in Germany 1760-1806," in Stone, op. cit. (note 156), 2, 495-531, on 525-529.

${ }^{175}$ Luise Neumann, Franz Neumann. Erinnerungsblätter von seiner Tochter (Tübingen \& Leipzig, 1904), p. 29.

${ }^{176}$ Turner, op. cit. (note 162), p. 256 (the words are Turner's). 
complete rejection of Brotstudium. Neumann took these sentiments completely to heart. ${ }^{177}$ But what kind of teachers did Neumann encounter? The professor of mathematics at Berlin, Johann Georg Tralles (1763-1822), did not normally lecture at all. When Neumann and some friends persuaded him to do so, he succeeded in driving away all but two students and then used this "lack of interest" as an excuse to stop lecturing. ${ }^{178}$ Even worse was Neumann's experience at the University of Jena, where he had gone in April 1818 and where he was again sorely disappointed. The lectures on Naturphilosophie by Oken and others failed to satisfy him; botany consisted in memorizing names and classifications; his minerology professor told stories of his trip to Switzerland; and his zoology professor began by saying that there were so many different kinds of fish he didn't know how else to begin than by talking about the tastiest! 179 Here was nothing for an idealistic student who wished to devote himself to Wissenschaft. Significantly, his daughter later remarked that "Neumann praised the spirit which prevailed among the students" during this period-not the spirit embodied by the professors. ${ }^{180}$ If Neumann was correct in sensing a common spirit among the students, then many students must have felt the same disappointment with their teachers. Certainly Neumann's experience convinced him that if he wished a scientific education he would have to obtain it on his own.

Medicine, too, evidently continued to be taught in the traditional encyclopedic and eclectic manner. Fechner, who began the study of medicine at Leipzig in 1817, was repulsed by the absence of method in the practice of medicine and as a result sought stimulation for a time in Oken's Naturphilosophie. ${ }^{181}$ Nor did he find much stimulation in his other courses at Leipzig, attending most of them only at the beginning or intermittently because he found he could instruct himself better and more conveniently from books. ${ }^{182}$

Liebig's recollection of the situation at the University of Bonn in the early 1820's reflects a similar dissatisfaction with the character of instruction:

At that time there had sprung up at the newly founded university in Bonn an extraordinarily lively scientific life, but in the

\footnotetext{
${ }^{177}$ Luise Neumann, op. cit. (note 175), p. 89. The text of Marheineke's address is on pp. $419-421$.

178Ibid., pp. 94-95.

179lbid., pp. 90-94.

180 lbid., p. 96.

${ }_{181}$ Johannes Emil Kuntze, Gustav Theodor Fechner (Dr. Mises). Ein deutsches Gelehrtenleben (Leipzig, 1892), p. 43; cf. also p. 39.

182Ibid., p. 37.
} 
branches of the natural sciences the degenerate philosophical research as embodied in Oken and, still worse, in Wilbrand had exerted the most pernicious influence, for it had led to a disregard, in lecture and in study, of experiment and of the sober observation of nature, which was ruinous for many gifted young men. The listener received ex cathedra an abundance of ingenious views [Anschauungen], but incorporeal as they were, one could do nothing with them. The lecturing by Kastner, who was considered to be the most famous chemist, was unorganized, illogical, and entirely like the jumble [Trödelbude] of knowledge I carried around in my head. ${ }^{183}$.

Although Naturphilosophie may have set the tone of instruction in certain disciplines, Liebig's criticism of Kastner's chemistry lectures was that they were an unordered mass of facts, not that they were too speculative. ${ }^{184}$ Liebig's well-known reaction against Oken and Schelling, who had captured his imagination for two years, should not obscure the fact that his disenchantment with the chemistry taught at German universities reflected a different state of affairs. For the history of science it is less important that men like Neumann, Fechner, and Liebig eventually turned from Naturphilosophie-and only Liebig spoke contemptuously of it later on-than that the younger generation as a whole felt no sympathy toward the way science was pursued by the members of the older generation of concretizing scientists and declined to take them as models. The failure of the latters' teaching to meet their students' expectations encouraged the younger men to forge their own model of science and contributed to the decisiveness of the generational split.

These institutional and ideological developments within the universities were important elements in the increasing professionalization of German science. Their impact can be gauged by comparing the career patterns of the members of the two generations. Although all representatives of concretizing science by definition devoted themselves at one time or another to a particular branch of physics, they were hardly all "physicists" in the sense of professional identification or limitation to subjects that either we or they would assign unequivocally to physics. Not only were Seebeck, Pfaff, Jäger, and Ritter all trained to be doctors, but Jäger was professionally never anything

\footnotetext{
${ }^{183}$ Liebig, op. cit. (note 154), p. 33. Johann Bernhard Wilbrand (1779-1846) was a physiologist; Karl Wilhelm Gottlob Kastner (1783-1857) was Liebig's chemistry teacher.

${ }^{184}$ In the 1820's Kastner lectured on "Encyklopädie der Naturwissenschaften," Die Tagebücher des Grafen von Platen, eds. Georg von Laubmann and Ludwig von Scheffler, 2 vols. (Stuttgart, 1896-1900), 2, 459.
} 
but a physician, and Pfaff, professor of chemistry in the medical faculty at Kiel, regarded the practice of medicine as his "true profession." 185 The independently wealthy Seebeck remained a Privatmann his entire life, and the perennially impoverished Ritter held no academic position until he went to the Munich Academy of Sciences in 1805. Nor does the fact that Erman, Muncke, Pfaff, Poggendorff, Pohl, Schmidt, and Schweigger were university professors imply that they had any strong sense of identification as physicist (Muncke, for example, was always called "Hofrat," not "Professor") or that they had received specialized training in physics. Erman never attended a university; and Poggendorff, Pohl, Schmidt, and (possibly) Muncke never earned a doctorate. Schweigger was the only member of the older g:neration to earn a Dr. Phil., and that was in classics.

By way of contrast, all the members of the younger generation attended a university, and all but Grassmann, Jacobi, and (possibly) Lenz earned a doctorate. The dissertation topics of those earning a $D r$. Phil. were in every case "physical": crystallography (Neumann), terrestrial magnetism (Riess), and acoustics (Weber). Moser's doctorate was in medicine, although he was awarded an honorary Dr. Phil. upon his Habilitation in Königsberg. Fechner went to Leipzig to study medicine and passed his exams in that field, but he did not take a medical degree. ${ }^{186}$ As for employment, only Grassmann, a secondary school teacher all his life, failed to gain a university appointment, though the independently wealthy Riess was an amateur until his appointment as associate professor of physics at Berlin in 1842. Ohm, a forerunner of the younger group, became professor of physics near the end of his life after languishing for years in secondary schools. Not only were all but Grassmann eventually university professors, but all except Jacobi, a professor of civil engineering, were professors of physics.

\footnotetext{
${ }^{185}$ Christoph Heinrich Pfaff, Lebenserinnerungen (Kiel, 1854), p. 267. For the sources of most of the biographical data presented here see Caneva, op. cit. (note 2), pp. 543-618. On Riess see Allgemeine deutsche Biographie, 56 vols. (Leipzig, 1875-1912; rpt. Berlin, 1967-1971), 28 (1889), 584-586, and the obituary notice by C. von Voit in Sitzungsberichte der mathematisch-physikalischen Classe der k. $b$. Akademie der Wissenschaften zu München, 14 (1884), 241-244. On Moser see Briefwechsel zwischen C. G. J. Jacobi und M. H. Jacobi, ed. Wilhelm Ernst Martin Georg Ahrens, Vol. 22 of Abhandlungen zur Geschichte der mathematischen Wissenschaften mit Einschluss ihrer Anwendungen, begründet von Moritz Cantor (Leipzig, 1907), and Hans Prutz, Die Königliche Albertus-Universität zu Königsberg $i$. Pr. im neunzehnten Jahrhundert, octavo ed. (Königsberg, 1894), passim. On Dove see esp. the article by his son, Alfred Dove, in Allgemeine deutsche Biographie, 48 (1904), 51-69; also Gustav Karsten, "Doves Doktorjubiläum," Im neuen Reich, Jg. 6, 1876, Bd. 1, pp. 381-387; and Hans Neumann, Heinrich Wilhelm Dove. Eine Naturforscher-Biographie (Liegnitz, 1925).

${ }^{186}$ I have not been able to determine the date, place, or subject of Fechner's reported Dr. Phil.
} 
More than half the university professors of the older generation also held other jobs. After his appointment at the University of Berlin in 1810, Erman kept his job at the Collège français until 1820 and at the Allgemeine Kriegsschule until the 1840's; Pohl kept his position at the Friedrich-Wilhelms-Gymnasium after becoming associate (ausserordentlich) professor at Berlin in 1829; Schmidt taught from 1811 to 1818 at the Giessen Pädagogium as well as at the University; and Pfaff continued to practice medicine. Perhaps Poggendorff and Schweigger should be included here, too, since their editorship of two of the most important German physical science journals must have been extremely time consuming. Whatever the reason for holding several jobs-usually because the pay of a university professor was inadequate to support a family-the practice militated against the development of a professional self-consciousness. Among the younger generation of abstracting scientists none except Lenz held outside jobs at secondary schools after he had attained professorial rank, and none maintained any kind of private practice.

Although most members of the older generation had studied some science at a university, none were or could have been trained to be physicists. The career scarcely existed, and a course of study leading to it did not exist at all. In eighteenth- and early nineteenthcentury Germany, science was taught in the lower, philosophical,faculty, where instruction was subordinated to the limited needs of the three professional faculties. Instruction in science and mathematics was consequently elementary and unspecialized and aimed at giving the student "a comprehensive survey of the whole field, an understanding of how the parts of science related to each other, and the basis of all in some philosophical ground."187 Not until the 1830's did advanced courses in the sciences appear in the lecture catalogs of the German universities. This state of affairs characterized both the education and the teaching of the members of the older generation. Said Pfaff of his own teaching experience: "In physics, especially in the first years, I had listeners from all faculties, but [the lectures] were later less [well] attended, especially by theologians. It was necessary to avoid a truly penetrating or, as it were, scientific presentation; in particular I sought continually to instill interest in my listeners and to hold their attention by means of experiments." 188 The superficial character of physics instruction meant that the professor received no stimulation from the classroom to occupy himself more deeply with his subject. 
The connection between the requirements of teaching and the disposition to keep physics as unmathematical as possible was expressed by the professor of physics at Dorpat, Georg Friedrich Parrot (17671852), in a letter venting his displeasure with Laplace's theory of capillarity: "I confess I would consider it unfortunate if physical phenomena and laws as simple as those of capillarity could [only] be understood [durchschauen] and handled with such an expenditure of analysis as would banish them forever from physics lectures, unless one wanted to proceed merely historically." 186 The professional concern of the university-affiliated concretizing scientists with the organization and presentation of material suggests an institutional rationale for the fact that their inductivism was directed more toward demonstration than toward discovery. As Thomas Kuhn observed, "it is ... direct demonstrations, like those of Atwood, that figure most largely in natural science texts and in elementary laboratory exercises. Because simple and unequivocal, they have the greatest pedagogic value."190 Erman's use of demonstration-like experiments in presenting his theory of transversal magnetism exemplifies the influence of the pedagogic tradition on the scientific style of concretizing scientists. ${ }^{191}$

Closely allied with the elementary nature of the older generation's teaching was the great variety of subjects on which one individual might lecture. Pfaff gave a vivid description of this state of affairs:

From 1799 on I lectured continuously on physics as well as on chemistry, often on both sciences in one semester, as well over

${ }^{189}$ Letter of circa 1809 to Johann Friedrich Pfaff (1765-1825), the famous mathematician and brother of Christoph Heinrich Pfaff, in Sammlung von Briefen gewechselt zwischen Johann Friedrich Pfaff und Herzog Carl von Würtemberg, F. Bouterwek, A. v. Humboldt, A. G. Kästner und Anderen, ed. Carl Pfaff (Leipzig, 1853), pp. 180-181. On the connection between teaching and the character of science see Johann Günther Grassmann's Gymnasialprogramm of October 1827, passages from which are quoted in H. G. Grassmann's Werke (note 96), 3, Pt. 2, 5. Note also the motivation behind the experiments undertaken by Paul Ludwig Simon (1767-1815) to test Coulomb's law in 'Ueber die Gesetze, welche dem electrischen Abstossen zum Grunde liegen," Annalen der Physik, 28 (1808), 277-298, on 278 , and cf. Oersted's lecture of 20 September 1830 before the ninth Versammlung deutscher Naturforscher und Aerzte, "Ueber die Verschiedenheit des physikalischen Vortrages von dem mathematischen, auch wenn beyde dieselben Wahrheiten darstellen," Isis von Oken, 24 (1831), cols. 854-857, in col. 857 (not in his Skrifter).

190Thomas S. Kuhn, "The Function of Measurement in Modern Physical Science," Isis, 52 (1961), 161-193, on 169.

191For Erman the pedagogical use of demonstration experiments had epistemological implications as well. In a program written in the 1790's for the Collège français in Berlin he said that " 400 to 500 experiments, thoroughly discussed with respect to possible deceptions and to the consequences necessarily resulting [from them], are the best preparation for the logical theory of sensible perception and of conceptual thought" (quoted in Wilhelm Erman, op. cit. [note 55], p. 45). 
the whole subject as on individual parts thereof, especially galvanism, magnetism, electromagnetism, electricity, meteorology, and steam engines; then from 1821 on analytical chemistry and (already earlier) pharmaceutical chemistry, as well as on the chemistry of materia medica, toxicology, [and] history of modern chemistry. In the first years I also lectured on mineralogy and geology, which Wiedemann then took over later. Notwithstanding this heavy load I could not in the meantime completely give up that science to which in earlier years I had almost exclusively devoted my energies, namely, medicine and its theoretical part; and in particular I lectured continuously till 1828 on general and special physiology, which were especially well liked, and in addition gave lectures on Gall's skull and brain theory (occasioned in part by the appearance of that original man in our circle), then on animal magnetism and, from 1820 until the end of my career, with particular predilection on macrobiotics. ${ }^{192}$

The contrast between this situation of superficial diversity and the specialized teaching of the younger generation of abstracting scientists is epitomized by the contrast between Neumann, who taught only physics and mineralogy (the latter primarily at the start of his career), and the man he replaced at Königsberg, Karl Gottfried Hagen (1749-1829). Hagen represented the encyclopedic teaching of the nonspecialist: he was professor of medicine, chemistry, physics, and natural history; he lectured on botany, zoology, mineralogy, chemistry, physics, medicine, and pharmacy; and he was a practicing pharmacist to boot! None of the younger generation was involved in this kind of teaching. Except for Dove, who taught a large number of physical science courses at the university and in secondary schools, none of the younger generation taught chemistry, much less medicine.

The necessity to lecture on more subjects than any one person could reasonably master reinforced the disposition of concretizing scientists to remain content with relatively superficial and unambitious researches. This is reflected in the frequent lack of depth and continuity shown by the different topics investigated successively by one individual. Erman, for example, seldom followed up the problems arising out of his own work, and his later investigations were often prompted by some chance observation, to which he would devote a single inexhaustive paper. ${ }^{193}$ Schweigger was a true polymath

${ }^{192}$ C. H. Pfaff, op. cit. (note 185), pp. 275-276. For a sketch of the situation in chemistry in the 1820's see Liebig, op. cit. (note 154), p. 33.

${ }^{193}$ Emil DuBois-Reymond, "Gedächtnissrede auf Paul Erman," Abhandlungen der Königlichen Akademie der Wissenschaften zu Berlin, 1853 (pub. 1854), pp. 1-27, on pp. 8-11. 
who devoted himself with apparently equal enthusiasm to physics, chemistry, and philology. Poggendorff, after his first paper on the electromagnetic multiplier (1821), directed his energies variously to chemistry, meteorology, and physical geography until 1838 when he turned his attention to electrochemistry and the pile.

Although science was becoming truly professionalized in nineteenth-century Germany, the first-generation representatives of abstracting science did not themselves embody all its mature characteristics. One reason for this is that they were not trained in the kind of physics that they eventually did, nor could they have been, given the nature of concretizing science and its status at the universities. The younger men received no significant help or stimulation from their predecessors, and there is a striking absence of any meaningful teacher-student relationship between the members of the two groups. The members of the younger generation taught themselves mathematics and mathematical physics from French works, especially Fourier's, where they learned a kind of physics not taught at the German universities. Among German authors only Euler seems to have been of comparable, though lesser, importance. ${ }^{194}$

The younger generation introduced the first seminars and advanced courses to train students to become professional physicists. The most famous and important was the mathematics and physics seminar set up by Neumann and Carl Gustav Jacob Jacobi (1804-1851) at Königsberg in 1834. ${ }^{195}$ Not Neumann but his pupil Gustav Robert Kirchhoff (1824-1887) represents the full-fledged German professional physicist of the last century. ${ }^{196}$ As a result of the efforts of the first generation of abstracting scientists, it was becoming possible by 1840 to receive university instruction designed to prepare specialists for original research. Weber's lectures, for example, "assigned principal importance not to particulars but to the thought process and method of scientific research."197 Weber himself stressed the importance of well-equipped laboratories for the training of competent researchers and recommended his and Gauss's magnetic and electromagnetic observations as models to be followed. ${ }^{198}$

\footnotetext{
${ }^{194}$ For evidence see Caneva, op. cit. (note 2), pp. 216-218.

${ }^{195}$ Dove and Moser had also taken part in earlier proposals to set up scientific seminars there; see Prutz, op. cit. (note 185), pp. 172-173.

${ }^{196}$ As identified, for example, by Russell McCormmach, "Editor's Foreword," Historical Studies in the Physical Sciences, 3 (1971), xii.

${ }^{197}$ Heinrich Weber, Wilhelm Weber. Eine Lebensskizze (Breslau, 1893), p. 107.

${ }^{198}$ Letter of 20 February 1845 to Sir Edward Sabine in Report of the Fifteenth Meeting of the British Association for the Advancement of Science; held at Cambridge in June 1845 (London, 1846), as part of the "Proceedings connected with the Magnetical and Meteorological Conference, held at Cambridge in June 1845," p. 15; reprinted in Weber, Werke (note 81), 2, 275-276.
} 
Just as the teaching of abstracting scientists was limited to physics, so was their research restricted to a few areas of it. The depth and ambitiousness of the research programs of Weber, Neumann, Riess, and Lenz were totally unlike the casual eclecticism that had marked much of the work of the older generation. Most of the youngergeneration physicists had done substantial scientific research before their first appointment: Fechner and Lenz had published good work in electricity; and Moser, Neumann, Riess, and Weber all had dissertations and a few publications behind them before they began their professional careers. The pattern that would become standard in Germany later in the century and which defined the possibility of a career in science is indicated by the way Neumann, Weber, Fechner, and Moser all proceeded up the university ladder from privatdocent through associate professor to full professor. An early commitment to physics was surely an important factor in the dedication shown by virtually all abstracting scientists to their work. In contrast, the relatively advanced age at which many of the older generation began to publish or at which they became professors reflects the weakness of their professional commitment to physics. Erman was thirty-seven before he published his first scientific paper and forty-six before he became professor of physics at Berlin. Pohl had been a secondary school teacher of a variety of subjects for nineteen years before becoming extraordinary professor of physics at the age of forty-one; and Schweigger had to wait until he was forty before being called to Halle as professor of physics and chemistry, having also taught at a variety of secondary schools. Several concretizing scientists became full professors before they had published anything at all (Schmidt, at age twenty-two) or anything significant even by the modest standards of the day (Muncke, at age thirty-eight). Among the amateurs, Seebeck was thirty-eight before he published his first paper.

One of the most important characteristics of eighteenth-and early nineteenth-century scholarship was the kind of literary activity it encouraged. As Turner put it, "in keeping with his pedagogical conception of his post and the encyclopedic preferences of his age, the professor devoted much of his publishing activity to handbooks, translations, and works of a pedagogical or encyclopedic nature."199 The scholarly values that ranked highest in this tradition were "the synthetic view, sensitivity to the relationship of the parts to the whole, breadth and clarity in presentation." 200 These literary demands reflected a conception of the professor as primarily a teacher 
and only secondarily a discoverer of new knowledge. In contrast to the "research imperative" which came to dominate university thinking during the Vormärz period, a viable and actively defended older viewpoint was that "the professor had no obligation to publish or to make discoveries." 201 The distinction that thereby existed between a person's professorial or professional work and his disciplinary or scientific work, a distinction which would have no validity for the younger generation, was given vivid expression in a letter by Johann Friedrich Pfaff. After mentioning three books he was writing, two on mathematics and one on the Leibniz-Newton controversy, he added: "By means of these three books I hope soon to have honorably satisfied the demand on a professor to write. Then for a time I will again study, properly speaking, in order to prepare myself for greater works and in peace contemplate working for science and, as much as within my power, to recommend my name to posterity."202 Most of my sample of university-affiliated concretizing scientists fit this generalization about the characteristic literary productions of eighteenth-and early nineteenth-century scholars. Muncke, for example, published three elementary physics texts. ${ }^{203}$ Schmidt wrote two texts on physical science, two on mathematics, and a volume of tables. ${ }^{204}$ Pfaff's major literary productions in the field of electricity were critical and expository books. ${ }^{205} \mathrm{His}$ total output was immense and included many texts and compendia on a variety of medical and chemical topics. $^{206}$ In his autobiography Pfaff identified himself as a writer

201 Ibid. p. 188. The sentiment was that of the influential critical defender of the universities Johann David Michaelis (1717-1791).

${ }^{202}$ Letter of 6 March 1796 to his brother Christoph Heinrich Pfaff, in Carl Pfaff, op. cit. (note 189), pp. 146-147.

${ }^{203}$ Muncke, Anfangsgründe der Naturlehre zum Gebrauche academischer Vorlesungen systematisch zusammengestellt, 2 vols. (Heidelberg, 1819-1820); Die ersten Elemente der gesammten Naturlehre zum Gebrauch für höhere Schulen und Gymnasien (Heidelberg, 1825; 2nd ed. 1829; 3rd ed. 1833; 4th ed. 1842); and Handbuch der Naturlehre, 2 vols. (Heidelberg, 1829-1830); in addition to his earlier System der atomistischen Physik nach den neusten Erfahrungen und Versuchen dargestellt (Hanover, 1809), and Physikalische und kosmologische Abhandlungen zur Erlernung der Naturkunde (Giessen, 1815). I have not seen any of the works cited in notes 203, 204, and 206 but have relied upon (sometimes inconsistent) bibliographic citations.

${ }^{204}$ Schmidt, Handbuch der Naturlehre. Zum Gebrauch für Vorlesungen, 2 vols. (Darmstadt \& Giessen, 1801-1803; 2nd ed. 1813); Hand-und Lehrbuch der Naturlehre (Physik). Zum Gebrauch für Vorlesungen und zum eignen Studium entworfen (Giessen, 1826 or 1827); Anfangsgründe der Mathematik. Zum Gebrauch auf Schulen und Universitäten, 5 pts. in 3 vols. (Frankfurt am Main, 1797-1807; 2nd ed. 1806-1829; 3rd ed. 1822-1830); Ebene und sphärische Trigonometrie (Giessen, 1817); and Kubische und logarithmische Tafeln (Giessen, 1821).

205See the books cited in note 43 .

206For example, Pfaff, Grundriss einer allgemeinen Physiologie und Pathologie des menschlichen Körpers. Zum Gebrauch bei academischen Vorlesungen (Kopenhagen, 1801); 
(Schriftsteller) whose goal was the career of a scholar (Gelehrtenberuf) and whose motto was "famam extendere, si non factis, tamen scriptis." 207 Never striving much after originality, he sought rather a systematic and clear arrangement of material derived mostly from others. ${ }^{208}$ Although Poggendorff did not write any texts, his Geschichte der Physik (1879) and his monumental Biographisch-literarisches Handwörterbuch zur Geschichte der exacten Wissenschaften (1863) place him, too, in the literary tradition.

The specialization in research spearheaded by the younger generation was reflected in the specialized nature of the sophisticated monographs and journal articles they published. Although Fechner wrote a number of Repertorien and textbooks and translated Biot's and Thenard's multivolumed physics and chemistry texts, he did so only early in his career to support himself financially and to popularize French science in Germany. These were not activities of the mature and established scientist. Dove's editorship of the Repetrorium der Physik reflects the extent to which his style of physics shared stronger affinities with concretizing science than with that of his age-cohort.

The vigor of the older textbook and compendium tradition, as well as the writing of books intended for a general readership, should not obscure the fact that all representatives of concretizing science published many more papers in journals than they did books. The most important journals were the Annalen der Physik and the Journal für Chemie und Physik, which together published roughly ten times as many papers as either the academy journals or the other independent journals. ${ }^{209}$ The existence of the widely accessible and frequently published Annalen der Physik was probably the most important determinant of a sense of community among German scientists during the first third of the nineteenth century. Publishing one's work in it, as all members of my sample did, effectively meant that one had joined the supraregional physical science community. The Annalen's role in this regard, supplemented for a period of years (1811-1833) by Schweigger's Journal, can hardly be overemphasized in a region like Germany containing so many centers of scientific activity of varying quality and

\footnotetext{
Handbuch der analytischen Chemie für Chemiker, Staatsärzte, Apotheker, Oeconomen und Bergwerkskundige. $\mathrm{Zu}$ akademischen Vorträgen und zum Selbststudium, 2 vols. (Altona, 1821-1822; 2nd ed. 1824-1825); System der Materia medica, nach chemischen Principien, 7 vols. (Leipzig, 1808-1824); and Pharmacopoea Slesvico-Holsatia (Kiliae, 1831 or 1832). He also published a medical critique, Revision der Grundsätze des Brown'schen Systems (Kopenhagen \& Wien, 1804) and a book on potatoes, Über unreife, frühreife und spätreife Kartoffeln... (Kiel, 1807).

${ }^{207}$ C. H. Pfaff, op. cit. (note 185), p. 282.

${ }^{208}$ Ibid., p. 283.

${ }^{209}$ For a first-approximation analysis of changing publishing patterns see Caneva, op. cit. (note 2), pp. 226-229.
} 
at a time when effective membership in the scientific community was still open to amateurs unaffiliated with university or academy. However, essential as these journals were, they were not without a possible negative influence on the tone of the science they published. Since they were private ventures supported by subscriptions, their desire to appeal to as broad a readership as possible discouraged the inclusion of overly technical papers as long as the mathematically adept portion of the German scientific community was small. ${ }^{210}$

One of the possible kinds of community determinant that became important only during the second half of the century was membership in a professional society, and the claim that the founding of the Gesellschaft deutscher Naturforscher und Ärte in 1822 represented an important step in the professionalization of German science is not supported by the evidence. ${ }^{211}$ On the contrary, until it was revitalized by Rudolf Virchow (1821-1902) in 1858 the society remained an unstructured hodgepodge of doctors and scientists of all stripes, without formal membership. ${ }^{212}$ Specialized physical societies emerged only just before midcentury. The founding of the Berlin Physikalische Gesellschaft in 1845 marked the self-conscious appearance of the generation of German scientists born around 1820.213

\section{Toward the Redefinition of the Individual in Society}

The institutional and professional changes affecting science were taking place within a wider context of profound social change precipi-

\footnotetext{
210See Ludwig Wilhelm Gilbert, "Vorrede," Annalen der Physik, 60 (1818), iv. Gilbert (1769-1824) was editor of the Annalen der Physik from 1799 to 1824.

${ }^{211}$ Everett Mendelsohn, "The Emergence of Science as a Profession in NineteenthCentury Europe," The Management of Scientists, ed. Karl B. Hill (Boston, 1964), pp. 3-48, on pp. 23-26. Mendelsohn failed to distinguish between the program put forth by its founder, Lorenz Oken (1779-1851), and the actual character of the membership, and he did not weigh the propagandistic motives of the enthusiastic English reports he cited. 212Max Pfannenstiel, Kleines Quellenbuch zur Geschichte der Gesellschaft Deutscher Naturforscher und Aerzte; Gedächtnisschrift für die hundertste Tagung der Gesellschaft (Berlin, Göttingen, \& Heidelberg, 1958), passim.

${ }^{213}$ The society's founders were Wilhelm Beetz (1822-1886), Emil Heinrich DuBoisReymond (1818-1899), Ernst Wilhelm Brücke (1819-1892), Wilhelm Heinrich Heintz (1817-1880), Gustav Karsten (1820-1900), and Karl Hermann Knoblauch (1820-1895). Harnack called it "the rallying place of the new generation of German physicists" in Berlin, regarding the older generation as having been made up of Poggendorff, Dove, Magnus, and Riess (op. cit. [note 152], p. 812). There is a remarkable similarity in the family background of Poggendorff, Dove, and Magnus, all of whom shared a style of physics that was at odds with that of most of their age-cohort. Poggendorff's father owned a factory, Dove's was a wholesale merchant, and Magnus had founded a large trading firm. The only others of their generation to come from commercial backgrounds were the two Jews: Riess's father was a jeweler, Jacobi's a banker. See also the other references cited in note 185 .
} 
tated by the Napoleonic Wars. Many of the new developments had their roots further back in German history, but the timing of their maturation was a function of the possibilities for rapid change brought about by war. ${ }^{214}$ From Napoleon's invasion of the Rhineland in 1792 to his final defeat in 1815 the multitude of German states experienced a bewildering succession of mergers, divisions, dissolutions, and other territorial, political, economic, social, and legal changes. Old patterns of stability were gone and change was now expected, whether it was wanted or not. In the view of one historian, the old Germany, "marked by traditionalism in Weltanschauung and obsolescence in political institutions," was gone by $1806 .{ }^{215}$ Drastic measures were called for after the collapse of the Prussian state, especially by the need to reform finances to meet the indemnity imposed by the French and to pay for the occupation forces. Rosenberg, who dated the Prussian reform period as roughly from 1807 to 1812, has shown in detail how Prussian leaders used this urgent need for immediate reform to serve their own economic and social ends. ${ }^{216}$ The reformers had in mind nothing less than the creation of a radically new society according to their own design. ${ }^{217}$ The spirit of reform, as embodied by the pivotal Prussian ministers Friedrich Karl, Freiherr vom und zum Stein (1757-1831) and Karl August, Fürst von Hardenberg (1750-1822) was marked by the desire to promote economic liberalism, which meant doing away with traditional class restrictions on economic activity. ${ }^{218}$ The Royal Edict of 9 October 1807 erased the differential legal rights of the separate classes. Class distinctions

\footnotetext{
${ }^{214}$ In addition to the works later referred to specifically, see John R. Gillis, "Aristocracy and Bureaucracy in Nineteenth-Century Prussia," Past and Present, No. 41 (December 1968), 105-129; Hajo Holborn, A History of Modern Germany: 1648-1840 (New York, 1967); and Reinhard Koselleck, Preussen zwischen Reform und Revolution. Allgemeines Landrecht, Verwaltung und soziale Bewegung von 1791 bis 1848 (Stuttgart, 1967). For parallel developments in two non-Prussian states see Wolfgang Zorn, "Gesellschaft und Staat im Bayern des Vormärz," and Wolfram Fischer, "Staat und Gesellschaft Badens im Vormärz," Staat und Gesellschaft im deutschen Vormärz 1815-1848, ed. Werner Conze (Stuttgart, 1962), pp. 113-142 and 143-171; for an excellent general account of political, economic, and social changes in the several German states see Conze, "Das Spannungsfeld von Staat und Gesellschaft im Vormärz," ibid., pp. 207-269.

${ }^{215}$ Klaus Epstein, The Genesis of German Conservatism (Princeton, 1966), p. 672.

216 Hans Rosenberg, Bureaucracy, Aristocracy and Autocracy: The Prussian Experience, 1660-1815 (Boston, 1966), p. 203; see esp. Chapter 9, "The Emergence of Bureaucratic Absolutism," pp. 202-228.

${ }^{217}$ Reinhart Koselleck, "Staat und Gesellschaft in Preussen 1815-1848," Moderne deutsche Sozialgeschichte, ed. Hans-Ulrich Wehler (Köln \& Berlin, 1966), pp. 55-84 and $474-481$, on p. 61.

${ }^{218} \mathrm{O}$ the importance of the Stein-Hardenberg reforms in changing the character of German society, especially by redefining the character of the aristocracy and the middle class, see Ernest K. Bramsted, Aristocracy and the Middle-Classes in Germany; Social Types in German Literature, 1830-1900, rev. ed. (Chicago \& London, 1964), pp. 36-37 and 44-45.
} 
themselves were not yet wholly abolished, but movement between classes became possible on a large scale, especiably according to one's economic position. The new society was to be constructed according to certain consciously chosen and externally imposed principles, such as freer trade and increased competition between individuals. ${ }^{219}$

One far-reaching effect of the implementation of these views was the redefinition of the idea of citizenship as a direct relationship between citizen and state as opposed to a relationship between subject and sovereign mediated by class or estate. ${ }^{220}$ The weakening of class distinctions was accompanied by a change in the concept of nobility, which a number of writers in the 1790's had already begun to redefine in terms of personal worth or service and not merely in terms of birth. ${ }^{221}$ These and other changes radically altered the basis on which a person defined himself in society. ${ }^{222}$ An address by Henrich Steffens in 1812 provides vivid evidence of the unsettling effect of these changes: "Before us, in the most recent past..., lay a time in which definite, established, [and] traditional forms seemed to guarantee [one's] life a peaceful, secure course. The force of custom had hallowed them and everyone felt that satisfaction which belongs to a person when he is able clearly to survey an already completed whole; everyone felt himself more at home, at peace, and a certain measure, a certain dominant order and agreement of the multitude seemed to carry everyone [along]." 223 But an irresistable current of events had destroyed all this, plunging the individual into a chaos of uncertainty. "Have not the customary supports of thought, belief, and life become shaky for all," Steffens asked, "so that no one dares to devote himself to them with the same old confidence?"224

Previously a person had known his place within a hierarchical class structure, and that place was felt to be an inalienable part of his

${ }^{219}$ Rosenberg, op. cit. (note 216), pp. 210-221.

220John G. Gagliardo, From Pariah to Patriot: The Changing Image of the German Peasant, 1770-1840 (Lexington, Ky., 1969), pp. 198-199 and 286.

221 lbid., pp. 170-171.

${ }^{222}$ Conze listed a number of specific ways in which personal relationships were perceived to have changed and elevated Entsittlichung to one of three Grundtendenzen characterizing the changes in German society between 1789 and 1848 (op. cit. [note 214], pp. 248 and 258-259). See also Jürgen Gebhardt, "Zur Physiognomie einer Epoche," Die Revolution des Geistes. Politisches Denken in Deutschland 1770-1830. Goethe-Kant-FichteHegel-Humboldt, ed. Jürgen Gebhardt (München, 1968), pp. 7-16, on p. 12; and Robert Anchor, Germany Confronts Modernization. German Culture and Society, 1790-1890 (Lexington, Mass., 1972), where "The Problem of Self-Redefinition" is the title of the first chapter and a major theme throughout.

${ }^{223}$ Henrich Steffens, "Ueber das Verhältniss unserer Gesellschaft zum Staate," Schriften. Alt and Neu, 2 vols. (Breslau, 1821), 1, 133-147, on 141; from a lecture delivered on 19 December 1812 before the Schlesische Gesellschaft für vaterländische Kultur.

224Ibid., p. 143. 
nature. Now he had become, ideally, a free agent whose place was determined by what he did. Oken's account of the 1828 meeting of the Gesellschaft deutscher Naturforscher und Ärzte described this development as it manifested itself within intellectual circles. He noted the open and relaxed character of Berlin society, cited its deemphasis of class distinctions, and observed that intellectual accomplishment (Bildung) had become the surest way to establish oneself socially: "In Berlin society people of all classes [Stände] and of every rank, from the highest to the lowest, are found together without claiming any other title than that of a cultured or educated person." 225

Profound change also marked economic affairs. The Royal Edict of 9 October 1807, in conjunction with Hardenberg's trade legislation three years later, abolished the monopoly of the guilds and opened all trades to anyone who paid the appropriate tax. The statutory economic distinctions between city and country were abolished, and city government was restructured. In 1812 the Jews in Prussia were emancipated, in accordance with Hardenberg's belief in a free competitive economy. As a result of these economic and social reforms, which upset the closed corporate order of the ancien régime and saw the Ständestaat replaced by the Klassenstaat, wealth became to an everincreasing extent the common measure of men and things. ${ }^{226}$ Nobles could now buy up peasants' and burghers' lands, and the reverse was also true in principle. Conservative contemporaries were dismayed because the management of large estates was thus transformed from a way of life into a business venture. These changes, already begun during the eighteenth century, were accelerated and given legal redefinition during the reform period. They came increasingly to be seen as exemplifying the unprecedented abstractness of the new social order. ${ }^{227}$

\footnotetext{
225[Lorenz Oken], "[Bericht über die] Versammlung der Naturforscher und Aerzte zu Berlin, im September 1828," Isis von Oken, 22 (1829), cols. 217-450, in col. 230; quoted in Heinz Degen, "Geschichte der Gesellschaft Deutscher Naturforscher und Aerzte e. V. VII: Die Naturforscherversammlung zu Berlin im Jahre 1828 und ihre Bedeutung für die deutsche Geistesgeschichte," Naturwissenschaftliche Rundschau, 9 (1956), 333-340, on 338.

${ }^{226} \mathrm{Cf}$. the useful summary in Helmut Böhme, Prolegomena zu einer Sozial- und Wirtschaftsgeschichte Deutschlands im 19. und 20. Jahrhundert (Frankfurt am Main, 1968), pp. 26-36. Conze noted that during the Vormärz, "Klasse became a category of the decorporated society, while Stand was regarded as belonging to the old civil society" (op. cit. [note 214], p. 249).

${ }^{227}$ Cf. Conze, op. cit. (note 214), pp. 249-250; Koselleck, op. cit. (note 217), p. 65; and Epstein, op. cit. (note 215), p. 320. Steffens referred to the new Germany as an "abstraction" which wished to dissociate itself from its past (Was ich erlebte. Aus der Erinnerung niedergeschrieben, 10 vols. [Breslau, 1840-1844], 9 [1844], 58-59). He noted a new preference for "abstract expressions" for people instead of just "Mensch" and condemned
} 
Another keynote of the reform movement was the increased competition that accompanied the breaking down of traditional barriers and restrictions. This feature, which was common to many of the economic and educational reforms, also characterized the decree of 1808 which formally opened the officer corps to talent on a competitive basis. ${ }^{228}$ Although examinations had been introduced into the bureaucracy as early as 1770 , it was only after the Prussian reforms of 1807 to 1812 that there was a "stiffening of competitive examinations on the basis of costly higher education and long in-service training," by which the Prussian bureaucracy came into a position of real power. ${ }^{229}$ With the increased bureaucratization of the state came the need for trained functionaries, which was in turn a major motive behind the reform of secondary schools and universities. In sharp contrast to eighteenth-century German society, competitiveness had become socially respectable.

Among the disruptions occasioned by the Napoleonic Wars was an attack on the wealth and political power of the Church. The ecclesiastical states were secularized, the Church's assets were widely confiscated by secular authorities, and many Church schools were forced to close. Even in Catholic Bavaria, "monastic libraries were sold by paper-weight as cheese paper and the cathedral of Freising was auctioned for a time to a local butcher."230 During this period the Church lost its control over primary education, the powers of censorship and of prosecuting heresy, and the ancient exemption of the clergy from civil jurisdiction. ${ }^{231}$ Weakening of Church power and corporate independence, together with the many territorial changes, strengthened the case for religious tolerance. ${ }^{232}$ These institutional losses came just when religion was again under heavy intellectual attack. ${ }^{233}$ Enlightenment rationalism had discredited traditional concepts

\footnotetext{
"the revolutionary, abstract rights of a restless bourgeoisie which destroy all variety of existence" (ibid., 10 [1844], 281 and 285). Cf. also his criticism of the tendency of the Prussian economic and social reforms and his own organic-hierarchical conception of the ideal state (ibid., 9 [1844], 39-41 and 8 [1843], 230-277).

${ }^{228}$ Rosenberg, op. cit. (note 216), pp. 214-215.

229lbid., p. 213; see also pp. 163, 178, and 202-228.

230John Walsh, "Religion: Church and State in Europe and the Americas," War and Peace in an Age of Upheaval, 1793-1830, ed. C. W. Crawley, Vol. 9 of The New Cambridge Modern History (Cambridge, 1965), pp. 146-178, on p. 155.

231 lbid., p. 170.

232lbid., p. 155. Other examples are Prussia's annexation of the Catholic Rhineland (p. 174) and the Bavarian Religious Edict of 1818 which granted equality of civil rights to non-Catholics (p. 171).

${ }^{233}$ Although both Protestant and Catholic Churches were in a state of flux, the former seemed relatively more beset by doctrinal, the latter by institutional and financial, problems.
} 
of revelation; miracles had become not evidences of Christianity but problems for it. The old proofs of God's existence had been denied by Hume and Kant (although the romantic reform of theology, due especially to Schleiermacher, drew heavily on the idealistic philosophy of Kant, Fichte, Schelling, and Hegel) and a "higher criticism" was being developed which questioned much of the assumed integrity of the Bible. Steffens recorded that he sensed a "depreciation of all religiosity" among the German people as a whole after the Wars of Liberation. ${ }^{234}$ Besides reinforcing the impression of an unsettled period in which old norms could not be taken for granted, such religious developments were of particular importance to the intellectual development of several members of the younger generation.

The point is frequently made that the Prussian reform movement failed and that by 1820 reaction was back in control. ${ }^{235}$ This may be true as far as political developments are concerned, but from the standpoint of German society as a whole post-1820 Germany was in no way a return to an earlier era. By the early Vormärz Germans felt that society had undergone profound qualitative changes. In trying to explain to his son in the 1830's how it was possible that those who had fought the French nevertheless considered themselves francophiles, the father of a friend of Neumann's said:

It's good you weren't born fifty or sixty years ago! If you had seen the unbelievable political and economic misery we were in then, you'd judge Napoleon differently. The Holy Roman Empire was patched together out of a thousand bits and pieces, most colorfully and detestably in the Upper Rhine. Here sat in confusion the members and estates of the Empire, puffed up with empty pride in their Imperial immediacy [Reichsunmittelbarkeit] but in miserably tattered robes: dukes and princes, counts and barons, princely and unprincely abbots and bishops, together with the Teutonic Order, free cities and towns-not to mention the reichsunmittelbar hamlet of Hammersbach!. . .

From the political misery flowed the economic. Each region clung to its own toll barriers, its own courts and gallows, its own weights and measures, and paralyzed the traffic, trade, and industry of its neighbors in the delusion thereby to promote its own interests....

I'm no worse a patriot than you, but we old-timers remember Napoleon with gratitude. Only his iron hand was capable of

${ }^{234}$ Steffens, op. cit. (note 227), 8, 417-418.

${ }^{235}$ See esp. Walter M. Simon, The Failure of the Prussian Reform Movement, 1807-1819 (Ithaca, 1955). 
pushing the broom which swept out the Augean stables of the Holy Roman Empire. I won't allow him to be rebuked, nor the French, either; without them there would be no constitutions in South Germany, nor the one in Baden which Grand Duke Charles bestowed upon his subjects in 1818 with shrewd understanding. ${ }^{236}$

While such anecdotes and impressions, taken singly, record only one individual's sense of change, taken together with other examples they become evidence of a far-reaching transformation of the social fabric.

\section{The Social Dimension of Scientific Knowledge}

\section{The Legitimation of Scientific Activity: A Functional Analysis}

If one looks at science in terms of the factors which define and legitimate it to the individual practitioner, one can begin to draw into a coherent picture a number of its disparate internal and external aspects. In this section I consider how socially induced changes in the professional and personal definition of the younger generation of abstracting scientists affected the kind of science they did.

A number of developments induced the scientist to identify more closely with his work. Not only were there more university positions, but these were also more specialized and more clearly related to career possibilities. Because of the new, natural progression from Promotion through Habilitation to associate or even full professor, an earlier and more rational decision could be made to devote oneself to a particular science. At the same time, the practice of maintaining second careers in secondary school teaching, medicine, or pharmacy all but disappeared. More rigorous criteria for appointment, a more sophisticated audience for scholarly publications, and a new conception of pedagogy that included the training of others to do research all reinforced the professional image of the scientist and influenced his notion of scientific work. These new career patterns and a culturally motivated emphasis on original research marked the transition from a corporate-collegiate to a disciplinary conception of the professorate.

One subtle but important theme in the transition from concretizing to abstracting science was a shift from a view of scientific truth as depending on the honesty of the individual to one in which commu-

${ }^{236}$ Adolf Kussmaul, Jugenderinnerungen eines alten Arztes, 11th-13th ed. (Stuttgart, 1899), pp. 73-74. Cf. also Conze's quotation of several contemporaries' observations on the decisiveness of the recent break with the past (op. cit. [note 214], p. 256, esp. a letter of 1820 cited there from Johann Carl Bertram Strüve nach Briefen und persönlichen Erinnerungen, ed. Gustav Strüve, 2 vols. [Hannover \& Leipzig, 1900], 1, 41). 
nity control was the only practical guarantee of objectivity. ${ }^{237}$ Concretizing scientists repeatedly asserted their honesty in really having performed a series of experiments in the order finally presented, in not having contrived any antecedent hypotheses, and in using corroborating witnesses as opposed to subsequent verification by someone else. Their internal standard of truthfulness-as if a scientific fact depended on the moral character of the scientist-differs completely from abstracting scientists' external reliance on public, objective testing. Although members of the younger generation undoubtedly personally believed in "the existence of truth," their public science did not concern itself with such considerations.

This distinction between private-internal and public-external modes can be used to analyze other aspects of the change from Gelehrter to Forscher. Where the former tended "to regard discovery as a matter of occasional inspiration or as the prerogative of genius," the latter believed that elaboration of a teachable methodology placed discovery within the reach of the merely competent or diligent. ${ }^{238}$ Turner has contrasted the internal character of the older scholarship to the external, objective character of the new science. Gelehrsamkeit, the traditional scholarly ideal, was characterized by "its status as a personal quality, the characteristic of a learned man; one is a scholar who possesses Gelehrsamkeit. In this sense the term differed from the nineteenth century's more external and objective Wissenschaft or wissenschaftlich, for Gelehrsamkeit always connoted style, evidence of intellectual refinement, fitness for the mode of life associated with a scholar." 239 By defining science in terms of method one has in effect abstracted from the concreteness of particulars in order to achieve wider applicability. To a considerable extent knowledge was coming to be regarded as scientific because it had been arrived at or verified according to a specific rigorous procedure.

The increasingly "objective" character of scientific knowledge, where objectivity is understood as belonging to the group and not to the individual, can also be identified in the use of the hypotheticodeductive method, which makes acceptability a matter of repeatable public testing according to community standards. That method ignores the origin of a hypothesis and thus represents a clear exclusion

\footnotetext{
${ }^{237} \mathrm{Cf}$. the treatment of objectivity as a social institution in Bloor, Knowledge and Social Imagery (note 174), pp. 85-87.

${ }^{238}$ Turner, op. cit. (note 162), p. 320. See the passage by August Boeckh from 1839 quoted there, and compare pp. 203-210 and 279.

239lbid., p. 51. Turner's allusion is to Johann Georg Meusel, Leitfaden zur Geschichte der Gelehrsamkeit (Leipzig, 1799). Cf. Johann Friedrich Pfaff's letter of 11 December 1785 to his brother Carl Friedrich Pfaff (1764-1836), in Carl Pfaff, op. cit. (note 189), p. 42.
} 
of the personal element from public science. Furthermore, insofar as the use of the hypothetico-deductive method means that practical success is the measure of the acceptability of a scientific proposition, it may be regarded as the manifestation within science of the more general social enhancement of the role of competition and the criterion of success. ${ }^{240}$

The role of the German universities as teachers of future functionaries, including the new Gymnasiallehrer, future professionals, and future scientists, coupled with the fact that the teachers themselves were servants of the state, may have introduced a certain bureaucratic mentality into the practice of science. ${ }^{241}$ Bureaucratization seeks the establishment of an objective, rational order, depersonalized and calculable according to clearly formulated and publicly known rules. Successful bureaucratic operation requires reliability of behavior and conformity to prescribed principles of action. The bureaucrat's job is to perform a certain function and to apply a fixed, learned procedure to different particular circumstances. By carrying out his job according to the letter, the bureaucrat justifies his activity and is above reproach. Similarly, by carrying out research according to established methodological guidelines, the scientist or scholar justifies both his professional activity and his results.

These changes in the definition of the professor's role were contemporaneous with other developments that profoundly changed modes of personal definition within the larger society. As already noted, the reform period saw a major attack on the older corporate society, with a weakening of class, regional, and religious distinctions and priviledges, as well as the beginnings of a new generalized concept of citizenship. Economic developments and the enhancement of competition also unsettled traditional behavior patterns. Both bureaucratization and the acceptance of the ideal of Bildung contributed to the notion that a person is defined by what he does or has done, not by where and to whom he was born. A person was to an increasing extent no longer automatically defined by his place in the social structure. Of particular importance is how social and religious

\footnotetext{
${ }^{240}$ For an extensive discussion of the importance and function of competition see Karl Mannheim, "Competition as a Cultural Phenomenon" and "On the Nature of Economic Ambition and its Significance for the Social Education of Man," Essays on the Sociology of Knowledge, ed. Paul Kecskemeti (London, 1952), pp. 191-229 and 230-275; also Helmut Plessner, "Zur Soziologie der modernen Forschung und ihrer Organisation in der deutschen Universität-Tradition und Ideologie," Diesseits der Utopie. Ausgewählte Beiträge zur Kultursoziologie (Düsseldorf \& Köln, 1966), pp. 121-142.

${ }^{241}$ On the general character of bureaucratization see Robert K. Merton, "Bureaucratic Structure and Personality," Social Theory and Social Structure, rev. ed. (New York \& London, 1968), pp. 249-260.
} 
changes made traditional values uncertain and led some to seek definition and security within the realm of abstract and unchanging scientific truth. The extent to which one's work could become the defining characteristic of one's life and the determinant of one's worth is suggested in a letter by Carl Gustav Jacob Jacobi to his brother Moritz. He asked rhetorically: "Does that which you have to do so make up the content of your life that you can say, 'I am the thing, if you respect it you must also respect me'?'"242 For several members of the younger generation, science served to replace nonexistent or deficient personal relationships. In a world of change and uncertainty, where traditional modes of social definition were weakened and personal relationships were unable to give security, science, both as activity and as knowledge, could provide something fixed and certain around which to organize one's life.

These developments were reinforced by changes in the religious definition and justification of the individual and in the increasingly abstract way in which immortality could be assured. A number of abstracting scientists made scientific work an outlet for religious drives. Grassmann, for example, realized that although God cannot be seen directly, $\mathrm{He}$ can be seen mediately in His works by means of science. ${ }^{243}$ Neumann and Grassmann, both deeply influenced by Schleiermacher, provide the strongest evidence of this relationship. It is probably also significant that Weber's father was a Protestant professor of theology, that Fechner's father and several other close relatives were Protestant preachers, and that Riess and Jacobi were among the first Jews to enter the world of science in Germany. ${ }^{244}$ All this suggests that widespread religious uncertainty contributed to the formation of a new generation of physicists. That some members of the younger generation required a theological justification for science at a time when the social and institutional definition of the new professional scientist was still in the process of development further suggests that they saw their own activity as something essentially different from that of the traditional scholar-teacher. As Robert Merton observed, institutionalized values are conceived as self-evident

\footnotetext{
${ }^{242}$ Letter of 28 December 1832, in Ahrens, op. cit. (note 185), p. 19.

${ }^{243}$ See note 253 .

${ }^{244}$ Kuntze gave the following description of Fechner's father: "His ambitious disposition was open to all noble and liberating progress. On the steeple of his church, which had been struck twice by lightening, he had the first lightening rod installed; his children were the first in the area to be innoculated; [and] he was the first among his neighboring colleagues to enter the pulpit without a wig, which so disconcerted the people that they were only calmed down when the mayor with presence of mind pointed out to them that the Lord Jesus himself had preached without a wig. He was also a diligent promoter of arboriculture" (op. cit. [note 181], p. 20).
} 
and require no vindication, but new patterns of conduct must somehow be justified if they are to be made personally and socially acceptable. ${ }^{245}$

Neumann affords the clearest and most dramatic case of a person who turned to science to fulfill basic psychological and religious needs. His unsettled and unhappy youth, marked by the total absence of his mother and the infrequent presence of his father, crippled his ability to establish close relationships with other people, and it was precisely his failure to find fulfillment in personal relationships that motivated him to turn away from the world and allowed him to find fulfillment in devotion to abstract science. ${ }^{246}$ Neumann's father, who had been employed as manager by the countess of an estate near Berlin, died in May 1821, whereupon Neumann left Berlin and his studies to help out with the administration of the estate. Sometime that summer he learned that the countess was actually his mother, whom he had been told had died at his birth. He soon decided to leave behind both the estate and his mother. ${ }^{247}$ In a letter to his mother he expressed the tension he felt between the demands of eternally valid science and the immediacy of human values:

Since I felt so unwell and so unhappy here, that ardent longing has now again awakened which from early youth drove me to science, which always tore me away with such force, in whose attainment I have always forgotten and neglected what people otherwise care for, for the convenience and comfort of life.

So be it! I am going back in order to direct my mind and my thoughts to that which [exists] beyond all time and its vicissitudes - to the eternal laws as revealed in human life and nature, in the formation of the world-I wish to submerge and engross myself in research [in order to see] whether I can thus perhaps forget myself and my harsh fate in association with the highest. 248

In another letter to his mother years later he wrote that "life is a difficult task, it is a dangerous game. The world early taught me to

${ }^{245}$ Robert K. Merton, "The Puritan Spur to Science," The Sociology of Science: Theoretical and Empirical Investigations, ed. Norman W. Storer (Chicago \& London, 1973), p. 231, reprinted from his Science, Technology and Society in Seventeenth-Century England (1938).

246See passages from his diary of 1817 and 1827 in Luise Neumann, op. cit. (note 175), pp. 80-82 and 252. See also a letter of 15 December 1831 from Carl Gustav Jacob Jacobi to his brother Moritz, lamenting Neumann's social ineptitude, in Ahrens, op. cit. (note 185), p. 11.

${ }^{247}$ Letter of (presumably) August 1821 to his best friend, in Luise Neumann, op. cit. (note 175), p. 175.

${ }^{248}$ Letter of (presumably) September 1821, ibid., p. 179. 
renounce it, [and] I have built myself another alien world. Only by submerging and engrossing myself in this world of mine, in science and in books, am I capable of bearing the other world. That is what sustains me." 249

Neumann also saw science as a way of establishing contact with eternity, of attaining immortality. His diary is filled with passages expressing his religious doubts and uncertainties and his desire to devote himself to something beyond the temporally and spatially immediate. ${ }^{250}$ At one place in his diary, after listing thirteen precepts exhorting himself to work, simplicity, self-sacrifice, and abstinence, he expressed his feelings of profound guilt with respect to his country, the world, God, and eternity and noted the importance of science in fulfilling these duties: "I owe it to the fatherland-it is a holy duty-I owe it to the world, to Thee, Almighty, to Thy son, to eternity. How magnificent is occupation with science, I study through it how Thy power has operated, how Thy will has been expressed among the peoples of the earth!"251 Neumann's religious sentiments did not allow him to take God's grace for granted. Grace had to be earned by hard work, and science offered the additional advantage of providing an insight into God's working in the world.

These same considerations of personal uncertainty, guilt, duty to God, knowledge of Him, and attainment of a kind of immortality through science also appear as motivations behind Grassmann's dedication to science. Grassmann expressed his doubts concerning religion and the role it should have in his practical life in several letters to his father and brother. He wrote in 1835: "My views won't really let themselves be pinned down, especially with respect to everything concerning my practical life, where my views change almost daily, one view placing itself over another without entirely driving it out. And thus my religious disposition, too, oscillates still between despair and an external security at rest with itself, and [I] cannot yet grasp the correct vigilance in the trust in God, the correct joy in the consciousness of God's unearned grace. Nevertheless, my hope is becoming ever firmer, and God will establish in me, too, the joy of His faith and the power of His love." 252 The connection between religious doubts and science came out in another letter from Grassmann to his father, where the dominant theme was personal and religious uncertainty. Grassmann feared appearing selfish and

\footnotetext{
249 Undated, but probably from March or April 1827, ibid., p. 248. Cf. his Prorektoratsrede of 1844 , ibid., p. 440 .

250lbid., pp. 75-76 and 81-82.

251 lbid., p. 77.

${ }^{252}$ Letter of 24 January 1835 to his father, in Grassmann, Werke (note 96), 3, Pt. 2, 53.
} 
wrote of his struggle for truth and virtue against sinful drives and pleasures. Although his life was still without a firm foundation, he was in the process of finding solace in devotion to science:

I have recently become much calmer, and in particular my whole religious orientation has begun to reconcile itself more with my life. I increasingly recognize how it is a futile endeavor to wish to see God always directly ... .; I increasingly recognize how God can also be seen indirectly in the activity of life in the study of science, how we there, too, can aspire toward the kingdom of God; I feel in myself how it is in precisely this way that the senses are again sharpened in order to see the divine directly from the other side and to grasp it with greater spirit and truth. Thus I also believe that it is in no way a transgression when one so submerges himself in science that he forgets himself in it in order to find truth, that is, his higher self. ${ }^{253}$

Grassmann felt that it was through his scientific work that his spirit would live on after him. Even if one had not been successful in producing students during one's lifetime, one might still be able to reach future generations through one's published work. This thought appealed to Grassmann. In the preface to the second edition of his Ausdehnungslehre (1862) he explained why he was offering a new version of a work which had thus far scarcely been noticed:

I am firmly confident that the work which I have expended on the science presented here, and which has required a significant period of my life and the most intense exertion of my powers, will not be lost. ... I know that even if I do not succeed in gathering around me a circle of students, in a position I have hitherto longed for in vain, whom I could impregnate [befrüchten] with those ideas and stimulate to develop and enrich them further, nevertheless these ideas will some day arise anew, even if in a different form, and will interact vigorously with the developments of the time. For truth is eternal and divine. ${ }^{254}$

As with Neumann, Grassmann's intellectualized approach to immortality through abstract science went along with his failure to establish close personal relationships with other people. According to a

${ }^{253}$ Letter of 9 March 1835, ibid.; cf. the letter of the same date to Robert, pp. 54-55.

${ }^{254}$ Grassmann, Die Ausdehnungslehre. Vollständig und in strenger Form bearbeitet (Berlin, 1862), "Vorrede," pp. ix-x; reprinted in his Werke, 1, Pt. 2 (1896), 10. This was a new edition of the work originally published in 1844. The statement in Caneva, op. cit. (note $2)$, p. 506, that Grassmann was unmarried and childless is incorrect. 
report concerning Grassmann's application for a position at the Berlin Trade School, "Herr Grassmann is a young man who does not lack knowledge. It is also evident that he has thought long and hard about the elements of mathematics in particular and thinks clearly about them. But he seems to have had little social intercourse and is therefore, in the customary forms of social life, backward, shy, easily embarrassed, and then awkward. None of that can be seen in the classroom as soon as he does not know he is being observed. He then moves easily, appropriately, and with assurance."255

There is some indication that Moritz Hermann Jacobi also sought in scientific work the solace and security that escaped him in his personal life. To his brother Carl he expressed both his profoundly felt sense of insecurity and his feeling, here shaken but later regained, that science was the surest and most stable thing in life:

Since, as you know, I am in life and in the flux of the phenomena without a stationary pole or any secure support; since every consequence and every force that appears seems to me more and more bottomless and superficial, pointing out to me the stationary abyss with greater severity; since this is just the way things are and can't conveniently be changed, it pains me all the more when I see how that which I have up to now considered to be the most stable and secure thing, namely, science, is transformed in my hands into a chaos of unutterable confusion, into a whirl, that is, [how it] becomes increasingly entangled [and] desolate as it continues to move back and forth, nowhere able to be seized, affording no foothold and having no bottom, and flinging one back and forth. I don't know what I want, what others want, what science wants or should be, and in order to find all this out, as well in science as in life, I've sought refuge-be amazed, but make no rejoinder!-in Hegel's Logic, for it now lies constantly on my desk, full of marks, lines, dog-ears, etc. Naturally my confusion has now become greater, the little bit of common sense gets lost, for I must, if I want to understand him, go beyond aforementioned common sense; but I'll be damned if I've understood even the slightest thing except for a few remarks. ${ }^{256}$

The direction of his later work shows that it was not in Hegel but in physics that he again found satisfaction. The feelings of insecurity and worthlessness which Moritz expressed in many of his letters

\footnotetext{
${ }^{25}$ Report of 17 October 1834 by the school's director, Karl Friedrich Klöden (17861856), in Grassmann, Werke, 3, Pt. 2 (1896), 46.

${ }^{256}$ Letter of 5 October 1826, in Ahrens, op. cit. (note 185), pp. 3-4.
} 
were probably intensified by the example of his brother, a brilliant and famous mathematician. The latter's advice in times of uncertainty and self-doubt was always to devote oneself fully to one's work, through which one could command a respect independent of personal contingencies: "The inclination and disinclination which we find [in social relationships] are variable and accidental, and nothing can be built upon them, but an honestly achieved piece of work affords us our securest foundation and commands the respect from others that for the ethical person is the vital air he breathes. Thus I have found it, and thus have you no doubt found and will find it."257 Here again is the pattern of public scientific work filling the psychological role of giving one's life focus and definition and of proving one's worth in an impersonal way. For Carl, science served also as a justification of one's existence both to oneself and to "fate." 258

Neumann, Grassmann, and Jacobi all tended to define themselves in terms of their scientific work. They sought in science the security, stability, and immortality that they could not derive from personal relationships, society, or conventional religion. ${ }^{259}$ Of course such factors can and do exist for some people at all times, but it is plausible to suggest that their occurrence and force were enhanced by the widespread and profound changes which virtually all aspects of German society were undergoing during the first decades of the nineteenth century.

\section{Social and Scientific Styles of Thought: A Structural Comparison}

I have so far sought to interpret some of the major features of the new science of the abstract by analyzing the role it played in the professional and personal lives of its representatives, with the origin of those new modes of professional and personal definition being in turn sought within the larger historical context of events. In this final section I will attempt to bridge the gap between the individual and society by calling attention to certain close structural parallels be-

\footnotetext{
${ }^{257}$ Letter of 20 November 1835, ibid., p. 23. Cf. the remark quoted at note 242 and Moritz's diary entry of 4 May 1832 (Ahrens, op. cit., p. 10).

${ }^{258}$ Letter of 27 November 1831, ibid., p. 10. Cf. an earlier letter to Moritz where he spoke of having to earn his own marital happiness through vigorous scientific work (pp. 8-9).

${ }^{259}$ The unprovable but believed truth of some kind of scientific knowledge must be distinguished from the conventionalist conception of public scientific knowledge as that which meets certain methodological tests.
} 
tween the two different conceptions of knowledge exemplified by concretizing and abstracting science and the character of the society within which their representatives lived. My presentation assumes that a mechanism exists by which a perception of social relations can be transformed into a metaphysical conception of the nature of knowledge in general. Building upon an earlier tradition in the sociology of knowledge, David Bloor has used recent work in anthropology, educational psychology, and the philosophy of science to argue that this mechanism is the creation of social and political ideologies that reflect existing social relations and that are then applied metaphorically to general epistemological questions. ${ }^{260}$

This approach gains plausibility from the presence in earlynineteenth-century Germany of two contrasting ideologies whose characteristics closely correspond to those of concretizing and abstracting science. The ideology congruent with concretizing science was associated with the older traditional and class-structured society, while the one associated with abstracting science belonged to the reformist, rationalizing, and competitive society which replaced it after the Napoleonic Wars. The identification of these two contrasting ideologies, as styles of thought that recur in various historical contexts, was one of the central insights of Karl Mannheim, who characterized them as "romantic-conservative" and "liberal-rationalist," respectively. As Mannheim emphasized, they are not just political ideologies but represent basic attitudes toward reality. The following pairs of contrasting characteristics make up the constellation of basic intentions belonging to Mannheim's "conservative" and "progressive" $^{\prime \prime}$ styles of thought: 261

CONSERVATIVE
concrete
qualitative
intuitive representation
internal essences
directed toward the past or
to the actually existing
particularist
organismic
spatial coexistence,
transcending time

\section{PROGRESSIVE}

abstract

quantitative

rational analysis

external relations

directed toward the future or

to the potentially existing

universalist

mechanistic

temporal succession

${ }^{260}$ See note 158 .

${ }^{261}$ This list was derived from two of Mannheim's essays. Although it makes no claims to completeness, it captures all the major traits. See "Conservative Thought," Essays on Sociology and Social Psychology, ed. Paul Kecskemeti (London 1953), pp. 74-164; and 
This table reveals the basic affinity between concretizing science and Mannheim's conservative style of thought on the one hand and between abstracting science and progressive thought on the other. This essential congruence suggests that the two scientific paradigms are only specific manifestations of more general attitudes rooted in the social experience of their different representatives. ${ }^{262}$

The two characteristics of abstracting science which seem, in their opposition to the corresponding characteristics of concretizing science, most clearly related to social structures are its abstractness and its use of the hypothetico-deductive method. I have already underscored the extent to which social relationships had become more abstract. From a general standpoint the entire enterprise of reforming society, of replacing traditional institutions by others conceived as being more rational, may be seen as a change of focus from the concreteness of the historically and actually given to the abstractness of that which exists only in the future. ${ }^{263}$ In the same way the schematic, representational, and anschaulich science of the concrete finds its parallel in the social definition of a person or class in terms of its natural place within a preexisting structure.

One difference between a traditional and a progressive society is that for the former the existing state of affairs is, as it were, the source of one's social principles, whereas society is conceived by the latter as the result of antecedently chosen principles. In a traditional society one derives generalized social patterns from that which already exists, whereas the social knowledge desired by someone bent on reform is not given by the experience of the actually existing. This reversal in the relationship between the concrete (experience) and the abstract (principles) parallels the change in methodology from the empiricism of concretizing science to the hypothetico-deductivism of abstracting science. Whereas empiricism regards experiment as preceding theory, the hypothetico-deductive method has experiment follow theory. Moreover while concretizing scientists were concerned that their theories had a natural and unforced relationship to experi-

\footnotetext{
"Competition as a Cultural Phenomenon," (note 240). Mannheim's terminology is somewhat variable. For a more extended discussion of related aspects of the sociology of knowledge see Caneva, op. cit. (note 2), pp. 485-501 and 524-529.

262Mannheim's stricture against applying the sociology of knowledge to the natural sciences has been attacked on theoretical grounds by David Bloor in "Wittgenstein and Mannheim on the Sociology of Mathematics," Studies in the History and Philosophy of Science, 4 (1973-1974), 173-191. Bloor applied Mannheim's categories to the PopperKuhn debate in Knowledge and Social Imagery (note 158), pp. 48-65.

${ }^{263}$ The enhanced importance of abstract thought to groups bent on changing the existing social order was noted by Paul Szende, "Das System der Wissenschaften und die Gesellschaftsordnung," Kölner Vierteljahrshefte für Soziologie, 2 (1922), 5-17, on 10.
} 